\title{
Social contagion of eating attitudes and behaviors among first year college women living in residence hall communities
}

\author{
Jeffrey S. VanLone \\ West Virginia University
}

Follow this and additional works at: https://researchrepository.wvu.edu/etd

\section{Recommended Citation}

VanLone, Jeffrey S., "Social contagion of eating attitudes and behaviors among first year college women living in residence hall communities" (2002). Graduate Theses, Dissertations, and Problem Reports. 1650. https://researchrepository.wvu.edu/etd/1650

This Dissertation is protected by copyright and/or related rights. It has been brought to you by the The Research Repository @ WVU with permission from the rights-holder(s). You are free to use this Dissertation in any way that is permitted by the copyright and related rights legislation that applies to your use. For other uses you must obtain permission from the rights-holder(s) directly, unless additional rights are indicated by a Creative Commons license in the record and/ or on the work itself. This Dissertation has been accepted for inclusion in WVU Graduate Theses, Dissertations, and Problem Reports collection by an authorized administrator of The Research Repository @ WVU.

For more information, please contact researchrepository@mail.wvu.edu. 
Social Contagion of Eating Attitudes and Behaviors Among First Year College Women Living in Residence Hall Communities

\author{
Jeffrey S. VanLone \\ Dissertation Submitted to the \\ College of Human Resources and Education \\ at West Virginia University \\ in partial fulfillment of the requirements for the degree of
}

Doctor of Philosophy

In

Counseling Psychology

Cynthia R. Kalodner, Ph.D., Chair

Robert P. Marinelli, Ed.D.

David J. Srebalus, Ed.D.

Richard T. Walls, Ph.D.

Catherine A. Yura, Ed.D.

Department of Counseling, Rehabilitation Counseling, and Counseling Psychology

Morgantown, West Virginia

2002

Keywords: Eating Disorders, Social Contagion, Student Adjustment Copyright 2002 Jeffrey S. VanLone 


\begin{abstract}
Social Contagion of Eating Attitudes and Behaviors Among First Year College Women Living in Residence Hall Communities
\end{abstract}

\title{
Jeffrey S. VanLone
}

The present investigation was designed to examine the development of disturbed eating patterns among college women. More specifically, this researcher investigated the social contagion of eating attitudes and behaviors among first year college women living in residence hall communities. The results demonstrated that college women developed eating attitudes and behaviors similar to those of other women in their small friendship clusters. Similarities in eating attitudes and behaviors were not found among participants in the study when residence hall floor membership was used as the independent variable. This study also found significant relationships between student adjustment to college and disturbed eating attitudes and behaviors. Finally, a significant relationship between socio-cultural awareness and internalization of the thinness ideal, and disturbed eating attitudes and behaviors. Future research in this area may be conducted to differentiate between the process of social contagion and the process of natural assortment. Longitudinal studies with similar designs to this study are recommended. 


\section{Acknowledgements}

I would like to express my deepest appreciation to my chair and advisor, Dr. Cynthia Kalodner, and to my committee members Dr. Robert Marinelli, Dr. David Srebalus, Dr. Richard Walls, and Dr. Catherine Yura. Cyndee, thank you for your continued support. I am grateful that you challenged and encouraged me to find creative ways to answer my research questions. You have been a positive influence for me throughout my experience at WVU and beyond, and I am fortunate to have you as a mentor. Bob, thank you for your careful review of my documents, your attention to detail, and your constructive feedback. Your solid presence on this committee has been appreciated. Dave, thank you for the support and insight you have offered throughout this process. Thanks also for teaching me so much about therapy, especially during my first two years of the program. Dick, thank you for your time and dedication. The guidance you provided with the statistical design of my study is much appreciated. I feel fortunate to have been associated with such a selfless and humble educator. Cathy, thank you for offering a practical, clinician's perspective to this study. Thanks also for being a supportive clinical supervisor.

I would also like to thank Dr. Ken Nafziger, Staff Psychologist at Penn State University, for providing additional statistical support and advice.

Finally, I would like to thank the following friends for their support over the past four years that I have been working on this dissertation: Jenn, Sam, Sam, Sarah, Kelli Lee, Brian, Julie, Ken, Nick, Cory, Tom, Janelle, and Herbie. 
Table of Contents

Acknowledgements....................................................... ii

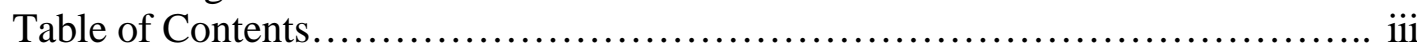

List of Tables...........................................................

Dedication................................................................. vi

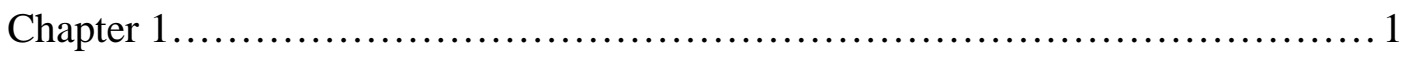

Introduction....................................................... 1

Socio-cultural Influences......................................... 2

Group/Peer Influences........................................... 3

Social Contagion.................................................. 4

Risk Factors.................................................... 5

Statement of the Problem............................................. 7

Purpose of the Study................................................ 9

Hypotheses....................................................... 11

Key Terms...................................................... 12

Chapter 2 - Literature Review.......................................... 14

Prevalence of Eating Disorders Among College Women................... 15

Socio-cultural Influences.......................................... 18

The College Environment......................................... 22

Peer Relationships............................................... 25

Social Contagion................................................ 31

Risk Factors.................................................. 35

Adjustment to College....................................... 36

Self-Esteem............................................... 38

Body Composition...................................... 40

Conclusion.................................................. 42

Chapter 3 - Method.................................................... 43

Participants...................................................... 43

Procedure......................................................... 44

Instrumentation............................................... 44

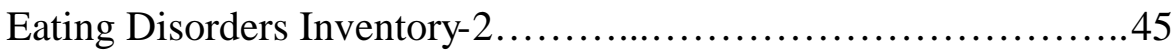

Student Adaptation to College Questionnaire......................49

Rosenberg Self-Esteem Scale.................................... 54

Socio-cultural Attitudes Towards College Questionnaire........... 55

Body-Mass Index........................................... 57

Friendship Networks.................................... 58

Research Design.................................................... 59

Data Analysis..................................................... 60

Friendship Group Membership............................... 60

Hypothesis Testing........................................6 60 
Chapter 4 - Results................................................... 63

Demographic Data............................................... 66

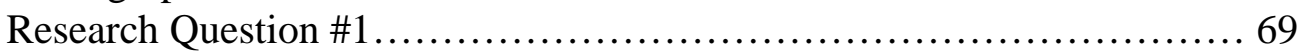

Research Question \#2............................................. 83

Research Question \#3............................................ 86

Research Question \#4............................................. 88

Summary.................................................... 93

Chapter 5 - Discussion................................................ 98

Overview........................................................ 98

Social Contagion of Eating Attitudes and Behaviors..................... 101

Relationship Between Adjustment to College and Disordered Eating........ 108

Relationship Between Socio-cultural Influence and Disordered Eating...... 110

Summary of Findings............................................ 111

Implications for Practice.......................................... 112

Limitations of the Study........................................... 116

Measurement.................................................. 116

Sampling................................................ 117

Research Design............................................118

Recommendations for Future Research.............................. 119

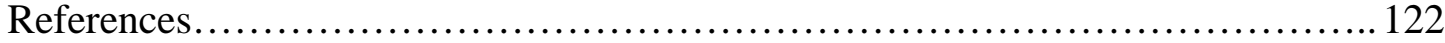

Appendices............................................................. 146

Friendship Networks ........................................... 146

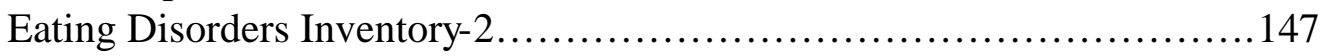

Socio-cultural Attitudes Towards Appearance Questionnaire................ 148

Rosenberg Self-Esteem Inventory ................................. 148 
List of Tables

Table \#1 - Means and Standard Deviations on All Dependent Variables

Table \#2 - First Year Student Participation by Residence Hall

Table \#3 - Friendship Clusters

Table \#4 - Means and Standard Deviations for the Component Analysis of Variance for the MANOVA, with Friendship Clusters as the Independent Variables, and 3 EDI-2 Subscales and 2 SATAQ Subscales as the Dependent Variables

Table \#5 - Means and Standard Deviations for the Component Analysis of Variance for the MANOVA Examining Only Those Friendship Clusters with 70 Percent or Higher Participation, with Friendship Clusters as the Independent Variables, and 3 EDI-2 Subscales and 2 SATAQ Subscales as the Dependent Variables

Table \#6 - Means and Standard Deviations for the Component Analysis of Variance for the MANOVA with Friendship Cluster Membership as a Dichotomous Independent Variable, and 3 EDI-2 Subscales and 2 SATAQ Subscales as the Dependent Variables

Table \#7 - Multivariate Analysis of Variance with Residence Hall Floor Membership as the Independent Variable, and 3 EDI-2 Subscales and SATAQ Subscales as the Dependent Variables

Table \#8 - Correlations Between Student Adaptation to College Questionnaire (SACQ) Subscales and Eating Disorders Inventory-2 (EDI-2) Subscales

Table \#9 - Correlations Between Socio-cultural Attitudes Towards Appearance Questionnaire (SATAQ) Subscales and Eating Disorders Inventory (EDI-2) Subscales

Table \#10 - Stepwise Multiple Regression of Student Adjustment to College Questionnaire (SACQ) Subscales and Socio-cultural Attitudes Towards Appearance Questionnaire (SATAQ) Subscales on the Eating Disorders Inventory-2 (EDI-2) Drive for Thinness Subscale 


\section{Dedication}

I would like to dedicate this dissertation to my mother and father. Your love and support have been the guiding forces in this endeavor, and throughout my life. I love you both very much. 


\section{CHAPTER 1}

Introduction

The college campus has become a haven for the development and/or maintenance of eating disorders. An overwhelming collection of literature points to widespread prevalence of eating problems among college women (Berg, 1988; Clark, Levine, \& Kinney, 1989; Coric \& Murstein, 1993; Franko \& Omori, 1999; Halmi, Falk, \& Schwartz, 1981; Heatherton, Nichols, Mahamedi, \& Keel, 1995; Herzog, Norman, Rigotti, \& Pepose, 1986; Hesse-Biber \& Marino, 1991; Klemchuk, Hutchinson, \& Frank, 1990; Mintz \& Betz, 1988; Mitchell \& Ekert, 1987; Nelson, Hughes, Katz, \& Searight, 1999). Some researchers have gone as to far to suggest that college women with normal eating habits are in the minority (Hesse-Biber, Marino, \& Watts-Roy, 1999; Kalodner \& Scarano, 1992; Mintz \& Betz, 1988).

This does not imply that the majority of college women have pathological eating disorders. In fact, it has been demonstrated that very few women develop clinical levels of eating disorders. Incidence of clinical levels of anorexia nervosa is reported to exist in only between .05 and 1 percent of late adolescent and early adult females (APA, 1994). Similarly, clinical levels of bulimia nervosa exist in approximately 1-3 percent of adolescent and young adult females (APA, 1994). While clinical eating disorders are not prevalent among college women, those with eating problems who do not meet full criteria for eating disorders are much more common.

Perhaps the best way to understand eating problems among college women is to consider the continuum theory (Mintz \& Betz, 1988; Scarano \& Kalodner, 1994; Shisslak, Crago, \& Estes, 1995; Tylka \& Subich, 1999). This theory suggests 
conceptualizing eating attitudes and behaviors along a continuum with normal eaters at one end and eating disordered individuals on the other end. Intervals on this continuum, often referred to as sub-clinical or symptomatic, represent women with significant eating problems that do not meet clinical diagnoses. Although there are not large numbers of college women with clinical eating disorders, the majority of college women do have eating problems that fall in the sub-clinical range.

Due to the alarmingly high frequencies of eating problems among college women, many have called for increased intervention on college campuses (Clark et al, 1989; Franko, 1998; Martz, Graves, \& Sturgis, 1997; Schwitzer, Bergholz, Dore, \& Salmi, 1998). However, before effective intervention and/or prevention programs can be developed, we must first investigate the risk factors of eating disorders among this population. When we better understand what may contribute to the high rates of eating disorders on college campuses, we may then construct intervention methods that target these factors.

\section{$\underline{\text { Socio-cultural Influences }}$}

One method of understanding the risk factors of eating disorders is to examine socio-cultural influences. This approach posits that cultural norms of our society, especially those related to thinness and physical appearance, have led to the development of disturbed eating patterns among women. A variety of studies have focused on sociocultural norms as determinants of eating disorders (Anderson \& DiDomenico, 1992; Faith \& Schare, 1993; Garner, Garfinkel, Schwartz, \& Thompson, 1980; Irving, 1990; Kalodner, 1997; Morris, Cooper, \& Cooper, 1989; Murray, Touyz, \& Beumont, 1996; Schwartz, Thompson, \& Johnson, 1982; Shaw \& Walker, 1995; Stice, 1994; Stice, 
Nemeroff, \& Shaw, 1996; Stice \& Shaw, 1994; Striegel-Moore, Silberstein, \& Rodin, 1986; Williamson, Cubic, \& Gleaves, 1993; Wiseman, Gray, Moismann, \& Ahrens, 1992). These studies have all linked social and cultural pressures to eating problems. This socio-cultural theory helps to explain why there are high prevalence rates of eating problems on college campuses. Research examining cultural norms specific to the college environment hints that college students may be at even greater risk for the development of eating disorders (Berg, 1988; Bowden-Woodward \& Levitz, 1989; Brouwers, 1988; Connor-Greene, StriegalMoore, \& Cronan, 1994). These studies examine some factors that exist on college campuses that may serve to intensify social and cultural norms to be thin and/or attractive. Thus, an understanding of the sociocultural environment on college campuses provides useful information that affords a greater understanding of high prevalence of eating disorders among this population.

The socio-cultural theory, however, does not provide us with enough information on its own. Though it is important to consider the influence of the cultural norms that exist within the college environment, this alone does not provide a sufficient understanding of the problem. This approach leaves an important question unanswered. All women living within the socio-cultural context of the college environment do not develop eating problems. How may it be explained, then, that some women acquire disordered eating attitudes and behaviors, while others do not?

\section{Group/Peer Influences}

Examining the social psychological processes of college women may provide an answer to this question, and consequently offer a more complete understanding of the risk factors associated with eating disorders on college campuses. There is significant 
evidence in the literature suggesting important links between social relationships and eating disturbance. Several studies have demonstrated that eating problems tend to run in social groups (Beren, Hayden, Wilfley, \& Striegal-Moore, 1997; Brooks-Gunn, Burrow, \& Warren, 1998; Druss \& Silverman, 1979; Silberstein, Mishkind, Striegal-Moore, Timko, \& Rodin, 1989). Additional studies have examined relationships between peer influence and eating problems, suggesting that peers may serve as transmitters of eating attitudes and behaviors (Crandall, 1986, Crandall, 1988; Herzog et al., 1986; Mitchell, Hatsukami, Pyke, \& Echert, 1986; Paxton, 1996; Pike, 1995). This research provides support for a social contagion theory of the development of eating problems.

\section{$\underline{\text { Social Contagion }}$}

The social contagion theory posits that individuals in social groups with clearly defined norms may develop the attitudes and behaviors of others as a result of a social contagion factor (Bovasso, 1996; Crandall, 1984; Crandall, 1988; Higgins \& Kruglanski, 1996; Paxton, Shutz, Wertheim, \& Muir, 1999; Prentice \& Miller; 1993; Prentice \& Miller, 1996; Rogers \& Rowe, 1993). In short, the attitudes and behaviors within groups become contagious and spread from one group member to another. This theory provides further insight into how attitudes and behaviors are transmitted. Two studies have utilized the social contagion theory to demonstrate how the eating attitudes and behaviors are similar among individuals in groups. Crandall (1988) demonstrated the social contagion of binge eating among sorority members, and Paxton et al. (1999) examined the contagion of body image concerns, dietary restraint, extreme weight-loss behaviors, and binge eating among adolescent friendship cliques. In his study, Crandall (1988) explains that binge eating behaviors spread across group members due to the social 
pressure to conform to group norms. Similarly, Paxton et al. (1999) demonstrate that girls were more alike members of their friendship groups in regards to eating attitudes and behaviors.

\section{$\underline{\text { Risk Factors }}$}

The social contagion theory also helps us to explain why some college women develop eating problems, while others do not. All individuals will not succumb to the social contagion factor. Individuals have different levels of susceptibility to social contagion based on specific personal factors such as global self-esteem and stressful life events (Crandall, 1988; Levine \& Smolak, 1992; Pike, 1995). The reason that eating problems appear to be especially prevalent on college campuses may be due to influences of the college environment. Factors specific to the college environment may cause some women to develop personal characteristics that make them more susceptible to social influence and social contagion.

Adjustment issues and the stressors that accompany adjustment to college may contribute to the susceptibility of college women to social contagion and the development of eating problems. For many individuals, adjusting to college can be produce a new set of academic, social, personal, and emotional stressors in their lives. College students have been shown to confront increased levels of stress, especially in their first year (Astin, 1977; Kashubeck et al., 1994; Murphy \& Archer, 1996; Sher, Wood, \& Gotham, 1996; Striegel-Moore, Silberstein, Frensch, \& Rodin, 1989; Thombs, Rosenberg, Mahoney, \& Daniel, 1996). Direct relationships between college student adjustment and eating problems have also been examined in the literature. Some researchers have suggested that both transition to high school (Gralen, Levine, Smolak, \& Muren, 1990) 
and transition to college (Bowen-Woodward \& Levitz, 1989; Hesse-Biber \& Marino, 1991) may account for increased levels of stress and, in tur $n$, be associated with disordered eating patterns. Additionally, one recent study demonstrated significant relationships between personal-emotional college adjustment and disordered eating attitudes and behaviors (VanLone \& Kalodner, 2000).

Two additional factors that may contribute to college women's susceptibility to social contagion and the development of eating problems include self-esteem and body weight and/or composition. College students often have lower levels of self-esteem in their first year as they are struggling with adjustment issues (Bettencourt, Charlton, Eubanks, Kernahan, \& Fuller, 1999; Chikering \& Reisser, 1993; Pascarella \& Terenzini, 1991). Not surprisingly, research has demonstrated relationships between low selfesteem and eating problems (Frederick \& Grow, 1996; Fryer, Waller, \& Kroese, 1997; Leary, Schreindorfer, \& Haupt, 1995; Shisslak, Crago, Renger, \& Clark-Wagner, 1998; Wood, Waller, \& Gowers, 1994). Additionally, college women frequently have difficulty with unstructured eating environments at college and often gain weight in their first year (Bowen-Woodward \& Levitz, 1989). Much research has shown that increased Body Mass Index (BMI), a measure of body composition, is related to disordered eating attitudes and behaviors (Ben-Tovim \& Walker, 1994; Davis, Shapiro, Elliot, \& Dionne, 1993; Greeno, Jackson, Williams, \& Fortmann, 1998; Hannan, Wrate, Cowen, \& Freeman, 1995; Kennet \& Nisbett, 1998; Kenny \& Adams, 1994; Klump, McGue, \& Iacono, 2000; Kolody \& Sallis, 1995; Lowry, Galuska, Fulton, Wechsler, Kann, \& Collins, 2000; Monteath \& McCabe, 1997; Mukai, Kambara, \& Sasaki, 1998; Pritchard, King, \& Czajka-Narins, 1997; Shisslak, Crago, McKnight, Estes, Gray, \& Parnaby, 1998; 
Strieger-Moore, Dohm, Soloman, Fairburn, Pike, \& Wilfley, 2000; Strong \& Huon, 1998; Taylor, Sharoe, Shisslak, Bryson, Estes, Gray, McKnight, Crago, Kraemer, \& Killen, 1998; Van Strien, 1985; Wassenaar, le Grange, Winship, \& Lachenicht, 2000; Yates, 1992).

\section{Statement of the Problem}

College women appear to be at significant risk for the development and/or maintenance of eating problems. The socio-cultural theory of eating disorders provides an understanding of why this may occur. Cultural norms to be thin and attractive may be intensified on college campuses. This theory fails, however, to answer an important question. It does not account for the fact that some college women develop eating disorders while others do not. For this reasons, there is a need to consider a new theory that may better explain the phenomena of widespread eating problems among college women.

The social contagion theory may assist us in providing a clearer understanding of eating problems among college women. This theory contends that eating attitudes and behaviors are trans mitted among individuals that are members of the same social groups. The idea is that members of groups have pressure to conform to the norms of their group. The first evidence of social contagion of eating behavior has been shown to exist in a sample of sorority members (Crandall, 1988). In this study, the bingeing behaviors of sorority members became more similar over time.

The original plan of this researcher was to examine the social contagion of eating attitudes and behaviors among college women living on residence hall floors. At first, this seemed to be a logical study to pursue. Women living within residence hall floor 
communities often develop close relationships with one another. Specific behavioral norms naturally form within these communities. Based on the literature regarding the prevalence of eating disorders on college campuses, one may infer that disordered eating attitudes and behaviors could become the norm in at least a modest percentage of residence hall floor communities. Eating attitudes and behaviors may become contagious in communities where disordered eating behaviors are the norm.

This hypothesis was not supported in the literature. Although a pilot study (VanLone and Kalodner, 2000) found significant relationships between disturbed eating attitudes and behaviors and poor adjustment to college, this study found no eating attitudinal or behavioral differences between residence hall floor communities. There were no statistical differences between floors on a measure of eating attitudes and behaviors. Although insignificant differences were found, these results do contribute to the understanding of social contagion. These data may be due to both the size of the groups studied and the amount of interaction between group members. The residence hall floors studied had approximately 15 to 30 students each. It may be that smaller groups or sub-cultures were formed on each floor. It is also probable that the amount of interaction between all floor members was not sufficient to elicit a social contagion factor.

A recent study examining the social contagion of eating attitudes and behaviors with an adolescent sample additionally contributed to the design of this researcher's current study. Paxton et al. (1999) found that both eating attitudes and behaviors were similar among members of small friendship clusters. These groups ranged in size from 3 girls to 10 girls. Because these groups were formed based on each participant's self 
report of who they spent the most time with the level of interaction between members of these groups is undoubtedly higher than that of the residence hall floor communities. Therefore, although it seems premature to discard the idea of a social contagion factor among residence hall floor communities, it makes sense that further research pay attention to smaller, friendship groups in which level of interaction and pressure to confirm to social norms may be more powerful.

\section{$\underline{\text { Purpose of the Study }}$}

One purpose of this study is to contribute to the literature examining the social contagion theory and its connection with eating attitudes, eating behaviors, and sociocultural influences. Investigating the social contagion factor among college women via floor communities and friendship groups is intended to assist in the understanding of two important questions that have yet been left unanswered for this population. First, why do college women develop and or maintain eating related problems? Do college women transmit eating attitudes and behaviors from one to another? Second, why do some college women develop eating problems while others do not? What are the factors that make college women more susceptible to social contagion and the development of disordered eating attitudes and behaviors?

Developing a greater understanding of peer relationships and the social contagion of eating attitudes and behaviors has significant implications for intervention for college women with eating problems. Paxton (1999) explains that if we are to identify friendship groups as important subcultures that contribute to the development of eating disturbances, we must focus on these small groups in our primary prevention efforts. Instead of offering large prevention programs in high schools and university settings, it may be 
more effective to develop educative programs that target smaller groups such as residence hall floors and smaller, friendship cliques. Paxton (1999) also suggest concentrating our secondary prevention efforts in smaller groups in which peer influence may work to our advantage. If relevant information and resources can be made readily available to women in peer groups, it seems likely that they would have great success in offering support in seeking help to each other. The influence and support of a peer may be more effective than that of an adult.

The results of this study may also help fill a hole in the peer influence literature. The influence of peers has been an important focus for numerous studies examining other forms of malignant behavior among adolescent and early adult populations. There is evidence that peer influence has links to smoking (Barber, Bolitho, \& Bertrand, 1999; West, Sweeting, \& Patrick, 1999; Yarnold, 1999), alcohol use (Clapp \& McDonnell, 2000; Marshal \& Chassin, 2000; Sieving, Perry, \& Williams, 2000), and other drug use (Alva, 1998; Farrell \& White, 1998; Oetting \& Donnermeyer, 1998). This study will potentially add a new component to the literature, examining the effect of peer influence on eating attitudes and behaviors.

Another purpose of this study is to examine adjustment to college as a potential risk factor for the development of eating disturbance. Although an integration of the literature implies a connection between student adjustment and disordered eating, no published studies to date directly examine the relationship between these two variables. It is expected that this study will corroborate the results of an earlier study that found a significant relationship between student adjustment and disordered eating attitudes and behaviors (VanLone \& Kalodner, 2000). Examining this relationship is potentially quite 
beneficial. Identifying the types of adjustment difficulties that are related to eating disturbance will have important implications for intervention.

An additional purpose of this study is to investigate the influence that sociocultural messages have on the development of disturbed eating attitudes and behaviors. There is evidence that Western society correlates thinness with beauty, especially in regards to evaluations of women (Stice, 1994; Striegal-Moore et al., 1993). Numerous researchers have suggested that socio-cultural messages related to thinness may be connected to the development of eating disturbances (Anderson \& DiDomenico, 1992; Faith \& Schare, 1993; Garner, Garfinkel, Schwartz, \& Thompson, 1980; Irving, 1990; Kalodner, 1997; Morris, Cooper, \& Cooper, 1989; Murray, Touyz, \& Beumont, 1996; Schwartz, Thompson, \& Johnson, 1982; Shaw \& Walker, 1995; Stice, 1994; Stice, Nemeroff, \& Shaw, 1996; Stice \& Shaw, 1994; StriegatMoore, Silberstein, \& Rodin, 1986; Williamson, Cubic, \& Gleaves, 1993; Wiseman, Gray, Moismann, \& Ahrens, 1992). This study hopes to provide some evidence for this popular theory.

\section{Hypotheses}

There are four goals of this study. First, the researcher intends to demonstrate the social contagion of eating attitudes and eating behaviors. Second, the researcher plans to show the social contagion of socio-cultural acceptance, and/or socio-cultural internalization of the attractiveness ideal. It is believed that the social contagion effect will be greater among friendship clusters than among residence hall floor communities. Third, the researcher will demonstrate that adjustment to college is related to eating attitudes and behaviors. Finally, the researcher will demonstrate that socio-cultural 
acceptance and/or internalization of the attractiveness ideal is related to eating attitudes and behaviors. The following are the hypotheses of this study:

1) There will be differences in eating attitudes, eating behaviors, socio-cultural awareness, and/or socio-cultural internalization between friendship clusters.

2) There will not be differences in eating attitudes, eating behaviors, socio-cultural awareness, and/or socio-cultural internalization between residence hall floor communities.

3) Poor adjustment to college will be related to disturbed eating attitudes and behaviors.

4) Socio-cultural awareness and/or social-cultural internalization of the attractiveness ideal will be related to disturbed eating attitudes and behaviors.

\section{$\underline{\text { Key Terms }}$}

\section{Adjustment to College}

This study will examine the academic, social, and personal-emotional adjustment of first year college students. This will be measured using the Student Adaptation to College Questionnaire (SACQ) (Baker \& Siryk, 1984).

\section{$\underline{\text { Body Mass Index (BMI) }}$}

This is a simple and accurate measure of body composition that allows us to assess healthy and unhealthy levels of body weight in proportion to height (Sharkey, 1997).

\section{$\underline{\text { Eating Disorder Continuum }}$}

A continuum of eating patterns with normal eating patterns on one end and clinical anorexia nervosa or bulimia nervosa on the other end. Includes sub-clinical or 
symptomatic levels of eating disorders and other behaviors that may consist of chronic dieting, binge eating, and purging behavior (Scarano \& Kalodner, 1994).

\section{$\underline{\text { Self Esteem }}$}

This study will examine a global, unidimensional construct of self-esteem. This will be measured using the Rosenberg Self-Esteem Scale (RSE) (Rosenberg, 1965).

\section{$\underline{\text { Social Contagion }}$}

The process in which individuals adopt the attitudes and/or behaviors of others in their social world (Bovasso, 1996). This occurs by means of social pressure to conform to group norms (Crandall, 1988).

$\underline{\text { Socio-cultural Influences }}$

This is the idea that societal/cultural ideals regarding attractiveness influence individuals' eating attitudes and behaviors (Stice, 1994). This will be measured using the Sociocultural Attitudes Towards Appearance Questionnaire (SATAQ) (Heinberg, Thompson, $\&$ Stormer, 1995) 


\section{CHAPTER 2}

\section{Literature Review}

The rapid spread of eating problems among college women has influenced researchers to develop explanations regarding this phenomenon. Much attention has been devoted to developing a greater understanding of the development and/or maintenance of eating disturbances among college women, as well as the risk factors that may make this population more susceptible to developing eating problems. A current trend in the research efforts is to examine the socio-cultural influences that exist within the college environment. New research is being conducted that investigates the influence that peer relationships have on young women. This type of research is conducted in an attempt to explain why some college women develop disturbed eating attitudes and behaviors.

The social psychological concept of social contagion has been proposed to facilitate a greater understanding of the near epidemic of eating problems among college women (Crandall, 1988; Paxton et al., 1999). Though the examination of the sociocultural factors involved in the development and/or maintenance of eating disturbances among college women is important, this approach fails to explain why some women develop eating problems while others do not. The social contagion theory may help to explain why some women develop eating problems since it posits that women adopt the attitudes and/or behaviors of other women that influence them (Bovasso, 1996). A variety of personal factors make some women more susceptible to this social influence than other women. These women are consequently more likely to be influenced by the social contagion factor. This study will demonstrate that that student adjustment, selfesteem, body composition, and socio-cultural influences regarding attractiveness are all 
related to eating disturbances. This study will additionally focus on the social contagion process as an explanation of the acquisition of eating problems among college women, without dismissing the importance of socio-cultural factors in explaining why college women may develop such problems.

In this review of the literature, the researcher will present evidence of high prevalence rates of eating disturbance among college women and explain the concept of the eating disorder continuum. The review will also examine the socio-cultural factors that influence women and focus on cultural norms specific to the college environment. The researcher will examine peer relationships of young women, presenting research that suggests that eating problems tend to run in social groups. This review will then explain the social contagion process and present evidence of this process in transmitting eating attitudes and behaviors from one woman to another. Finally, the researcher will demonstrate how personal factors such as adjustment to college, self-esteem, and body composition may make college women at risk to social contagion, and thus, the development of eating problems.

\section{$\underline{\text { Prevalence of Eating Disorders Among College Women }}$}

The American Psychiatric Association (APA, 1994) reports incidence rates of anorexia nervosa of only .05 percent to 1 percent of late adolescent and early adult females. Incidence of bulimia nervosa is approximately 1 to 3 percent of adolescent and young adult females (APA, 1994). The literature presents evidence of increased prevalence rates of these disorders among college women (Berg, 1988; Clark et al., 1989; Coric \& Murstein, 1993; Halmi et al., 1981; Heatherton et al., 1995; Herzog et al., 1986; Mitchell \& Ekert, 1987; Nelson et al., 1999). As will be discussed in the following 
paragraphs, evidence suggests that even higher percentages of college women develop some type of eating problem.

A review of prevalence studies indicates that there is a higher prevalence of eating disorders for the college women population as compared to the general incidence rates (Berg, 1988; Clark et al., 1989; Coric \& Murstein, 1993; Halmi et al., 1981; Heatherton et al., 1995; Herzog et al., 1986; Mitchell \& Ekert, 1987; Nelson et al., 1999). Some studies illustrate modest rates of eating disorder incidence among college women (Heatherton et al., 1995; Mitchell \& Ekert, 1987). In their review, Mitchell and Eckert (1987) estimate that bulimia nervosa among college women is probably less than 5 percent. Similarly, in their study of subjects at a private northeastern college, Heatherton et al. (1995) find that prevalence of bulimia nervosa decreased from 7.2 percent in 1982 to 5.1 percent in 1992 .

Additional studies report considerably higher prevalence rates among the college women population (Berg, 1988; Clark et al., 1989; Coric \& Murstein, 1993; Halmi et al., 1981; Herzog et al., 1986; Nelson et al., 1999). In their study of college women at a private, liberal arts college, Coric and Murstein (1993) found that 11.3 percent of their sample fit the criteria for bulimia nervosa. Another study conducted at a suburban state university found that 13 percent of their sample of college women fit the criteria for bulimia nervosa (Halmi et al., 1981). Similarly, Berg (1988) found that 12 percent of women living in residence halls at a large urban university scored in the disordered eating range on the Eating Attitudes Test (EAT). Additionally, in their study of female business, law, and medical students, Herzog et al. (1986) revealed that 12 percent of their sample met the criteria for bulimia nervosa. More shocking studies presents estimates of 
bulimia that range as high as 19 percent (Clark et al., 1989), and estimates of anorexia as high as 20 percent (Nelson et al., 1999) among college women.

When considering the prevalence rates of eating disorders, one may also include women with eating problems that do not meet full criteria for an eating disorder. Kashubeck and Mintz (1991) explain that in addition to college women having higher rates of clinical eating disorders than other women, college women also have higher levels of eating disorder symptomatology. In one study, although only 3 percent of college women were classified as bulimic, 61 percent were classified as having some form of an eating behavior problem (Mintz \& Betz, 1988). Hesse-Biber et al. (1999) estimate that between 60 and 80 percent of college women engage in disordered eating behaviors. Similarly, additional studies have demonstrated that the majority of college women have problems with body dissatisfaction (Klemchuk et al., 1990), dieting behaviors (Franko \& Omori, 1999), and bulimic behaviors (Hesse-Biber \& Marino, 1991).

One way to better understand the eating attitudes and behaviors of college women is to consider the continuum theory. Scarano and Kalodner (1994) believe that eating disorders are best conceptualized on a continuum, with "normal" eaters at one end and eating disordered individuals on the other end. Similarly, Shisslak et al. (1995) refer to a spectrum of eating disorders, suggesting that there are many women with eating problems not at the clinical level that have significant eating problems. These individuals represent midpoints on the continuum referred to as sub-threshold, partial-syndrome, sub-clinical, or symptomatic (Kalodner \& Scarano, 1992; Shisslak et al., 1995; Tylka \& Subich, 1999). Thus, although individuals with anorexia and bulimia are not extremely prevalent 
on colleges and universities, there are great numbers of women on the eating disorder continuum who still need help.

Using the continuum theory, it has been estimated that more than half of college women have significant eating problems. Seventeen to 27 percent of college women have been reported to be at the sub-clinical level of bulimia (Kalodner \& Scarano, 1992). An additional 10 to 14 percent of college women have been reported to represent each of three other groups on an eating disorder continuum consisting of chronic dieters, bingeeaters, and purgers (Kalodner \& Scarano, 1992; Mintz \& Betz, 1988). Based on these data, it appears that college women with normal eating attitudes and behaviors are in the minority.

\section{$\underline{\text { Socio-cultural Influences }}$}

The alarming estimates of eating problems among college women suggest a need to understand some of the risk factors associated with disturbed eating attitudes and behaviors. Why do so many college women develop eating disorders? A number of researchers have contributed to a socio-cultural approach to answering this question (Anderson \& DiDomenico, 1992; Faith \& Schare, 1993; Garner, Garfinkel, Schwartz, \& Thompson, 1980; Irving, 1990; Kalodner, 1997; Morris, Cooper, \& Cooper, 1989; Murray, Touyz, \& Beumont, 1996; Schwartz, Thompson, \& Johnson, 1982; Shaw \& Walker, 1995; Stice, 1994; Stice, Nemeroff, \& Shaw, 1996; Stice \& Shaw, 1994; Striegel-Moore, Silberstein, \& Rodin, 1986; Willimason, Cubic, \& Gleaves, 1993; Wiseman, Gray, Moismann, \& Ahrens, 1992). These studies suggest that social and cultural norms have some influence in the development of problematic eating attitudes and behaviors. 
The socio-cultural approach to understanding the etiology of eating disorders posits that societal norms related to thinness and physical appearance are ultimately responsible for the development and/or maintenance of eating disorders. These norms are internalized by women, and lead to both negative self-evaluations and body dissatisfaction. These negative self-images among women are related to negative affect and ultimately lead to disturbed eating and bulimic symptomatology in some women (Stice \& Shaw, 1994).

It appears that the cultural norm of thinness has become more apparent over the past forty years. Garner et al. (1980) were the first to study this cultural norm of thinness by examining our culture's exemplars of "ideal" beauty in the form of Playboy Magazine centerfolds and Miss America contestants from 1959 through 1978. In this study, it was found that women determined to be cultural examples of "ideal" beauty were consistently thinner than the actual norms for comparable women in the population (Garner et al., 1980). In this same study, magazine articles on dieting and weight loss showed a significant and systemic increase over twenty years (Garner et al., 1980). This evidence points to cultural norms emphasizing thinness and dieting in our society.

In a replication of this study from 1979 through 1988, Wiseman et al. (1992) point to evidence of a continued increase in the emphasis on thinness in our society. This study shows that the body weight of Miss America contestants and Playboy Magazine centerfolds was 13 to 19 percent below expected body weight for women in that age group (Wiseman et al., 1992). The study also illustrates a significant increase in both diet articles and exercise articles over these years (Wiseman et al., 1992). A similar study of fashion models demonstrated that the body shapes of these models had become thinner 
from 1967 to 1987 (Morris et al., 1989). These studies provide continued evidence that this culture continues to be based on a thinness ideal. In fact, the emphasis on thinness appears to have intensified, creating a cultural norm of thinness that is virtually unattainable.

It appears that the cultural norm for thinness has discriminating effects between women and men. The emphasis on physical appearance seems to be a central component of the female gender role in our society (Stice, 1994; Striegel-Moore et al., 1986). Western society appears to be absorbed with the physical appearance of women, and this societal value leads to increased pressure on women to be thin. Research has shown that females are more likely than males to espouse negative images of their bodies (Faith \& Schare, 1993). Additional research demonstrates how the culture's beauty ideal equates attractiveness with thinness among women, possibly accounting for the higher incidence of eating disorders among women (Striegel-Moore et al., 1993).

Anderson and DiDomenico (1992) contend that the substantial difference in incidence of eating disorders between women and men is a direct result of socio-cultural norms promoting the thinness ideal. The results of this study show that the top 10 most commonly read magazines by young women contain 10.5 times more articles promoting weight loss than the top 10 most commonly read magazines by young men (Anderson \& DiDomenico, 1992). This data presents a lopsided proportion of cultural influence to be thin for women compared to men. This study provides additional evidence suggesting that increased socio-cultural pressures among women to conform to a thinness ideal accounts for increased incidence of eating disorders in women as compared to men. 
The pressure on women to achieve the thinness ideal appears to be related to disordered attitudes and behaviors regarding eating (Mintz \& Betz, 1988; Murray et al., 1995; Shaw \& Walker, 1990; Stice, Nemeroff, and Shaw, 1996; Stice \& Shaw, 1994; Williamson et al., 1993). One study shows that the greater tendency to endorse sociocultural beliefs regarding the desirability of female thinness was strongly correlated with degree of disturbed eating among college women (Mintz \& Betz, 1988). In another study, Stice et al. (1996) suggests that this socio-cultural norm of thinness is internalized by women and leads to their own body dissatisfaction. Recent studies provide evidence supporting the theory that being exposed to the norm of thinness causes women to be less satisfied with their own bodies (Shaw \& Waller, 1990; Stice \& Shaw, 1994). It has further been shown that body dissatisfaction is related to bulimic symptomatology (Stice \& Shaw, 1994; Williamson et al., 1993). An additional study illustrates that eating disorder patients are more likely than non-patients to report being influenced by body ideals (Murray et al., 1995). Thus, there appears to be a relationship between the cultural norm to be thin and the development of eating problems.

The pressure on women to adhere to the thinness ideal does not always lead directly to the development of an eating disorder. This socio-cultural influence has been shown to have more subtle effects, promoting disordered thinking and behaving among normal populations. Irving (1990) suggests that the media has an influence on women's self-evaluations regardless of their level of bulimic symptoms. In her study of noneating-disordered college women, Kalodner (1997) provides support to the theory that the cultural ideal to be thin affects women not diagnosed with eating disorders. In this study, participants who looked at pictures of thin models had significantly higher levels of 
private self-consciousness, body competence, and state anxiety (Kalodner, 1997). It appears that cultural influences emphasizing the thinness ideal plant the seeds of disordered attitudes and behaviors regarding eating even among normal populations such as college students.

As women become dissatisfied with their own bodies due to their inability to achieve the thinness ideal, they become psychologically distressed (Polivy \& Herman, 1985; Stice et al., 1996). It has been suggested that body dissatisfaction among women leads to bulimic symptomatology and is mediated by both negative affect and dieting restraint (Polivy \& Herman, 1985; Stice et al., 1996). The negative affect that a woman develops after she becomes dissatisfied with her body may, in turn, lead to the development of dieting and/or bulimic behaviors in an attempt to conform to the thinness ideal. Thus, the social and cultural factors that emphasize the thinness ideal appear to have a connection to the development of eating problems.

\section{$\underline{\text { The College Environment }}$}

The high prevalence rates of eating disorders among college women bring the socio-cultural influences of the college environment into question. Is there something about the college environment that contributes to the eating disturbances among college women? Although there is a lack of literature that specifically examines the college environment in this way, some researchers argue that the cultural norms regarding thinness and physical appearance may be intensified on college campuses for a variety of reasons (Berg, 1988; Bowden-Woodward \& Levitz, 1989; Brouwers, 1988; Hesse-Biber \& Marino, 1991; Striegel-Moore et al., 1986). Could it be that institutions of higher learning construct dynamics that contribute to the eating problems of college women? 
It may be that people on college campuses place greater emphases on beauty and thinness ideals. There is some evidence that college women with eating problems perceive that there were factors on their college campuses that contributed to an emphasis on social and cultural values to be beautiful. Connor-Greene et al. (1994) demonstrated that college women who were preoccupied with their weight believed that the environment at their college or university put a greater emphasis on appearance and beauty. Thus, it appears that an intensified pressure to meet beauty ideals exists on college campuses, at least in the perception of those who have developed disturbances in eating attitudes and/or behaviors.

The competitive environments that exist on college campuses may serve to intensify socio-cultural norms regarding thinness. Striegel-Moore et al. (1986) suggest that the stressful, competitive, and semi-closed environment of the college campus may serve to increase socio-cultural pressures to be thin. They explain that the competitive environment at a college or university may foster not only academic competition, but also competition regarding the achievement of beauty. Similarly, Brouwers (1988) suggests that by emphasizing competition, perfection, motivation, and attractiveness, the college environment may exacerbate distorted thinking and indirectly contribute to the development and maintenance of eating problems among college women. Some women may look to physical appearance and thinness as a way to compete with others.

Additional characteristics of the college environment appear to be related to the development of eating problems. Bowen-Woodward and Levitz (1989) collected data from 20 bulimic women receiving treatment who had attended college. Unanimous and overwhelming responses from these women indicated that the college environment 
directly contributed to their development and/or exacerbation of bulimia. The women explained that in addition to the emphasis of social, academic, and aesthetic competition, unstructured eating environments and separation from parents contributed to their development of bulimia (Bowden-Woodward \& Levitz, 1989).

The increased pressure on women to be thin and beautiful may also be connected to close interaction that college women have with college men. One explanation regarding how the college environment may contribute to the development of eating problems suggests that women living in close quarters with college men may have intensified pressure to conform to the thinness ideal. Berg (1988) illustrated that women living on co-educational rather than single sex residence hall floors had higher scores on measures of body dissatisfaction, drive for thinness, and self-induced vomiting. One may conclude that women living in close contact with men for the first time may have increased pressure to be thin and attractive, which may ultimately contribute to the development of eating disorders. While women who return home to a community consisting of other women may feel that they can relax, women who return home to a community consisting of men may feel as though the must continue to maintain their appearance at all times.

The period of adjustment to college itself may also contribute to the high prevalence of eating disorders among college women. In their study, Hesse-Biber and Marino (1991) assess changes in women's self-concept from high school to college, and assess the relationship between changes in self-concept and eating disorders. The finding that a decline in self-concept was associated with eating disorder symptoms suggests that transition to college may be a vulnerable time for women to develop eating problems 
(Hesse-Biber \& Marino, 1991). This relationship between student adjustment and eating attitudes and behaviors is an important risk factor associated with eating problems.

The socio-cultural approach provides a sound explanation for understanding the development of eating problems. Cultural norms regarding the thinness ideal and the emphasis of physical appearance have the potential to effect women in such a way that they may develop eating disturbances and disorders. College women may be at greater risk than other women based upon socio-cultural issues present on college campuses. Competition, unstructured eating environments, separation from parents, and adjustment issues may all contribute to the dynamics that appear to intensify socio-cultural influence to be thin and attractive. What the socio-cultural approach does not explain, however, is why some college women develop eating problems while others do not. To further explain this phenomenon, we will first examine the peer relationships of women.

\section{$\underline{\text { Peer Relationships }}$}

The influence that peers have on one another, especially during adolescence and early adulthood, are quite powerful. As children grow older, their peer relationships become more influential than parental and family relationships. Beginning in early adolescence, both girls and boys tend to look more to individuals their same age for modeling and advice (Pipher, 1994; Pollack, 2000). The influence of peers begins to shape the thoughts, attitudes, and behaviors of young people. Studies cited throughout this section of this chapter suggest that this influence from peers continues for individuals throughout early adulthood, well into their college years.

The power of peer influence has been demonstrated in many areas of the psychological literature. For example, the influence of peers has been found to be an 
important factor in the smoking behavior of young adults. Barber et al. (1999) found that peer pressure was significantly associated with smoking in a study of 2,000 junior high and high school students. Additionally, in her study of high school students, Yarnold (1999) found that having friends who smoke was the most significant factor influencing the probability of smoking among participants. More strikingly, in a longitudinal study of over 1,000 young people, West et al. (1999) found that the smoking behavior of peers increased the likelihood of participant smoking by up to ten times in their growth from age 15 to age 23 . This literature examining the smoking behavior of adolescents and young adults demonstrates the power of peer influence in contributing to the acquisition of a harmful behavior, such as smoking.

The influence of peers is also considered in the study of alcohol use among young people. Sieving et al. (2000) demonstrate in their study of nearly 2,000 junior high school students that adolescents whose friends used alcohol were significantly more likely to engage in alcohol use. There is also some evidence that parental influences do not impact the influences of peers. Marshal and Chassin (2000) show that regardless of parental support, peer alcohol use was identified as the primary influence in the alcohol use of adolescent boys and girls. It has additionally been demonstrated that this peer influence is just as powerful among the college student population (Clapp \& McDonnell, 2000). This study demonstrates that college student perceptions of peer drinking behavior significantly predicted their own alcohol use (Clapp \& McDonnell, 2000). This body of literature contributes to the notion that peers often influence each other to develop harmful behaviors. 
Peer behavior also seems to quite influential in young people's experiences with illegal drugs. In a study of 10th grade boys and girls, it was shown that both peer pressure and peer drug use were significantly related to the reported frequency of drug use (Farrell \& White, 1998). This peer influence has also been demonstrated at the college level. Alva's (1998) study examined the importance of peer norms in the development of alcohol and drug behaviors, demonstrating that sorority and fraternity members tended to develop the alcohol and drug behaviors of those in their organization. An additional study suggested that peer clusters have great power in transmitting deviant norms such as alcohol and drug behaviors (Oetting \& Donnermeyer, 1998). This literature additionally contributes to the portrayal of the power of peer influence.

The evidence of powerful peer influences among adolescent and young adults in their smoking, alcohol and illegal drug behaviors have some application to the eating attitudes and behaviors of college women. It makes sense that similar peer influences would exist among young women in regards to eating. The research in this area, however, is not as developed as the peer influence research examining smoking, alcohol, and illegal drug behaviors. Although peers have been suggested as potential sources of socio-cultural influence (Levin et al., 1994; Stice, 1994), to date, peer influences have received only moderate attention in the eating disorder literature. The literature does demonstrate that eating disordered behaviors tend to run in social groups (Beren et al., 1997; Brooks-Gunn et al., 1998; Druss \& Silverman, 1979; Silberstien et al., 1989). An early study illustrates an example of how eating disorders spread through a social group or subculture of ballerinas (Druss \& Silverman, 1979). In this study, subjects describe their subculture as having an emphasis on the desire to be thin as a 
means to succeed in a performance activity and to please their dancing instructors. As individuals became part of this culture, they frequently developed these disturbed attitudes and often developed bulimic symptoms (Druss \& Silverman, 1979). In this case, the pressure to perform and to fit into the norms of the subculture contributes to the development of eating problems.

Another study illustrates a similar social process occurring among female athletes (Brooks-Gunn et al., 1988). In this study of figure skaters, ballet dancers, and swimmers, it was shown that each of the three groups developed norms for thinness based upon performance needs. Skaters and dancers reported a desire to weigh less than swimmers in order to achieve their performance goals. Conversely, swimmers reported a higher ideal weight than skaters and dancer, in an effort to retain strength and endurance needed for success in their sport. This development of a cultural norm to achieve greater thinness led to more disordered eating behaviors among both skaters and dancers (Brooks-Gunn et al., 1988).

Additional studies have shown how eating disorders have tended to spread among both the gay male and lesbian subcultures (Beren et al., 1997; Silberstein et al., 1989). In their study of lesbian college students, Beren et al. (1997) explained that the lesbian culture was clearly accompanied by ideals of thinness and physical appearance and that women identifying with this subculture were more at risk than heterosexual women to be dissatisfied with their bodies. In a study with similar results, Silberstein et al. (1989) found that gay men considered physical appearance central to their sense of self, reported greater body dissatisfaction, and had more behaviors associated with disordered eating 
then did straight men. This finding supports the idea that a subculture that emphasizes appearance may heighten the vulnerability of their members to develop eating disorders.

It may be said that peer groups develop their own subcultures. These subcultures often intensify the already existing cultural norm to be thin. Individuals within these subcultures must follow these norms if they are to fit in with their group. Paxton (1996) suggests that these subcultures may either enhance or diminish the cultural ideal of thinness and engaging in weight loss strategies. Those peer groups who develop cultural norms of thinness and weight loss will influence other members of the groups to follow these norms. In their study of high school girls, Paxton et al. (1999) demonstrate that girls formed friendship groups among classmates and these friends developed eating attitudes and behaviors of other members in their group.

For the purposes of this study, it is important to consider gender differences in peer influence. It appears that peer influence can be quite strong among young college women. Presenting a particular striking study of peer influence among college women may be the best way to demonstrate this point. McClintock (1971) demons trated that women living together in college residence halls developed synchrony in their menstrual cycles over time. McClintock (1971) contends that the social interaction between women living in residence hall communities had a strong effect on the resulting synchronized menstrual cycles of women living in these communities. This study points to evidence suggesting that social interaction among women living in a small residence hall communities has an influence so strong that it allows for the transfer of not only behavioral processes, but even physiological processes between women living in these communities. 
In a replication of this study, Weller, Weller, and Avinir (1995) explain that menstrual synchrony exists only among women living in residence hall communities who were close friends. This suggests a relationship between the closeness of the women in the study and the potential for menstrual synchrony. The idea that the degree of social closeness between women has an impact on the adoption of characteristics similar to other women within a particular subculture or community has important implications for further research studies. This suggests that small groups of close friends may have greater influences over each other than larger groups of college women such as sororities and residence hall communities.

There are additional indications that peer influence of eating attitudes and behaviors may be more powerful among women than among men. As women become members of peer groups, they begin to compare their bodies with other women in their groups. Studies have shown that females are more likely than males to compare their bodies with their peers (Beebe, Holmbeck, Schober, Lane, Rosa, 1996; Murray et al., 1995). Women are also more likely to have their bodies criticized, and to talk about dieting with members of their peer groups (Murray et al., 1995). Paxton (1996) refers to this as "fat talk", explaining that the dialogue between friends regarding weight and body image has a significant impact on the eating behaviors of girls. Thompson, Coovert, and Stormer (1999) additionally demonstrate that appearance related teasing among college women is significantly correlated with eating disturbances. It is evident that women begin to compete with each other in their attempts to adhere to the thinness ideal. This may be a result of the increased socio-cultural pressures on women. 
It also appears that acceptance into a social peer group plays an important role in a woman's development of eating problems. Dunn and Ondercin (1981) demonstrate that women with eating disorders show a greater need for approval and acceptance from others compared to women without eating disorders. Additionally, women with eating disorders have reported significantly more social impairment than women without eating disorders, and their eating disorder behaviors have been shown to be associated with degree of social impairment (Herzog et al., 1986). Further research shows that women with bulimia report less social support, less social competence, and are rated as less socially effective (Grisset \& Norvell, 1992). Thus, the need for social approval and acceptance tends to be important for women.

The studies presented in this section provide strong evidence that suggests that the eating attitudes and behaviors of groups may spread among individuals within these groups. The studies demonstrate that attitudes and behaviors of individuals in certain groups, subcultures, or communities often become more like other individuals in those groups. The studies also suggest that the closeness of members within these groups may predict the degree to which attitudes and/or behaviors are transmitted between group members. A theory explaining specifically how certain attitudes and/or behaviors a transmitted from one individual to the next is needed to fully understand this phenomena.

\section{$\underline{\text { Social Contagion }}$}

One proposed method of understanding group influences on individuals is through the social contagion theory. This theory suggests that individuals have attitudes and behaviors similar to those around them. Social contagion has been defined as the process by which individuals adapt the attitudes and/or behaviors of others that influence them 
(Bovasso, 1996). Another description of this process states that the social contagion process occurs as strong social norms evoke individual conformity to social standards, even when this conformity may be in conflict with personal attitudes, values, and standards (Prentice \& Miller, 1996).

Wheeler (1966) provides a similar definition of social contagion as a process resulting in the transfer of a behavior. Wheeler (1966) explains that an individual, in most cases, will usually not act out a behavior that may lead to some sort of negative outcome. However, when there is a strong impulse or urge toward a fulfillment of a need, the acting out of that conflictual behavior by a model, increases the likelihood of that behavior being performed (Wheeler, 1966). Presented in the context of the acquisition of eating disorders, a disordered eating behavior, such as vomiting after eating, may be a behavior that most individuals would rather avoid. An individual may conduct this behavior (vomit) as an attempt to fulfill a need (thinness, group acceptance) if others within the group model that behavior.

The theory of social contagion has been used to develop a greater understanding of the social psychological processes in studies of various group behaviors. The phenomena of social contagion helps to explain how specific group behaviors are acquired by individuals within groups. Rodgers and Rowe (1993) used a social contagion model to examine how sexual behavior spread through the adolescent population. They found that individuals who made contacts with networks in which sexual behavior was the norm had increased levels of sexual behavior (Rodgers \& Rowe, 1993). Prentice and Miller (1993) utilized the social contagion theory in their examination of the spread of alcohol use among college students, finding that male students shifted toward the norm 
drinking behavior of their groups. Ennet \& Bauman (1994) demonstrated that smoking behavior spread between peers as a result of a both a contagion factor and peer selection. Additionally, Bovasso (1996) used the social contagion concept to examine teamwork norms among business executives. He found that individuals in the groups were influenced by the ideas of strong group leaders (Bovasso, 1996).

Crandall (1988) was the first known researcher to utilize the social contagion theory to explain the development of disordered eating behaviors. He explains that bulimia is most likely a social disease that individuals acquire from their friends, much like the way people acquire contagious biological diseases from each other (Crandall, 1984). In an important study, Crandall (1988) presents a theory of social contagion of binge eating, suggesting that behaviors may be transmitted from one individual to another through a social psychological process. While an understanding of the socio-cultural influences explains why women might develop eating disorders, this theory of social contagion sheds more light on how the eating disorder behaviors are acquired by women. This theory posits that if a disordered eating behavior (binge eating) is a cultural norm within a subculture (sorority), this behavior may be transmitted to individuals within that subculture (Crandall, 1988). In essence, the actual behavior is contagious among group members.

This process of social contagion is achieved through the social influence within a group (Crandall, 1988). Social influence refers to the social pressure placed upon individuals within the group to conform to group norms. Additionally, in order for an individual to be affected by social influence, there must be some sort of closeness between group members. Crandall (1988) used a measure of popularity as an indicator of 
the closeness between individuals in the group. He illustrated the presence of social influence by examining the relationship between an individual's deviation from the binge eating norm and that individual's popularity in the group (Crandall, 1988). The results demonstrated that the popularity of group members was directly related to their level of conformity to the binge eating group norm (Crandall, 1988).

Paxton et al. (1999) contribute to the social contagion literature in their study of adolescent friendship group influences on the eating attitudes and behavior of each other. In this study, 79 friendship groups of 523 tenth grade girls were formed by asking participants a few questions about their friendships, and then using a statistical package to calculate friendship clusters created the groups in this study. Among these 79 friendship groups, there were greater between group differences than within group differences for body image concerns, dietary restraint, and extreme weight- loss behaviors (Paxton et al., 1999). In this study, BMI, depression, and self-esteem were used as covariates as they were suggested to be consistently observed as being related to eating problems. The general results of this study were that both some eating attitudes and eating behaviors of the girls were more similar among particular friendship group members than among those not in the groups.

This study is important in that it was the first to consider the social contagion process among the eating attitudes and behaviors of adolescent girls. It demonstrated that this process is also at work among these younger girls. It was also the first to examine the social contagion of eating attitudes and behaviors smaller friendship groups. It suggests that similarities in eating attitudes and behaviors may be more powerful in smaller friendship groups with a lot of social interaction than in larger groups in which 
members do not have as much opportunity to react. Thus, it would be expected that the social contagion effect be greater among small, friendship groups than larger subcultures such as sororities and residence hall communities.

\section{$\underline{\text { Risk Factors }}$}

Though social influence among groups can be quite powerful, not all individuals will be influenced by the pressure to conform to the attitudinal and behavioral group norms. Personal factors determine levels of susceptibility to social influence and thus, social contagion. Crandall (1988) indicates that personality characteristics such as impulsivity, poor family environment, and a poorly developed sense of self may make individuals more susceptible to the social contagion factor. Others have found that individuals who encounter stressful life events are more susceptible to social influences (Gralen et al., 1990; Levine \& Smolak, 1992).

It is also suggested that individuals under stress due to transitional events in their lives may become more susceptible to group influences. Pike (1995) demonstrates that ninth grade girls become more susceptible to social influence because of the stress that accompanies transition to high school. Crandall (1986) also illustrates that people with low self-esteem are more open to the social influence that may contribute to the development of bulimic behaviors. This evidence suggests that future studies of social contagion should examine personal factors similar to those listed above. In doing so, a researcher may be able to identify what factors may make individuals more susceptible to social contagion.

In addition to examining factors that increase susceptibility to social contagion, it is also important to consider risk factors that may make college women susceptible to the 
development of eating disorders. As demonstrated in this review of the literature, some aspects of the college environment appear to promote the development of personal factors that put college women at-risk for the development of eating disorders. Adjustment difficulties, reductions in self-esteem, and increases in the body weight that often effect women in their first year of college make these women more prone to the development of eating problems.

In this study, adjustment to college, self-esteem, and body composition will be examined as risk factors for the development of eating problems. Additionally, both adjustment to college and self-esteem will be studied as factors that make individuals more susceptible to the social contagion effect. These three variables were chosen due to their connection to the college experience and their proven relationship to eating problems and/or their links to the social contagion process.

\section{Adjustment to College}

Student adjustment to the college environment has been an increasingly popular topic of study over the past 20 to 25 years. Astin (1977) was one of the first to focus on the types of stressors that college students face. He explained that college students, particularly in their first year, endure increased levels of academic and personal stress (Astin, 1997). The finding that most college students were found to feel more challenged by course material and experience stress related to academics was expected. What was novel about Astin's (1977) works was that he discussed the personal stress that college students experience in their transition to a new environment away from family and friends. Subsequent to Astin's focus on the stressors of college students, much attention 
has been directed toward both the academic and personal stress that students experience throughout their college years.

Current research confirms increases in the stress levels of college students, especially in the first year of college. Murphy and Archer (1996) demonstrate that college student continue to experience increased levels of stress in their four years of college as compared to their stress levels before entering college. They identify examinations, grades, class environment, and time demands as pervasive academic stressors, and intimate relationships, finances, and parental conflicts as significant personal stressors (Murphy \& Archer, 1996). Additionally, in a four-year longitudinal study, Sher et al. (1996) demonstrate that psychological distress among college students is greater in their first year, and levels of stress decline systematically over each of the four years of their years in college.

It has been suggested that the increased levels of stress accompanied with adjustment to the college environment is related to the development of eating problems (Bowen-Woodward \& Levitz, 1989; Hesse-Biber \& Marino, 1991; Hesse-Biber et al., 1999; Striegel-Moore et al., 1989). Hesse-Biber and Marino (1991) explain that as students transition from high school to college, they face changes in their social, psychological, and academic environments that produce great stress. This stress also may account for the increase in eating problems among the college women population (HesseBiber \& Marino, 1991). In similar studies, researchers have concurred with the theory that this stress associated with transition is related to increases in eating disturbance (Hesse-Biber et al., 1999; Bowen-Woodward \& Levitz, 1989; Striegel-Moore et al., 1989). Additional studies have demonstrated that this adjustment stress, although maybe 
not as intensive, also is generated in the transition from junior high school to high school (Gralen et al., 1990; Pike, 1996).

There is currently a lack of research that looks directly at relationships between student adjustment and eating problems. However, one recent study demonstrates relationships between college student adjustment to college and eating disturbance. In this study of first year college women in their first semester of school, it was found that disturbances in student adjustment to college predicted some problematic eating attitudes and behaviors (VanLone \& Kalodner, 2000). Specifically, the study demonstrated that dieting behaviors were predicted by personal and emotional adjustment difficulties (VanLone \& Kalodner, 2000). This study suggests a continued examination of student adjustment and behavioral and attitudinal eating variables.

In addition to being related to eating disturbance, it also appears that student adjustment may play an important role in the social contagion process. The link between stress and the social contagion process is clear. Levin and Smolak (1992) demonstrate that stressful events render individuals more susceptible to social influence. It additionally appears that adjustment stress has similar connections to social contagion. Pike (1995) suggests that the stress related to student adjustment issues may make students more likely to be influenced by the social contagion process. Thus, it seems important to consider student adjustment variables in a study of social contagion among college women.

\section{$\underline{\text { Self-Esteem }}$}

The college environment also appears to affect the self-esteem of many students. It has been demonstrated that although the college experience may serve to increase 
individual's levels of self-esteem in the long run, students in their first year of college often have lower scores on measures of self-esteem than they did when they were in high school (Chickering \& Reisser, 1993; Pascarella \& Terenzini, 1991). One study of 142 first year college students, demonstrates a significant relationship between adjustment to college and self-esteem (Bettencourt et al., 1999), such that poor adjustment to college was related to lower levels of self-esteem. Thus, it appears that college students, at least in their first year of school, may have lower levels of self-esteem.

Research has also pointed to relationships between self-esteem and eating problems (Connors, 1996; Shisslak et al., 1998; Wood et al., 1994). In a study of adolescent girls it was demonstrated that poor self-esteem was associated with unhealthy eating attitudes and behaviors (Wood et al., 1994). An additional study suggests strong associations between self-esteem and eating disturbance for both adolescent and young adult females (Connors, 1996). It has been argued that the link between self-esteem and eating disorders appears so important that current intervention strategies should be developed to target the enhancement of self- esteem as a buffer for the development of eating problems (Shisslak et al., 1998).

Although a strong relationship between self-esteem and eating disturbance has been consistently supported in the literature (Connors, 1996; Shisslak et al., 1998; Wood et al., 1994), the specific reasons for this link are not particularly clear. This relationship may be connected to stress levels among young women. Fryer et al. (1997) demonstrate that the stressors that students endure lead to low levels of self-esteem that are very strongly associated with disturbed eating attitudes. Leary et al. (1995) suggests that the link between self-esteem and eating problems may be mediated by a fear of rejection by 
others. It may be argued that such a desire for social acceptance may be intensified for students in their first year of college, perhaps making this relationship even stronger. An additional theory suggests that a lack of autonomy is related to self-esteem, and thus connected to the development of eating disturbance (Frederick \& Grow, 1996). Again, first year college women, often in search of autonomy, may have strong connections between their self-esteem and eating attitudes and behaviors.

Based on this literature, it is clear that low self-esteem may be considered a risk factor for the development of eating problems. It has been suggested that low levels of self-esteem may make individuals more susceptible to social contagion (Crandall, 1988; Levin \& Smolak, 1992; Pike, 1995). A good example of this is Crandall's (1988) study of sorority women. In this study, it is demonstrated that the subjects became more popular as they submitted to social influence and practiced the norm behaviors of their group. It makes sense that those individuals with lower levels of self-esteem may be at risk to engage in behaviors that would help them to ease the tension associated with a poor self-concept. It is reasonable to infer that women with low levels of self-esteem would look to others to help them improve their concept of themselves.

\section{$\underline{\text { Body Composition }}$}

Body composition and body weight, as measured by the Body Mass Index (BMI), has been consistently demonstrated to be very strongly related to the development of eating problems (Ben-Tovim \& Walker, 1994; Davis, Shapiro, Elliot, \& Dionne, 1993; Greeno, Jackson, Williams, \& Fortmann, 1998; Hannan, Wrate, Cowen, \& Freeman, 1995; Kennet \& Nisbett, 1998; Kenny \& Adams, 1994; Klump, McGue, \& Iacono, 2000; Kolody \& Sallis, 1995; Lowry, Galuska, Fulton, Wechsler, Kann, \& Collins, 2000; 
Monteath \& McCabe, 1997; Mukai, Kambara, \& Sasaki, 1998; Pritchard, King, \& Czajka-Narins, 1997; Shisslak, Crago, McKnight, Estes, Gray, \& Parnaby, 1998;

Striegel-Moore, Dohm, Soloman, Fairburn, Pike, \& Wilfley, 2000; Strong \& Huon, 1998; Taylor, Sharoe, Shisslak, Bryson, Estes, Gray, McKnight, Crago, Kraemer, \& Killen, 1998; Van Strien, 1985; Wassenaar, le Grange, Winship, \& Lachenicht, 2000; Yates, 1992). A sampling of some of this literature will help to produce a more detailed understanding of the connection between body weight and disturbed eating attitudes and behaviors.

Mukai et al. (1998) demonstrate in their recent study that BMI was a significant predictor of eating disturbances among American college women. For women in this study, being overweight predicted their development of an eating problem. A number of additional studies demonstrated relationships between high BMI scores disordered eating attitudes. High BMI has been related to poor body image (Kolody \& Sallis, 1995) and perceived body weight (Prithcard et al., 1997). More studies have demonstrated strong relationships between BMI scores and disordered eating behaviors. High BMI has been shown to be associated with dieting behavior (Davis et al., 1993; Strong \& Huon, 1998), lack of control over eating (Greeno et al., 1998) and other specific weight control behaviors (Shisslak et al., 1998). It is clear that increased body weight has strong associations with disturbed eating attitudes and behaviors.

College women often gain weight during their first year. It has been argued that they may be more likely to increase their weight during their first year of college due to less structured eating environments (Bowen-Woodward \& Levitz, 1989). Compared to the structured time that women had to eat during their high school years, the college 
environment leaves rules for eating more undefined, often leading to increases in body weight. It has additionally been argued that this weight gain will have greater effects on women than on men. In one study that demonstrated that 35 percent of a sample of college students were overweight or obese, it was found that females were more likely to attempt to lose weight after gaining this weight in college (Lowry, Galuska, Fulton, Wechsler, Kann, and Collins, 2000). The potential for weight gain among first year college women may put them at greater risk for the development of eating problems. Thus, it seems important to consider the variable of body weight in a study of eating disturbance among this population.

\section{$\underline{\text { Conclusion }}$}

In this chapter, it has been demonstrated that eating problems are quite prevalent among college women. Using the continuum theory, it is suggested that the majority of college women have some type of eating problem. The literature presented suggests that this may be due to socio-cultural norms that exist on college campuses, which may intensify the thinness ideal. Additional literature presented in this chapter demonstrates the importance of peer influences in the development of eating attitudes and behaviors among college women. It is further suggested that the social contagion theory may be useful in understanding the development of eating disturbances among college women. This theory suggests that college women may develop the norm eating attitudes and behaviors of their group or subculture. This theory may help to explain why some women develop eating problems while others do not. Finally, adjustment to college, selfesteem, and body composition were proposed as variables that may make college women at risk to the social contagion process and the development of eating problems. 


\section{CHAPTER 3}

Method

This chapter outlines the specific methods utilized to test the hypotheses indicated in the first chapter of this document. The chapter is broken down into the following sections: participants, procedure, instrumentation, research design, and data analysis.

\section{$\underline{\text { Participants }}$}

The participants in this study are women in their first semester of college living in an all female residence hall. They are at a large state university in the mid-atlantic region of the United States. Two hundred and twelve women were surveyed from 2 residence halls. The participants are from 14 separate residence hall floor communities. One hundred and ninety-six surveys were used in this study due to some incomplete surveys. Only a handful of participants indicated their ethnic background (less than ten percent). We can assume that the ethnic background of participants mirrored the data available of students at this university. Data collected from university records indicate that 7 percent of first year students in the Spring of 2000 semester identify as being from ethnic minorities (West Virginia University, 2001, para. 1). The mean body-mass index of the subjects is 21.66 , with a range of 17 to 38 .

The researcher obtained Institutional Review Board approval and adhered to the policies and procedures for treatment of human subjects. Confidentiality of individual results was maintained and participants were treated in accordance with the ethical standards of the American Psychological Association (APA, 1992). Informed consent was addressed preceding all data collection. The researcher read a short script that included a detailed description of the study as well as a statement assuring confidentiality 
of individual results. Residence hall staff were provided with contact information of the researcher in case any questions or problems arise during the course of the study.

\section{$\underline{\text { Procedure }}$}

Participants completed questionnaires in groups at scheduled residence hall floor meetings. There were 14 separate meetings for each of the 14 distinct residence hall floor communities. The groups completing these measures ranged in size from 5 to 23 . With the cooperation of residence hall staff members, 66 percent of 299 possible participants attended these meetings. The researcher had success obtaining a 55\% participation rate from the same population in the Fall of 1998 (VanLone \& Kalodner, 2000). In an effort to ensure a good response rate, the researcher offered additional incentives for individuals to participate in the study. All participants were entered in a raffle that awarded 8 participants 25-dollar gift certificates. These certificates were purchased from the Morgantown Mall. Participants were instructed that the questionnaire was a "study of residence hall community life, friendship, and eating attitudes and behaviors" and were informed that they could receive a report of the results of the study when it is completed.

The questionnaires in this study measure eating attitudes and behaviors, sociocultural influences regarding attractiveness, adjustment to college, global self-esteem, and body weight and composition. An additional instrument is used to assign participants into a number of friendship clusters. All measures are reviewed in the next section of this chapter.

\section{$\underline{\text { Instrumentation }}$}

Several measures were administered to participants. They answered 4 questions used to identify friendship networks (see Appendix A). They completed the Eating 
Disorder Inventory-2 (EDI-2) to measure eating behaviors and attitudes (see Appendix B), the Rosenberg Self-Esteem Scale (RSE) to measure global self-esteem (see Appendix C), the Socio-cultural Attitudes Towards Appearance Questionnaire (SATAQ) to measure awareness and internalization of socially accepted standards of appearance (see Appendix C), and the Student Adaptation to College Questionnaire (SACQ) to measure adjustment to college (Appendix D).

\section{Eating Disorder Inventory-2 (EDI-2)}

The original EDI was designed by Garner and Olmstead (1983) to measure attitudinal and behavioral dimensions relevant to anorexia and bulimia. In 1991, Garner developed the EDI-2, a revised version of the EDI. The EDI-2 contains the original subscales from the EDI and includes three new subscales that measure additional dimensions of eating disorders (Garner, 1991).

Current research on the EDI-2 suggests that the measure is an economical, reliable, and useful instrument for assessing the psychological and behavioral dimensions of eating disturbance among both clinical and non-clinical populations (Lee, Lee, Leung, \& Yu, 1997; Schoemaker, van Strien, van der Staak, 1994). Crowther and Sherwood (1997) explain that the EDI-2 can be useful in differentiating between college women who meet diagnoses for clinical eating disorders and college women who have eating problems at sub-clinical levels. This suggests the utility the EDI has in measuring different levels of eating disorder attitudes and behaviors across a continuum. Numerous researchers have used either the EDI or EDI-2 as measures of sub-clinical levels of eating attitudes and behaviors for the college women population (Berg, 1988; Connor-Greene et al., 1994; Davis \& Cowles, 1989; Friedlander \& Siegal, 1990; Kashubeck \& Mintz, 1996; 
Kashubeck et al., 1994; Meyer, 1997; Skowron \& Friedlander, 1994; Taub \& Blinde, 1992; Warren, Stanton, \& Blessing, 1990).

\section{Content of the EDI}

The EDI was developed on the premise that eating disorders are multidetermined and multidimensional (Garner, 1991). The original EDI contained 8 subscales with 64 items intended to measure a number of dimensions of eating disorders. The subscales of the original EDI are Drive for Thinness, Bulimia, Ineffectiveness, Interpersonal Distrust, Perfectionism, Interoceptive Awareness, and Maturity Fears (Garner, 1991). The EDI-2 is an extended version of the EDI that contains 91 self-report items measuring 11 behavioral and psychological traits associated with eating disorders (Garner, 1991). The 3 subscales added in the EDI-2 are Asceticism, Impulse Regulation, and Social Insecurity (Garner, 1991).

Responses to the items on all subscales are marked and scored on a 6-point Likert type scale from (1) never to (6) always. High scores on the EDI represent maladaptive attitudes and behaviors associated with eating. The EDI was initially normed on subjects with clinically diagnosed eating disorders. A more current normative sample consists of 129 anorexia nervosa restrictors, 103 anorexia nervosa bulimics, and 657 bulimia nervosa patients (Garner, 1991). Though there are normative data on 770 female college students, the EDI-2 manual does not provide any norms for the three new subscales.

In an effort to be efficient and to sufficiently measure both eating attitudes and behaviors, the Drive for Thinness, Bulimia, and Body Dissatisfaction subscales will be used in this study. This is not the first time that the use of the EDI- 2 has been limited to these subscales. For example, Heinberg, Thompson, and Stormer (1995) used only these 
3 subscales to examine both the eating attitudes and behaviors of their participants. Limiting this study to these subscales will effectively reduce the size of the overall instrument, while still providing an adequate assessment of the eating attitudes and behaviors of the participants.

$\underline{\text { Drive for Thinness }}$

This scale includes seven items that assess both attitudes and behaviors regarding an individual's desire to be thin. Examples of items on this subscale include, I am terrified of gaining weight and I eat sweets and carbohydrates without being nervous (Garner, 1991). Alpha levels for this subscale have been reported to fall between .81 and .91 (Garner \& Olmstead, 1984; Lee et al., 1997; Raciti \& Norcross, 1987; Shore and Porter, 1990; Vanderheyden et al., 1987).

\section{$\underline{\text { Bulimia }}$}

This scale includes seven items that measure bingeing and purging behaviors among individuals. Examples of items on this subscale include, I stuff myself with food and I have thought of trying to vomit to lose weight (Garner, 1991). Alpha levels for this subscale has been reported to fall between .69 and .83 (Garner \& Olmstead, 1984; Lee et al., 1997; Raciti \& Norcross, 1987; Shore \& Porter, 1990; Vanderheyden et al., 1987).

\section{$\underline{\text { Body Dissatisfaction }}$}

This scale includes nine items intended to measure an individual's attitude regarding her or his body. Examples of items on this subscale include I think my stomach is too big and I think my hips are too big (Garner, 1991). Alpha levels for this subscale has been reported to fall between .89 and .93 (Garner \& Olmstead, 1984; Lee et al., 1997; Raciti \& Norcross, 1987; Shore \& Porter, 1990; Vanderheyden et al., 1987). 


\section{$\underline{\text { Administration }}$}

The administration of the full EDI-2 takes about 20 minutes (Garner, 1991). The administration of the 3 subscales used in this study is estimated to take approximately 5 minutes. The 3 subscales account for 23 of the 91 items. The EDI- 2 may be administered to either groups or individuals, and it is intended for use with ages of 12 years and up (Garner, 1991). This suggests the instrument's utility in being administered to small groups of college women.

\section{$\underline{\text { Reliability }}$}

Alpha coefficients for the EDI total scores range from .80 to .93 (Garner, 1991; Garner and Olmstead, 1984; Joiner \& Heatherton, 1998; Lee, et al. 1997; Schoemaker, et al.1994 Swassing, 1989). Additionally, the EDI-2 manual reports that the measure has sufficient test-retest reliability (Garner, 1991). Specific test-retest reliability ranges of EDI-2 subscales have been reported at .61 to .75 (Crowther, Lily, Crawford, Shepard, \& Oliver, 1990), .65 to .97 (Wear \& Pratz, 1987), and .67 to .95 (Welch, 1988). Garner (1991) explains that the stability of the traits of the EDI is relatively enduring in nature.

\section{$\underline{\text { Validity }}$}

One method of assessing the criterion-related validity of the EDI is to determine the ability of items that discriminate between individuals with clinical levels of eating disorders and individuals not diagnosed with eating disorders. In the original validation study of this measure, it was illustrated that every item met this criterion (Garner, Olmstead, \& Polivy, 1983).

The EDI has also been shown to demonstrate strong convergent validity when compared to the Eating Attitudes Test-26 (EAT-26), the Restraint Scale, the Beck 
Depression Inventory (BDI), and the Hopkins Symptom Checklist (Garner, 1991).

Additionally, the EDI correlates with a number of measures of body weight and body image (Garner, 1991).

\section{$\underline{\text { Summary }}$}

The EDI and EDI-2 are widely used instruments in eating disorder research that have demonstrated strong reliability and validity. Because the EDI-2 is relatively new, there is less research supporting the quality of the three new subscales. However, the EDI-2 appears to be a useful instrument for the measurement of eating disorder attitudes and behaviors that exist on a continuum. For this reason, the EDI represents a measure useful for the purposes of this study.

\section{$\underline{\text { Student Adaptation to College Questionnaire (SACQ) }}$}

The first version of the SACQ, developed by Baker and Siryk (1984), was intended to define how well a first year college student is adapting to the demands of the college experience (Murphy, Conoley, \& Impaza, 1994). The most current edition of this measure was published in 1989. This measure may be utilized for two purposes. First, it provides a source of dependent variables in the investigations of the role of personality and environmental determinants of adjustment to college. Second, it may be employed as a diagnostic tool for identification of students who have difficulties adjusting to college and may need assistance (Baker \& Siryk, 1984).

The measure has been shown to have a high potential for a number of research applications (Asher, 1992; Dahmus, Bernardin, \& Bernerdin, 1992). The instrument has been used to illustrate associations between college adjustment and academic major decidedness (Smith \& Baker, 1987), competitiveness (Haemmerlie, Robinson, \& Carme, 
1991), dissociation (Sandberg \& Lynn, 1992), family environments (Garbarino \& Strange, 1993; Kenny \& Doneldson, 1992; Kenny \& Stryker, 1996; Lopez, Campbell, \& Watkins, 1988; Palladino-Schultheiss \& Blustein, 1994; Rice, 1992; Rice \& Whaley, 1994), learning disabled students (Scaracoglu, Minden, \& Wilchesky, 1989), personal and individual factors (Brooks \& DuBois, 1995), religion (Low \& Handel, 1995), traumatic life events (Zamostony, Slyter, \& Rios, 1993), and disordered eating (VanLone \& Kalodner, 2000).

\section{Content of the SACQ}

The SACQ has a total of 4 subscales with 67 items. The sub-scales include Academic Adjustment (24 items), Social Adjustment (20 items), Personal-Emotional Adjustment (15 items), and Goal Commitment-Institutional Attachment (15 items) (Dahmus et al., 1992). Two additional items are included in the Full Scale score, but are not included in any of the subscales. Student responses on the sub-scales are marked and scored on a 9-point Likert type scale from (1) applies very closely to me to (2) doesn't apply to me at all (Dahmus et al., 1992).

High scores on the Full Scale and on each individual scale represent successful adjustment to college (Asher, 1992). More accurately, the higher the score, the better the self-assessed adjustment to college. Conversely, the lower the score, the greater the reported difficulty (Dahmus et al., 1992). No cutoff scores for the Full Scale, or for any of the subscales, have been determined. The SACQ was initially normed on 1,424 college freshmen at Clark University in 1980-81, 1981-82, 1982-83, and 1983-84 (Asher, 1992). 


\section{$\underline{\text { Academic Adjustment Scale }}$}

This subscale represents a measure of a student's success in coping with the various educational demands characteristic with the college experience. Items specifically assess the amount and type of studying of students, their ability and motivation to keep up in classes, and their formulation of academic goals. Examples of items on this sub-scale include, Recently I have had trouble concentrating when I try to study and I really haven't had much motivation for studying lately (Baker \& Siryk, 1989). Alpha levels for this subscale have been reported to fall between .81 and .90 (Asher, 1992; Baker \& Siryk, 1984; Baker \& Siryk, 1986; Dahmus et al., 1992).

\section{$\underline{\text { Social Adjustment Scale }}$}

This subscale assesses a student's success in coping with interpersonal-societal demands of the college experience. It specifically examines an individual's involvement in interpersonal and social group activities at the university, an individual's coping with relocation to college, and an individual's satisfaction with the social aspects of the college environment. Examples of items on this subscale include, I am meeting as many people and making as many friends as I would like to and I have several close ties at college (Baker \& Siryk, 1989). Alpha levels for this subscale have been reported to fall between .83 and .91 (Asher, 1992; Baker \& Siryk, 1984; Baker \& Siryk, 1986; Dahmus et al., 1992).

\section{$\underline{\text { Personal-Emotional Adjustment Scale }}$}

This scale represents a measure of a student's general psychological and physical distress and some related somatic problems during his or her adjustment to college. Items specifically focus on the degree to which a student may be experiencing either 
psychological distress and physical problems. Examples of items on this subscale include, I have been feeling tense and nervous lately and I have not been feeling in good health lately (Baker \& Siryk, 1986). Alpha levels for this subscale have been reported to fall between .73 and .86 (Asher, 1992; Baker \& Siryk, 1984; Baker \& Siryk, 1986; Dahmus et al., 1992).

\section{$\underline{\text { Goal Commitment-Institutional Attachment Scale }}$}

This scale assesses both the students' degree of commitment-attachment to educational and institutional goals, and the students' degree of attachment to the particular institution she or he is attending. Examples of items on this subscale include, $I$ expect to stay at ... for a bachelor's degree and I am pleased now about my decision to go to college (Baker \& Siryk, 1986). Alpha levels for this subscale have been reported to fall between .85 and .91 (Asher, 1992; Baker \& Siryk, 1984; Baker \& Siryk, 1986; Dahmus et al., 1992).

\section{$\underline{\text { Administration }}$}

It has been suggested that this instrument should be used within the first semester of college because this is when students typically begin to recognize their adjustment difficulties (Asher, 1992). The administration of the SACQ takes about 20 minutes, and it can be administered to either individuals or groups (Murphy et al., 1994). This suggests the utility of the SACQ in being administered to small groups of women in their first semester of college.

\section{$\underline{\text { Reliability }}$}

The variables measured by the SACQ are not intended to be enduring properties of individuals. These variables should vary as both the students themselves and their 
environment change. Therefore, the estimates of internal consistency reliability are more appropriate than test-retest reliability (Baker \& Siryk, 1989). Full Scale alpha coefficients are reported to range from .92 to .95 (Asher, 1992; Baker \& Siryk, 1986; Dahmus et al., 1992).

\section{$\underline{\text { Validity }}$}

Each sub-scale of the SACQ has been compared to an individual criterion in order to assess the criterion-related validity of the instrument. The Academic Adjustment Scale has been found to have significant correlations of .17 to $.53(\mathrm{p}<.01)$ with first year grade point average (Asher, 1992; Dahmus et al., 1992). The Social Adjustment Scale demonstrates the most promising validity with significant correlations of .66 to .79 $(\mathrm{p}<.01)$ with measures of social activity (Baker \& Siryk, 1984; Dahmus et al., 1992). The PersonalEmotional Adjustment Scale has been found to have modest correlations of -.23 to $-.34(\mathrm{p}<.01)$ between the scale score and whether or not the student had contacted psychological services at their institution (Dahmus et al., 1992). The Goal CommitmentInstitutional Attachment Scale was found to significantly correlate -.27 to $-.41(\mathrm{p}<.01)$ with first year attrition at college (Dahmus et al., 1992).

The SACQ appears to have strong construct validity. Dahmus et al. (1992) states that the results from 28 different studies illustrate significant relationships between personality variables measured using some well known instruments and the SACQ with constructs of self-esteem, self-efficacy, emotional dependence, and loneliness. The SACQ manual illustrates significant correlations between the SACQ subscales and the following measures: the Academic Locus of Control Scale, the Goal Stability Scale, the Interpersonal Dependency Inventory, the Interpersonal Orientation Inventory, the 
Psychological Coping Resources Scale, the Self-Esteem Inventory, the Emotional Dependence Scale, the UCLA Loneliness Scale, and the Social Avoidance Scale (Baker \& Siryk, 1989).

\section{$\underline{\text { Summary }}$}

The SACQ appears to be a useful measure for examining the adjustment of college students. Although initially developed as a diagnostic tool for practitioners working on college campuses, the SACQ has proven to be an effective measure for research applications. The psychometric principles of the SACQ appear sound and the constructs measured by the SACQ are relevant to this study.

\section{$\underline{\text { Rosenberg Self-Esteem Scale (RSE) }}$}

The RSE, originally developed in 1965 for use with adolescents, is currently the most widely used measure of global self-esteem among a variety of populations (Blaskovich \& Tomaka, 1991). Both past and current research supported the use of the RSE as a unidimensional measure of self-esteem (Gray-Little, Williams, \& Hancock, 1997; Hensely \& Roberts, 1976; Sheven, Bunting, \& Lewis, 1995). The RSE has ten items that were developed to provide researchers with a measure of global self-esteem. The RSE may be scored using a Likert type scale from 1 to 5.

\section{$\underline{\text { Reliability }}$}

Research supports the RSE as a reliable instrument for measuring global selfesteem. Gray-Little, Williams, and Hancock (1997) suggest the success of the instrument in measuring a single factor of self-esteem, demonstrating an alpha level of .88. Shevlin, Bunting, and Lewis (1995) concur that the RSE is a unidimensional measure with strong internal consistency. Additional research suggests that the RSE has good test-retest 
reliability. Fleming and Watts (1980) report a test-retest coefficient of .91, and Fleming \& Courtney (1984) report a test-retest coefficient of .82 .

\section{$\underline{\text { Validity }}$}

Construct validity has been demonstrated by illustrating correlations between the RSE and other widely used measures of self-esteem. McCurdy and Kelly (1997) demonstrate that the RSE correlated highly with the Low Self-Esteem Content Scale, and the Coopersmith Self-Esteem Inventory. Francis and Wilcox (1995) also demonstrate a modest but significant correlation between the RSE and the Coopersmith Self-Esteem Inventory of .52, suggesting that the two instruments measure different aspects of selfesteem. The RSE was also shown to correlate with Harter's Self-Perception Profile for Adolescents, with a coefficient of .89 (Hagborg, 1996).

\section{$\underline{\text { Summary }}$}

The RSE appears to be a strong measure of global self-esteem. Thousands of studies have used the RSE for this purpose. The test quality of the RSE is sound, as evidenced by the strong reliability and validity data for this measure. Additionally, the RSE provides an economical assessment of the self-esteem of individuals. The instrument takes only a brief amount of time. The RSE will provide a measure of selfesteem for subjects in this study without overextending the time period for data collection.

\section{$\underline{\text { Socio-cultural Attitudes Towards Appearance Questionnaire (SATAQ) }}$}

The SATAQ was developed by Heinberg, Thompson, and Stormer (1995) in an effort to measure how women are affected by societal standards of attractiveness. It has been argued that there is a need for this instrument due to evidence that suggests societal 
standards of beauty play a role in the development of eating problems (Thompson, Heinberg, Altabe, \& Tantleff-Dunn, 1999). The purpose of this measure is twofold. First, the measure determines if women are aware of socially presented views regarding attractiveness. Second, the measure determines if women internalize these views (Heinberg et al., 1995).

\section{Content}

The SATAQ has 14 items and two subscales. The Awareness subscale has 6 items and the Internalization subscale has 8 items. Individuals completing the SATAQ respond to statements that target appearance standards communicated through various types of media such as magazines, radio, television, and movies. Items are rated on a 5 point Likert type scale ranging from strongly disagree (1) to strongly agree (5). High scores on the subscales represent increased awareness and/or increased internalization of socio-cultural norms of attractiveness. The SATAQ was initially normed on 194 college students. Forty- four items were cut to 14 items based on an analysis of factor loading on the awareness and internalization constructs (Heinberg et al., 1995).

\section{Awareness Subscale}

The Awareness subscale assesses an individual's recognition of dominant messages regarding attractiveness as communicated in the media. An example of an item from this subscale includes, In our society, fat people are not regarded as unattractive.

\section{$\underline{\text { Internalization Subscale }}$}

The Internalization subscale assesses an individual's acceptance or internalization of messages regarding attractiveness as communicated in the media. An example of an 
item from this subscale includes, Women who appear in TV shows and movies project the type of appearance that I see as my goal.

\section{$\underline{\text { Reliability and Validity }}$}

In the initial validation study, the researchers found alpha levels of .81 for the awareness scale and .93 for the internalization scale (Heinberg et al., 1995). In an additional study, Irving, DuPen, and Berel (1998) reported alpha levels of .74 for the awareness scale and .92 for the internalization scale. Additionally, both the Awareness subscale $(r=.28$ to .44$)$ and the Internalization subscale $(r=.36$ to .61$)$ were shown to correlate with the Rosenberg Self-Esteem Inventory, the Physical Appearance State and Trait Anxiety Scale, the Multidimensional Body Self-Relations Questionnaire, the Body Image Avoidance Questionnaire, and the Eating Disorders Inventory (Heinberg et al., 1995)

\section{$\underline{\text { Utility }}$}

The SATAQ is a relatively new instrument that has not yet been used by many researchers. However, Heinberg, Thompson, \& Stormer (1995) argue that this measure has great utility in measuring both the awareness and internalization of cultural norms of attractiveness. Additional support for the use of the SATAQ is demonstrated in a study which uses the measure to show that eating disordered patients internalize socio-cultural attitudes towards their appearance to a greater extent that do members of the normal population (Griffiths, Beumont, Russell, Schotte, Thornton, Touyz, \& Varano, 1999).

\section{$\underline{\text { Body-Mass Index (BMI) }}$}

$\mathrm{BMI}$ is a recommended measure of body composition due to both the simplicity and accuracy of the measurement (Leith, 1994). One suggested method of calculating 
BMI includes first converting English measurements of height and weight into metric measurements. The index is calculated by identifying the participants' height (in meters) and weight (in kilograms). The next step is to square the participants' height. The final step is to divide the body weight of the individual by her or his squared height (Sharkey, 1997). Although there may be some question regarding the validity of a self-report measure of weight, Bowman and DeLucia (1992) concluded that women's self-reports of their body weight are sufficiently accurate.

After each individual's BMI is calculated, this index may then be utilized to represent an indication of body composition. A BMI of below 19 is characteristic of underweight individuals and is often associated with health problems. A BMI of 19-25 represents healthy body composition and is associated with low risk of illness in most people. A BMI of 26 or higher is characteristic of an overweight individual and is associated with health problems for most individuals (Sharkey, 1997).

\section{$\underline{\text { Friendship Networks }}$}

The measurement of friendship networks is similar to the protocol followed by Paxton et al. (1999). Each participant was given a list of all women living in their residence hall. In an effort to maintain confidentiality, the researcher prepared a code sheet, and a code (the first three letters of the first name of the participants and the first three letters of the last name of the participants) were used instead of participant names. These code numbers were used to investigate the social networks within the residence hall floor communities. This allowed the author to identify a friendship cluster for each participant. Participants answered the following questions (Paxton et al., 1999): 
1) Write down the numbers of your best friends, that is, the women you hang around with the most and are closest to.

2) Is there one particular "group" you normally hang around with? (a) yes; (b) No, I hang around with a number of different "groups" or with people from a number of different "groups"; (c) No, I spend most of my time alone; (d) No, I spend most of my time with one other friend.

3) If you answered (a) "yes" to the previous question, write down the numbers of women in the "group" you hang around with.

4) If you answered (b) to question 2, write down the numbers of the women from the different "groups" you hang around with.

This data was analyzed using the UCINET IV statistical program (Borgatti, Everett, \& Freeman, 1992). A detailed expla nation of this analysis was presented in the data analysis section of this chapter.

\section{$\underline{\text { Research Design }}$}

In this study there are two independent variables: residence hall floor community membership and friendship group membership. There is one class of dependent variables in this study representing the eating attitudes and behaviors of participants. Three subscales of the EDI-2 will measure participant eating attitudes and behaviors. These subscales are Drive for Thinness, Bulimia, and Body Dissatisfaction. There is a second class of dependent variables representing the acceptance and internalization of sociocultural attractiveness ideal. Two subscales of the SATAQ were used to measure sociocultural acceptance and awareness. Additionally, in an effort to assess the influence of floor community membership and friendship group membership on the eating attitudes 
and behaviors, the author co-varied additional dependent variables that were hypothesized to be related to eating attitudes and behaviors. These variables include student adjustment to college, global self-esteem, and body composition.

\section{Data Analysis}

\section{Friendship Group Membership}

The UCINET IV statistical package (Borgatti, Everett, \& Freeman, 1992) was used to analyze the sociometric data resulting from participant responses to friendship network questions. This program created mutually identified friendship groups of 2 or more individuals. Due to the indication that dyads function differently from groups of 3 or more individuals (Paxton et al., 1999), the author removed dyads from the sample. Additionally, based on the suggestion of Paxton et al. (1999), participants who were not easily assigned to any friendship group, and/or those who are loosely tied to a friendship group were omitted. Finally, in order to effectively compare friendship groups, individuals with membership in more than one group were assigned only to the group in which they have the strongest friendship ties, as indicated by the statistical package. These groups represent the levels of the first independent variable in this study.

\section{Hypothesis Testing}

The SPSS statistical package was used to conduct all hypothesis tests. The procedures and measures were used to test the following research questions:

1) Are there differences in eating attitudes, eating behaviors, socio-cultural awareness, and/or socio-cultural internalization between friendship clusters? A multivariate analysis of variance (MANOVA) and a multivariate analysis of covariance (MANCOVA) were used to answer this question. First, a MANOVA was used 
to identify possible covariates. In this MANOVA, friendship membership was the independent variable. The 6 dependent variables were 4 subscales of the SACQ, the RSE score, and BMI. This MANOVA determined significant differences between friendship groups. Second, a MANCOVA was used to determine differences between friendship groups in regards to eating attitudes, eating behaviors, socio-cultural awareness, and socio-cultural internalization. The independent variable in the MANCOVA was friendship group membership. The covariates included any of the dependent variables of the previous MANOVA that were shown to be significant. The dependent variables in the MANCOVA were the 3 EDI-2 subscales: Drive for Thinness, Bulimia, and Body Dissatisfaction, and the 2 SATAQ subscales: Awareness and Internalization.

2) Are there differences in eating attitudes, eating behaviors, socio-cultural awareness, and/or socio-cultural internalization between residence hall floor communities?

A MANOVA and a MANCOVA were used to answer this question. First, a MANOVA was used to identify possible covariates. In this MANOVA, residence hall floor community membership was the independent variable. The 6 dependent variables were 4 subscales of the SACQ, the RSE score, and BMI. This MANOVA determined if there were significant differences between residence hall floor community groups. Second, a MANCOVA was used to determine differences between residence hall floor community groups in regards to eating attitudes, eating behaviors, socio-cultural awareness, and socio-cultural internalization. The independent variable in the MANCOVA was residence hall floor community membership. The covariates included any of the dependent variables of the previous MANOVA that were shown to be 
significant. The dependent variables in the MANCOVA were the 3 EDI-2 subscales: Drive for Thinness, Bulimia, and Body Dissatisfaction, and the 2 SATAQ subscales: Awareness and Internalization.

3) How is adjustment to college related to disturbed eating attitudes and behaviors? Correlational analyses were used to answer this question. Relationships between the 4 subscales of the SACQ and the 3 subscales of the EDI were examined.

4) How are socio-cultural awareness and/or socialcultural internalization related to eating attitudes and behaviors?

Correlational analyses were used to answer this question. Relationships between the 2 subscales of the SATAQ and the 3 subscales of the EDI- 2 were examined. 


\section{Chapter 4}

\section{Results}

The present investigation was designed to examine the development of disturbed eating patterns among college women. More specifically, this researcher investigated the social contagion of eating attitudes and behaviors among first year college women living in residence hall communities. The first research hypothesis posited that there would be differences in eating attitudes and behaviors between friendship clusters, suggesting the possible presence of a contagion factor. It was additionally hypothesized that no differences in eating patterns would exist between individuals living on different residence hall floors. It was expected that, due to the large number of participants living on residence hall floors, there would be greater within group differences than between group differences.

This study was also intended to explore the relationship between the development of disordered eating attitudes and behaviors and adjustment to college. Based on prior research (VanLone \& Kalodner, 2000), it was expected that correlations would be found between a measure of eating patterns and a measure of college student adjustment. Finally, this researcher predicted relationships between an awareness and internalization of social-cultural pressures to be thin, and the development of disturbed eating attitudes and behaviors.

The results of the statistical analyses are presented in six separate sections of this chapter. The first section presents demographic data obtained for this sample. The second section examines the influence of friendship group membership on eating attitudes and behaviors. The third section explores the impact that residence hall floor 
membership has on eating patterns. The fourth section describes the relationship between adjustment to college and eating disturbance. Finally, the fifth section describes the relationship between disordered eating attitudes and behaviors and socio-cultural awareness and internalization.

As discussed in Chapter 3, participants in this study were adult women (over the age of 18) living in single sex residence hall floor communities. They were all in their first year of college. All participants lived in one of 14 floors in two residence halls. They completed a brief questionnaire that asked them to list their height and weight. Participants also were asked to complete three subscales of the Eating Disorders Inventory-2 (EDI-2), the Rosenberg Self-Esteem Inventory (RSE), the Socio-cultural Attitudes Towards Appearance Questionnaire (SATAQ), and the Student Adaptation to College Questionnaire (SACQ). They also were asked 4 questions used to identify friendship networks. These questions can be found in Appendix A. The order of the questionnaires varied to decrease the chance of order effects. The data were spotchecked in an effort to ensure accuracy. Means and standard deviations of this sample for all dependent variables are presented in Table 1. 
Table 1

$\underline{\text { Means and Standard Deviations on All Dependent Varibles }}$

\begin{tabular}{llll}
\hline Variable & $\underline{N}$ & $\underline{X}$ & $\underline{\text { SD }}$ \\
& 208 & 21.66 & 3.39 \\
BMI & 211 & 1.49 & 2.39 \\
EDI Bulimia & 211 & 4.99 & 5.23 \\
EDI Drive for Thinness & 211 & 11.50 & 8.18 \\
EDI Body Dissatisfaction & 212 & 39.06 & 7.90 \\
Rosenberg Self-Esteem & 209 & 51.04 & 9.72 \\
SACQ Academic & 209 & 49.67 & 10.10 \\
SACQ Social & 209 & 45.42 & 9.96 \\
SACQ Personal Emotional & 212 & 20.41 & 3.67 \\
SATAQ Awareness & 212 & 25.37 & 7.72 \\
SATAQ Internalization & & & \\
\hline
\end{tabular}




\section{Demographic Data}

A total of 212 people participated in this study. Sixteen of the participants were not first year students and were subsequently removed from the study. Thus, 196 completed sets of questionnaires were included in the analysis. Basic demographic data were requested of each participant on the Student Adaptation to College Questionnaire. The demographic information included gender, age, academic year, and ethnic background. All participants in the study were women. Only a handful of participants indicated their ethnic background (less than 10 percent). We can assume that the ethnic background of participants mirrored the data available on students at this university. Data collected from university records indicate that 7 percent of first year students in the Spring 2000 semester identify as being from ethnic minorities (West Virginia University, 2001, para. 1). There is no record of the breakdown of specific racial/ethnic groups. All of the 196 participants used in the study are women in their first year of college. The mean body mass index score, measuring body composition, was 21.66 with a range from 17 to 38 .

The 196 participants represented 66 percent of the 299 total first year residents living on the 14 residence hall floor communities where data was collected. All participants lived on single sex residence hall floors. Eight of the floors were in one residence hall and the remaining 6 floors were from another residence hall. One floor that was examined in the study had only 5 first year students in residence. All 5 of these students participated in the study, representing a 100 percent participation rate on that floor. The number of first year residents differed on each of the 14 residence hall floors. 
The percentage of first year student participation by residence hall floor is presented in Table 2. 
Table 2

$\underline{\text { First Year Student Participation by Residence Hall Floor }}$

\begin{tabular}{|c|c|c|c|}
\hline Floor & Participants & First Year Students on Floor & \\
\hline & $\underline{\mathrm{n}}$ & $\underline{\mathrm{N}}$ & Percent \\
\hline 1 & 17 & 21 & 81 \\
\hline 2 & 9 & 16 & 56 \\
\hline 3 & 5 & 5 & 100 \\
\hline 4 & 21 & 28 & 75 \\
\hline 5 & 5 & 14 & 36 \\
\hline 6 & 22 & 30 & 73 \\
\hline 7 & 12 & 20 & 60 \\
\hline 8 & 10 & 19 & 55 \\
\hline 9 & 8 & 19 & 42 \\
\hline 10 & 15 & 19 & 79 \\
\hline 11 & 18 & 28 & 64 \\
\hline 12 & 17 & 26 & 65 \\
\hline 13 & 14 & 27 & 54 \\
\hline 14 & 23 & 27 & 85 \\
\hline
\end{tabular}




\section{$\underline{\text { Research Question \#1 }}$}

Are there differences in eating attitudes, eating behaviors, and socio-cultural awareness and internalization of attractiveness ideals between women in different friendship clusters? Hypothesis 1 proposed that there would be greater between group than within group differences on measures of eating attitudes, eating behaviors, sociocultural awareness, and/or socio-cultural internalization between friendship clusters.

To test this hypothesis, the researcher first needed to identify friendship clusters from the overall sample $(n=196)$. This was done using the UCINET IV statistical package (Borgatti, Everett, \& Freeman, 1992). UCINET IV is a statistical program developed to assist in measuring and interpreting socio-metric data. In this study, UCINET IV was used to measure the social proximity of the participants. All participants were included in a relational matrix which indicated their self reported closeness to other participants in the study. Based on the connections in this relational matrix, the UCINET IV program identified 56 friendship clusters. Each of these friendship clusters had cohesion coefficients of .50 or higher. The cohesion coefficient represents the degree of affiliation of the members in each friendship cluster. Table 3 illustrates the derivation of friendship clusters by the computer program. In this table, it may be noted that (a) Participant 49 identified participants 74, 77, and 78 as close friends, (b) Participant 74 identified participants 77 and 78 as close friends, (c) Participant 77 identified participants 74 and 78 as close friends, and (d) Participant 78 identified participant 74 as a close friend. The overall Friendship Cluster Cohesion Coefficient (FCCC) of .67 for this cluster is derived by dividing the actual number of within-clique links (8) by the possible number of within group links (12). 
Table 3

$\underline{\text { Friendship Clusters }}$

\begin{tabular}{|c|c|c|c|c|c|}
\hline \multicolumn{2}{|c|}{ Participants } & 49 & 74 & 77 & 78 \\
\hline 49 & Identified & - & $X$ & $X$ & $X$ \\
\hline 74 & Identified & 0 & - & $X$ & $X$ \\
\hline 77 & Identified & 0 & $X$ & - & $X$ \\
\hline 78 & Identified & 0 & $X$ & 0 & - \\
\hline
\end{tabular}

$\underline{\text { Note. }}$

Possible number of within-clique links $=3+3+3+3=12$.

Actual number of within-clique links $=8$.

Friendship Cluster Cohesion Coefficient $(\mathrm{FCCC})=8 / 12=.67$. 
When examining the 56 friendship clusters, the researcher noticed that all of these clusters were not independent groups, and some participants were members of more than one cluster. Comparing means between groups with the same participants would have been a violation of the statistical independence of groups. In an effort to solve this problem, some of the 56 friendship clusters were eliminated. This was done by comparing the Friendship Cluster Cohesion Coefficient (FCCC) between two clusters with the same participant or participants. For example, the original cluster 7 includes participants 21, 24, and 26, and has a FCCC of .83. The original cluster 6 includes participants 21, 24, and 25, and has a FCCC of .67. Thus, cluster 7 was maintained in the final collection of 32 friendship clusters, while cluster 6 was eliminated. This was to ensure that the more cohesive clusters were retained.

Using these 32 friendship clusters, a Multivariate Analysis of Variance (MANOVA) was computed with friendship cluster as the independent variable. The dependent variables in this MANOVA were the following subscales: EDI-2 Bulimia, EDI-2 Drive for Thinness, EDI-2 Body Dissatisfaction, SATAQ Internalization, and the SATAQ Awareness. The omnibus MANOVA test yielded $\mathrm{F}(155,376)=1.27, \mathrm{p}=.035$. Table 4 illustrates that significant between group differences were found for friendship clusters on the EDI-2 Drive for Thinness $(\mathrm{F}[31,79]=1.62, \mathrm{p}<.05)$ and the EDI-2 Body Dissatisfaction $(\mathrm{F}[31,79]=1.68, \mathrm{p}<.05)$ subscales. However, the re are no significant between group differences for friendship clusters on the EDI-2 Bulimia subscale or on the SATAQ Awareness and Internalization subscales. This suggests that the participants had similar eating attitudes and behaviors to other women in their friendship cluster. 
Conversely, the participants did not share socio-cultural values of the women in their friendship clusters. 
Table 4

Means and Standard Deviations for the Component Analyses of Variance for the

MANOVA, with Friendship Clusters as the Independent Variables, and 3 EDI-2

Subscales and 2 SATAQ Subscales as the Dependent Variables

\begin{tabular}{|c|c|c|c|c|c|c|}
\hline \multicolumn{2}{|c|}{$\begin{array}{l}\text { Friendship } \\
\text { Clusters }\end{array}$} & $\begin{array}{l}\text { EDI-2 } \\
\text { Body Diss. }\end{array}$ & $\begin{array}{l}\text { EDI-2 } \\
\text { Bulimia }\end{array}$ & $\begin{array}{l}\text { EDI-2 } \\
\text { Thinness }\end{array}$ & $\begin{array}{l}\text { SATAQ } \\
\text { Awareness }\end{array}$ & $\begin{array}{l}\text { SATAQ } \\
\text { Internalization }\end{array}$ \\
\hline 1 & $\underline{\mathrm{M}}$ & 20.67 & 2.00 & 10.67 & 24.33 & 33.67 \\
\hline & $\underline{\mathrm{SD}}$ & 7.77 & 1.73 & 4.51 & 1.15 & 7.57 \\
\hline 2 & $\underline{\mathrm{M}}$ & 18.25 & 4.25 & 11.25 & 23.00 & 30.00 \\
\hline & $\underline{\mathrm{SD}}$ & 8.06 & 7.23 & 5.50 & 2.16 & 5.42 \\
\hline 3 & $\underline{\mathrm{M}}$ & 12.67 & 3.33 & 7.67 & 21.67 & 30.67 \\
\hline & $\underline{\mathrm{SD}}$ & 5.13 & .58 & 6.66 & 4.04 & 1.53 \\
\hline 4 & $\underline{\mathrm{M}}$ & 4.00 & .00 & 1.33 & 17.67 & 19.67 \\
\hline & $\underline{\mathrm{SD}}$ & 6.08 & .00 & 2.31 & 4.16 & 7.77 \\
\hline 5 & $\underline{\mathrm{M}}$ & 12.75 & .75 & 7.00 & 20.25 & 24.25 \\
\hline & $\underline{\mathrm{SD}}$ & 3.30 & 1.50 & 7.02 & 5.68 & 11.44 \\
\hline 6 & $\underline{\mathrm{M}}$ & 3.67 & .67 & .00 & 16.67 & 21.33 \\
\hline & $\underline{\mathrm{SD}}$ & 2.08 & 1.15 & .00 & 1.53 & 1.53 \\
\hline 7 & $\underline{\mathrm{M}}$ & 14.60 & .40 & 4.40 & 20.60 & 27.40 \\
\hline & $\underline{\mathrm{SD}}$ & 10.43 & .89 & 4.04 & 1.67 & 4.67 \\
\hline 8 & $\underline{\mathrm{M}}$ & 10.00 & .33 & 2.00 & 19.33 & 20.67 \\
\hline & $\underline{\mathrm{SD}}$ & 12.17 & .58 & 3.46 & 1.53 & 7.37 \\
\hline
\end{tabular}


Table 4 (Continued)

\begin{tabular}{|c|c|c|c|c|c|c|}
\hline \multicolumn{2}{|c|}{$\begin{array}{l}\text { Friendship } \\
\text { Clusters }\end{array}$} & $\begin{array}{l}\text { EDI-2 } \\
\text { Body Diss. }\end{array}$ & $\begin{array}{l}\text { EDI-2 } \\
\text { Bulimia }\end{array}$ & $\begin{array}{l}\text { EDI-2 } \\
\text { Thinness }\end{array}$ & $\begin{array}{l}\text { SATAQ } \\
\text { Awareness }\end{array}$ & $\begin{array}{l}\text { SATAQ } \\
\text { Internalization }\end{array}$ \\
\hline 9 & $\underline{\mathrm{M}}$ & 20.33 & 4.00 & 9.00 & 24.00 & 32.67 \\
\hline & $\underline{\mathrm{SD}}$ & 11.55 & 3.00 & 6.56 & 3.46 & 6.43 \\
\hline 10 & $\underline{\mathrm{M}}$ & 5.67 & .67 & 4.00 & 18.00 & 30.00 \\
\hline & $\underline{\mathrm{SD}}$ & 2.52 & 1.15 & 3.61 & 4.35 & 9.17 \\
\hline 11 & $\underline{\mathrm{M}}$ & 22.50 & 1.00 & 9.50 & 21.50 & 33.75 \\
\hline & $\underline{\mathrm{SD}}$ & 5.45 & .82 & 5.07 & 1.00 & 4.79 \\
\hline 12 & $\underline{\mathrm{M}}$ & 8.50 & 3.50 & .50 & 19.75 & 25.50 \\
\hline & $\underline{\mathrm{SD}}$ & 8.06 & 1.73 & 1.00 & 3.30 & 6.56 \\
\hline 13 & $\underline{\mathrm{M}}$ & 13.67 & .33 & 6.67 & 18.67 & 31.33 \\
\hline & $\underline{\mathrm{SD}}$ & 4.16 & .58 & 4.73 & 2.08 & 7.02 \\
\hline 14 & $\underline{\mathrm{M}}$ & 4.00 & .50 & 2.75 & 22.25 & 22.75 \\
\hline & $\underline{\mathrm{SD}}$ & 5.23 & .58 & 2.06 & 4.57 & 3.10 \\
\hline 15 & $\underline{\mathrm{M}}$ & 5.33 & .00 & .33 & 22.67 & 19.33 \\
\hline & $\underline{\mathrm{SD}}$ & 8.39 & .00 & .58 & .58 & 5.03 \\
\hline 16 & $\underline{\mathrm{M}}$ & 10.00 & 2.33 & 2.00 & 18.67 & 23.33 \\
\hline & $\underline{\mathrm{SD}}$ & 11.36 & 2.08 & 1.73 & 2.52 & 7.57 \\
\hline 17 & $\underline{\mathrm{M}}$ & 12.80 & 1.40 & 4.80 & 20.80 & 29.60 \\
\hline & $\underline{\mathrm{SD}}$ & 6.53 & 1.67 & 5.40 & 4.76 & 6.50 \\
\hline
\end{tabular}


Table 4 (Continued)

\begin{tabular}{|c|c|c|c|c|c|c|}
\hline \multicolumn{2}{|c|}{$\begin{array}{l}\text { Friendship } \\
\text { Clusters }\end{array}$} & $\begin{array}{l}\text { EDI-2 } \\
\text { Body Diss. }\end{array}$ & $\begin{array}{l}\text { EDI-2 } \\
\text { Bulimia }\end{array}$ & $\begin{array}{l}\text { EDI-2 } \\
\text { Thinness }\end{array}$ & $\begin{array}{l}\text { SATAQ } \\
\text { Awareness }\end{array}$ & $\begin{array}{l}\text { SATAQ } \\
\text { Internalization }\end{array}$ \\
\hline \multirow[t]{2}{*}{18} & $\underline{\mathrm{M}}$ & 20.00 & .67 & 9.67 & 20.33 & 29.00 \\
\hline & $\underline{\mathrm{SD}}$ & 1.00 & 1.15 & 4.04 & 3.79 & 4.58 \\
\hline \multirow[t]{2}{*}{19} & $\underline{\mathrm{M}}$ & 4.67 & 2.67 & 3.67 & 20.00 & 25.33 \\
\hline & $\underline{\mathrm{SD}}$ & 2.08 & 4.62 & 5.51 & 3.46 & 8.02 \\
\hline \multirow[t]{2}{*}{20} & $\underline{\mathrm{M}}$ & 13.00 & .33 & 9.00 & 21.67 & 31.00 \\
\hline & $\underline{\mathrm{SD}}$ & 8.66 & .58 & 7.00 & 5.51 & 6.08 \\
\hline \multirow[t]{2}{*}{21} & $\underline{\mathrm{M}}$ & 7.33 & .33 & 2.00 & 17.00 & 25.00 \\
\hline & $\underline{\mathrm{SD}}$ & 1.53 & .58 & 1.00 & 6.00 & 8.19 \\
\hline \multirow[t]{2}{*}{22} & $\underline{\mathrm{M}}$ & 16.67 & 5.00 & 6.67 & 23.67 & 27.67 \\
\hline & $\underline{\mathrm{SD}}$ & 11.68 & 8.66 & 7.23 & 5.51 & 10.79 \\
\hline \multirow[t]{2}{*}{23} & $\underline{\mathrm{M}}$ & 12.00 & .00 & 2.67 & 20.67 & 23.00 \\
\hline & $\underline{\mathrm{SD}}$ & 8.66 & .00 & 2.52 & 2.08 & 4.36 \\
\hline \multirow[t]{2}{*}{24} & $\underline{\mathrm{M}}$ & 5.33 & 1.67 & 3.33 & 21.33 & 24.33 \\
\hline & $\underline{\mathrm{SD}}$ & 5.13 & 1.53 & 4.93 & 4.16 & 4.16 \\
\hline \multirow[t]{2}{*}{25} & $\underline{\mathrm{M}}$ & 16.00 & 3.60 & 7.20 & 17.20 & 27.40 \\
\hline & $\underline{\mathrm{SD}}$ & 7.28 & 3.21 & 5.12 & 3.03 & 4.93 \\
\hline \multirow[t]{2}{*}{26} & $\underline{\mathrm{M}}$ & 7.67 & 5.00 & 2.67 & 17.33 & 25.67 \\
\hline & $\underline{\mathrm{SD}}$ & 6.11 & 3.46 & 4.62 & 4.04 & 12.10 \\
\hline
\end{tabular}


Table 4 (Continued)

\begin{tabular}{|c|c|c|c|c|c|c|}
\hline \multicolumn{2}{|c|}{$\begin{array}{l}\text { Friendship } \\
\text { Clusters }\end{array}$} & $\begin{array}{l}\text { EDI-2 } \\
\text { Body Diss. }\end{array}$ & $\begin{array}{l}\text { EDI-2 } \\
\text { Bulimia }\end{array}$ & $\begin{array}{l}\text { EDI-2 } \\
\text { Thinness }\end{array}$ & $\begin{array}{l}\text { SATAQ } \\
\text { Awareness }\end{array}$ & $\begin{array}{l}\text { SATAQ } \\
\text { Internalization }\end{array}$ \\
\hline 27 & $\underline{\mathrm{M}}$ & 9.33 & 2.33 & 4.67 & 19.33 & 33.00 \\
\hline & $\underline{\mathrm{SD}}$ & 8.50 & 2.52 & 6.43 & 4.04 & 6.25 \\
\hline 28 & $\underline{\mathrm{M}}$ & 11.50 & 5.25 & 4.50 & 17.25 & 20.50 \\
\hline & $\underline{\mathrm{SD}}$ & 11.73 & 4.50 & 3.32 & .96 & 4.12 \\
\hline 29 & $\underline{\mathrm{M}}$ & 15.00 & 2.00 & 11.00 & 19.00 & 28.50 \\
\hline & $\underline{\mathrm{SD}}$ & 11.31 & 2.83 & 14.14 & 1.41 & 12.02 \\
\hline 30 & $\underline{\mathrm{M}}$ & 7.33 & .67 & 4.33 & 19.33 & 24.00 \\
\hline & $\underline{\mathrm{SD}}$ & 2.08 & 1.15 & 6.66 & 4.04 & 7.00 \\
\hline 31 & $\underline{\mathrm{M}}$ & 9.67 & .50 & 1.83 & 19.67 & 22.33 \\
\hline & $\underline{\mathrm{SD}}$ & 8.55 & .84 & 2.32 & 1.63 & 4.68 \\
\hline 32 & $\underline{\mathrm{M}}$ & 11.50 & 2.75 & 2.75 & 20.00 & 27.00 \\
\hline & $\underline{\mathrm{SD}}$ & 2.38 & 2.75 & 2.06 & 3.16 & 5.60 \\
\hline $\mathrm{F}$ & & $1.68 *$ & 1.24 & $1.62 *$ & 1.23 & 1.38 \\
\hline
\end{tabular}

Note. ${ }^{*} \mathrm{p}<.05$. 
A second MANOVA was computed to identify possible covariates. In this MANOVA, friendship cluster was the independent variable. Three subscales of the Student Adaptation to College Questionnaire (SACQ), the Body Mass Index (BMI), and the Rosenberg Self-Esteem Inventory were the dependent variables in this analysis. The omnibus MANOVA test yielded $F(155,351)=1.20, p=.081$. Significant between group differences were found for friendship clusters on BMI $(\mathrm{F}[31,74]=1.89, \mathrm{p}<.01)$ and the Personal-Emotional Adjustment Subscale of the SACQ $(F[31,74]=2.07, \mathrm{p}<.01)$. However, there are no significant between group differences on the RSE, the Academic Adjustment Subscale of the SACQ, or the Social Adjustment Subscale of the SACQ. A Multivariate Analysis of Covariance (MANCOVA) was computed using BMI and the Personal-Emotional Adjustment Subscale of the SACQ as covariates. This statistical test was intended to examine if between group differences would continue to emerge when the variables of personal adjustment and body weight had been removed from the equation. Using the same 32 friendship clusters as in the original MANOVA, the independent variable for this test was the friendship group membership. The dependent variables in this MANCOVA were the averages for each cluster on the following subscales: EDI-2 Bulimia, EDI-2 Drive for Thinness, EDI-2 Body Dissatisfaction, SATAQ Internalization, and the SATAQ Awareness. No significant differences were found in the omnibus test when the BMI and Personal-Emotional Adjustment variables were used as covariates. This suggests that personalemotional adjustment to college and body composition influence the development of similar eating attitudes among participants in this study. 
The researcher made the decision to run an additional analysis using this data in an effort to improve the external validity of the study. In this MANOVA, the researcher examined only the friendship clusters that were drawn from those residence hall floors with a participation rate of 70 percent or higher. Thirteen friendship clusters were identified which met this criteria. The independent variable was friendship cluster. The dependent variables were the following subscales: EDI-2 Bulimia, EDI-2 Drive for Thinness, EDI-2 Body Dissatisfaction, SATAQ Internalization, and the SATAQ Awareness. The omnibus MANOVA test yielded $F(60,149)=1.24, p=.015$. Table 5 illustrates that significant between group differences were found for friendship clusters on the EDI-2 Drive for Thinness Subscale $(F[12,35]=2.68, p<.05)$. However, there are no significant between group differences for friendship clusters on the EDI-2 Body Dissatisfaction subscale, the EDI-2 Bulimia subscale or on the SATAQ Awareness and Internalization subscales. This finding provides further evidence of similarities between friendship group members regarding their eating attitudes and behaviors.

A second MANOVA was computed to identify possible covariates for the 13 friendship clusters taken from residence hall floors with a 70 percent rate of participation in the study. In this MANOVA, friendship cluster was again the independent variable. Three subscales of the Student Adaptation to College Questionnaire (SACQ), the Body Mass Index (BMI), and the Rosenberg Self-Esteem Inventory (RSE) were the dependent variables in this analysis. The omnibus test found no significant between group differences on the any of the variables: the 3 subscales of the SACQ, BMI, and RSE. Therefore, there was no need to compute a MANCOVA for this analysis. 
Table 5

Means and Standard Deviations for the Component Analysis of Variance for the

MANOVA Examining Only Those Friendship Clusters with 70 Percent or Higher

$\underline{\text { Participation, with Friendship Clusters as the Independent Variables, and } 3 \text { EDI-2 }}$

$\underline{\text { Subscales and } 2 \text { SATAQ Subscales as the Dependent Variables }}$

\begin{tabular}{|c|c|c|c|c|c|c|}
\hline \multicolumn{2}{|c|}{$\begin{array}{l}\text { Friendship } \\
\text { Clusters }\end{array}$} & $\begin{array}{l}\text { EDI-2 } \\
\text { Body Diss. }\end{array}$ & $\begin{array}{l}\text { EDI-2 } \\
\text { Bulimia }\end{array}$ & $\begin{array}{l}\text { EDI-2 } \\
\text { Thinness }\end{array}$ & $\begin{array}{l}\text { SATAQ } \\
\text { Awareness }\end{array}$ & $\begin{array}{l}\text { SATAQ } \\
\text { Internalization }\end{array}$ \\
\hline 1 & $\underline{\mathrm{M}}$ & 18.25 & 4.25 & 11.25 & 23.00 & 30.00 \\
\hline & $\underline{\mathrm{SD}}$ & 8.06 & 7.23 & 5.50 & 2.16 & 5.42 \\
\hline 2 & $\underline{\mathrm{M}}$ & 12.67 & 3.33 & 7.67 & 21.67 & 30.67 \\
\hline & $\underline{\mathrm{SD}}$ & 5.13 & .58 & 6.66 & 4.04 & 1.53 \\
\hline 3 & $\underline{\mathrm{M}}$ & 14.60 & .40 & 4.40 & 20.60 & 27.40 \\
\hline & $\underline{\mathrm{SD}}$ & 10.43 & .89 & 4.04 & 1.67 & 4.67 \\
\hline 4 & $\underline{\mathrm{M}}$ & 10.00 & .33 & 2.00 & 19.33 & 20.67 \\
\hline & $\underline{\mathrm{SD}}$ & 12.17 & .58 & 3.46 & 1.53 & 7.37 \\
\hline 5 & $\underline{\mathrm{M}}$ & 20.33 & 4.00 & 9.00 & 24.00 & 32.67 \\
\hline & $\underline{\mathrm{SD}}$ & 11.55 & 3.00 & 6.56 & 3.46 & 6.43 \\
\hline 6 & $\underline{\mathrm{M}}$ & 8.50 & 3.50 & .50 & 19.75 & 25.50 \\
\hline & $\underline{\mathrm{SD}}$ & 8.06 & 1.73 & 1.00 & 3.30 & 6.56 \\
\hline 7 & $\underline{\mathrm{M}}$ & 13.67 & .33 & 6.67 & 18.67 & 31.33 \\
\hline & $\underline{\mathrm{SD}}$ & 4.16 & .58 & 4.73 & 2.08 & 7.02 \\
\hline
\end{tabular}


Table 5 (Continued)

\begin{tabular}{|c|c|c|c|c|c|c|}
\hline \multicolumn{2}{|c|}{$\begin{array}{l}\text { Friendship } \\
\text { Clusters }\end{array}$} & \multirow{2}{*}{$\begin{array}{l}\text { EDI-2 } \\
\text { Body Diss. } \\
4.00\end{array}$} & \multirow{2}{*}{$\begin{array}{l}\text { EDI-2 } \\
\text { Bulimia } \\
.50\end{array}$} & \multirow{2}{*}{$\begin{array}{l}\text { EDI-2 } \\
\text { Thinness } \\
2.75\end{array}$} & \multirow{2}{*}{$\begin{array}{l}\text { SATAQ } \\
\text { Awareness } \\
22.25\end{array}$} & \multirow{2}{*}{$\begin{array}{l}\text { SATAQ } \\
\text { Internalization } \\
22.75\end{array}$} \\
\hline 8 & $\underline{\mathrm{M}}$ & & & & & \\
\hline & $\underline{\mathrm{SD}}$ & 5.23 & .58 & 2.06 & 4.57 & 3.10 \\
\hline 9 & $\underline{\mathrm{M}}$ & 5.33 & .00 & .33 & 22.67 & 19.33 \\
\hline & $\underline{\mathrm{SD}}$ & 8.39 & .00 & .58 & .58 & 5.03 \\
\hline 10 & $\underline{\mathrm{M}}$ & 7.33 & .33 & 2.00 & 17.00 & 25.00 \\
\hline & $\underline{\mathrm{SD}}$ & 1.53 & .58 & 1.00 & 6.00 & 8.19 \\
\hline 11 & $\underline{\mathrm{M}}$ & 7.33 & .67 & 4.33 & 19.33 & 24.00 \\
\hline & $\underline{\mathrm{SD}}$ & 2.08 & 1.15 & 6.66 & 4.04 & 7.00 \\
\hline 12 & $\underline{\mathrm{M}}$ & 9.67 & .50 & 1.83 & 19.67 & 22.33 \\
\hline & $\underline{\mathrm{SD}}$ & 8.55 & .84 & 2.32 & 1.63 & 4.68 \\
\hline 13 & $\underline{\mathrm{M}}$ & 11.50 & 2.75 & 2.75 & 20.00 & 27.00 \\
\hline & $\underline{\mathrm{SD}}$ & 2.38 & 2.75 & 2.06 & 3.16 & 5.60 \\
\hline $\mathrm{F}$ & & 1.36 & 1.57 & $2.68 *$ & 1.33 & 1.88 \\
\hline
\end{tabular}

Note. ${ }^{*} \mathrm{p}<.05$. 
A second additional analysis was conducted to compare differences between participants who were members in a friendship cluster and individuals who were not included in any friendship cluster. Essentially, this was a comparison of friendship clusters with a FCCI of .5-1.0 (those identified as cohesive friendship clusters by the UCINET IV program) with friendship clusters with a FCCI of 0-.5 (those not identified by UCINET IV). A MANOVA was computed comparing all participants that were members of friendship clusters, with all participants who were not members of friendship clusters.

In this MANOVA, the dichotomous independent variable was friendship cluster. One level of the independent variable examined those participants who were in a cluster, while the other level of the independent variable examined those participants who were not in a cluster. The following subscales were used as dependent variables: EDI-2 Bulimia, EDI-2 Drive for Thinness, EDI-2 Body Dissatisfaction, SATAQ Internalization, and the SATAQ Awareness. The omnibus MANOVA test yielded $F(5,205)=3.55$, $\mathrm{p}=.010$. Table 6 illustrates that significant between group differences were found for friendship clusters on the EDI-2 Bulimia Subscale $(F[1,209]=5.46, p<.05)$ and the SATAQ Awareness Subscale $(\mathrm{F}[1,209]=6.75, \mathrm{p}<.01)$. However, there are no significant between group differences for friendship clusters on the EDI-2 Body Dissatisfaction subscale, the EDI-2 Drive for Thinness subscale or on the SATAQ Awareness subscale. These findings suggest that women in cohesive friendship groups are more similar to each other regarding eating behaviors and the internalization of sociocultural ideals of thinness and beauty. 
Table 6

$\underline{\text { Means and Standard Deviations for the Component Analysis of Variance for the }}$ $\underline{\text { MANOVA with Friendship Cluster Membership as a Dichotomous Independent }}$

$\underline{\text { Variable, and } 3 \text { EDI-2 Subscales and } 2 \text { SATAQ Subscales as the Dependent Variables }}$

\begin{tabular}{|c|c|c|c|c|c|c|}
\hline \multicolumn{2}{|c|}{$\begin{array}{l}\text { Friendship } \\
\text { Clusters }\end{array}$} & $\begin{array}{l}\text { EDI-2 } \\
\text { Body Diss. }\end{array}$ & $\begin{array}{l}\text { EDI-2 } \\
\text { Bulimia }\end{array}$ & $\begin{array}{l}\text { EDI-2 } \\
\text { Thinness }\end{array}$ & $\begin{array}{l}\text { SATAQ } \\
\text { Awareness }\end{array}$ & $\begin{array}{l}\text { SATAQ } \\
\text { Internalization }\end{array}$ \\
\hline In & $\underline{\mathrm{M}}$ & 12.12 & 1.83 & 5.11 & 20.28 & 26.83 \\
\hline & $\underline{\mathrm{SD}}$ & 8.30 & 2.86 & 5.34 & 3.62 & 6.87 \\
\hline Out & $\underline{\mathrm{M}}$ & 10.30 & 1.04 & 4.68 & 20.47 & 24.00 \\
\hline & $\underline{\mathrm{SD}}$ & 7.48 & 1.53 & 5.08 & 3.81 & 8.30 \\
\hline $\mathrm{F}$ & & 2.54 & $5.46^{*}$ & .32 & .12 & $6.76^{*}$ \\
\hline
\end{tabular}

Note. ${ }^{*} p<.05$. 
A second MANOVA was computed to identify possible covariates for this comparison of participants in friendship clusters with participants not in friendship clusters. In this MANOVA, friendship cluster was again the independent variable. Three subscales of the Student Adaptation to College Questionnaire (SACQ), the Body Mass Index (BMI), and the Rosenberg Self-Esteem Inventory (RSE) were the dependent variables in this analysis. The omnibus test found no significant between group differences on the any of the variables: the 3 subscales of the SACQ, BMI, and RSE. Therefore, there was no need to compute a MANCOVA for this analysis.

\section{$\underline{\text { Research Question \#2 }}$}

Are there differences in eating attitudes, eating behaviors, and socio-cultural awareness and internalization of attractiveness ideals between women in different residence hall floors? Hypothesis 2 proposed that there would not be greater between group than within group differences on measures of eating attitudes, eating behaviors, socio-cultural awareness, and/or socio-cultural internalization between residence hall floors. It was hypothesized that because of the large number of participants living on the same residence hall floor this independent variable would not provide a cohesive enough group to suggest similarities between floor members. Although this researcher posited that college women may be more similar to each other on many of these variables, it was hypothesized that these differences would not be reflected on residence hall floors as they were reflected among closer, friendship clusters.

A Multiple Analysis of Variance (MANOVA) was computed with residence hall floor as the independent variable. The dependent variables in this MANOVA were the following subscales: EDI-2 Bulimia, EDI-2 Drive for Thinness, EDI-2 Body 
Dissatisfaction, SATAQ Internalization, and the SATAQ Awareness. Table 7 illustrates that the omnibus test found no significant between group differences on any of the dependent variables. Based on this finding, a Multivariate Analysis of Covariance (MANCOVA) was not necessary. 
Table 7

Multivariate Analysis of Variance with Residence Hall Floor Membership as the

Independent Variable, and 3 EDI-2 Subscales and 2 SATAQ Subscales as the Dependent $\underline{\text { Variables }}$

\begin{tabular}{lccc}
\hline Source & df & $\underline{\mathrm{F}}$ & $\mathrm{p}$ \\
& & .686 & .69 \\
$\begin{array}{l}\text { EDI-2 } \\
\text { Body Dissatisfaction }\end{array}$ & 13 & .287 & .29 \\
$\begin{array}{l}\text { EDI-2 } \\
\text { Bulimia }\end{array}$ & 13 & .778 & .78 \\
$\begin{array}{l}\text { EDI-2 } \\
\text { Drive for Thinness }\end{array}$ & 13 & & .20 \\
$\begin{array}{l}\text { SATAQ } \\
\text { Awareness }\end{array}$ & 13 & .204 & .51 \\
$\begin{array}{l}\text { SATAQ } \\
\text { Internalization }\end{array}$ & 13 & .514 & \\
\end{tabular}

Note. There are no significant $\mathrm{F}$ values for this analysis. 


\section{$\underline{\text { Research Question \#3 }}$}

Is there a relationship between adjustment to college and eating attitudes and behaviors? Hypothesis 3 proposed that poor adjustment to college would be related to disturbed eating attitudes and behaviors. Based on previous research (VanLone \& Kalodner, 2000), it was believed that personal-emotional adjustment, in particular, would be related to disordered eating.

To test this hypothesis, a correlation analysis was used to identify relationships between the four subscales of the Student Adaptation to College Questionna ire (SACQ) and the three subscales of the EDI-2. Table 8 demonstrates several statistically significant relationships between the adjustment variables and the eating variables. Significant correlations were found between the SACQ Academic Adjustment subscale and the EDI-2 Bulimia subscale (-.30), and the EDI-2 Body Dissatisfaction subscale (.31). Additional significant correlations were found between the SACQ Social Adjustment subscale and the EDI-2 Bulimia subscale (-.18), the EDI-2 Body

Dissatisfaction subscale (-.24), and the EDI-2 Drive for Thinness subscale (-.18). Furthermore, the was a significant correlation between the SACQ Personal-Emotional Adjustment subscale and the EDI-2 Bulimia subscale(-.28). The strongest correlations existed between the SACQ Personal-Emotional Adjustment subscale and EDI-2 Drive for Thinness subscale (-.35), and between the SACQ Personal-Emotional Adjustment subscale and EDI-2 Body Dissatisfaction subscale (-.38).

These correlations suggest that as adjustment to college increases, disturbed eating attitudes and behaviors decrease. This seems to be especially true regarding the personal and emotional adjustment of college women. This may account for the fact that 
Table 8

$\underline{\text { Correlations Between Student Adaptation to College Questionnaire (SACQ) Subscales }}$ and Eating Disorder Inventory-2 (EDI-2) Subscales

Subscale

EDI-2 Thinness EDI-2 Bulimia

EDI-2 Body Diss.

Academic

$-.13$

$-.30 * *$

$-.31 * *$

SACQ

$-.18 * *$

$-.18 *$

$-.24 * *$

Social

SACQ

$-.35 * *$

$-.28 * *$

$-.38 * *$

Personal-Emotional

SACQ

$-.16^{*}$

$-.22 * *$

$-.17^{*}$

Attachment

Note. $* \mathrm{p}<.05 . * * \mathrm{p}<.01$. 
personal-emotional adjustment was identified as a legitimate covariate when comparing the eating attitudes and behaviors between friendship clusters. The personal and emotional adjustment of first year women seems to play a significant role in their development of disordered eating attitudes and behaviors.

\section{$\underline{\text { Research Question \#4 }}$}

Is there a relationship between eating attitudes and behaviors and socio-cultural awareness and/or socio-cultural internalization of the attractiveness ideal in our Western society? Hypothesis 4 proposed that both socio-cultural awareness and socio-cultural internalization, to a greater extent, will be related to disturbed eating attitudes and behaviors.

To test this hypothesis, a correlation was used to identify relationships between the two subscales of the Socio-cultural Attitudes Towards Appearance Questionnaire (SATAQ) and the three subscales of the EDI-2. Table 9 demonstrates several statistically significant relationships between the socio-cultural variables and the eating variables. Significant correlations were found between the SATAQ Awareness subscale and EDI-2 Drive for Thinness subscale (.39), and the EDI-2 Body Dissatisfaction subscale (.27). An additional correlation was found between the SATAQ Internalization subscale and the EDI-2 Bulimia subscale (.29). The strongest correlations, however, existed between the SATAQ Internalization subscale and EDI-2 Drive for Thinness subscale (.62), and between the SATAQ Internalization subscale and EDI-2 Body Dissatisfaction subscale (.47).

These correlations suggest that as an awareness and internalization of cultural thinness norms increase, the development of eating attitudes and behaviors also increase. 
Table 9

$\underline{\text { Correlations Between Socio-cultural Attitudes Towards Appearance Questionnaire }}$

$\underline{\text { (SATAQ) Subscales and Eating Disorder Inventory-2 (EDI-2) Subscales }}$

\begin{tabular}{llll}
\hline Subscale & EDI-2 Thinness & EDI-2 Bulimia & EDI-2 Body Diss. \\
& & & \\
SATAQ & $.39 * *$ & .09 & $.27 * *$ \\
Awareness & $.62 * *$ & $.29 *$ & $.47 * *$ \\
$\begin{array}{l}\text { SATAQ } \\
\text { Internalization }\end{array}$ & & & \\
\hline
\end{tabular}

Note. ${ }^{*} \mathrm{p}<.05 . * * \mathrm{p}<.01$. 
This seems to be especially true when the relationship of the cultural thinness norm and disturbed eating attitudes are examined. This finding suggests that when first year college women internalize the implicit social and cultural thinness ideal, they tend to develop problematic ideas regarding eating.

To further test Hypothesis 3 and Hypothesis 4, additional analyses were conducted. Multiple regression analyses were used to identify predictive relationships of the student adjustment variables, and the socio-cultural awareness and internalization variables, on the eating attitudes and behaviors variables. In order to determine the best predictors of the drive for thinness, the first analysis utilized a stepwise multiple regression model. In this analysis, the four subscales of the SACQ (Academic, Social, Personal-Emotional, and Attachment) and the two subscales off the SATAQ (Awareness and Internalization) were entered as the independent or predictor variables. The dependent or criterion variable in this first analysis was the EDI-2 Drive for Thinness subscale. The resulting two models are displayed in Table 10.

Model 1 eliminated five of the six predictor variables, retaining only the SATAQ Internalization subscale. This variable accounted for $38.2 \%$ of the variance in drive for thinness. In addition, $R(.618)$ was found to be significant, $F(1,208)=127.794, \mathrm{p}<.01$. Model 2 entered an additional predictor, personalemotional adjustment to college, and resulted in a $1.8 \%$ increase in variance accounted for, $\mathrm{p}<.01$. 
Table 10

$\underline{\text { Stepwise Multiple Regression of Student Adjustment to College Questionnaire (SACQ) }}$

$\underline{\text { Subscales and Socio-cultural Attitudes Towards Appearance Questionnaire (SATAQ) }}$

$\underline{\text { Subscales on the Eating Disorders Inventory-2 (EDI-2) Drive for Thinness Subscale }}$

\begin{tabular}{|c|c|c|c|c|c|}
\hline Predictors & $\underline{B}$ & $\underline{\text { SEB }}$ & $\underline{\beta}$ & $\underline{\mathrm{R}}^{2}$ & $? \underline{\mathrm{R}}^{2}$ \\
\hline Model 1 & & & & .382 & .382 \\
\hline $\begin{array}{l}\text { SATAQ } \\
\text { Internalization }\end{array}$ & $.420 * *$ & .037 & .618 & & \\
\hline Model 2 & & & & .400 & .018 \\
\hline $\begin{array}{l}\text { SATAQ } \\
\text { Internalization }\end{array}$ & $.385^{* *}$ & .039 & .566 & & \\
\hline $\begin{array}{l}\text { SACQ } \\
\text { Personal-Emotional }\end{array}$ & $-.076 *$ & .030 & -.144 & & \\
\hline
\end{tabular}

Note. $* \underline{p}<.05 . * * \underline{p}<.01$. 
The stepwise model 1 was selected as the most parsimonious model, accounting for ample variance. This finding provides further support for Hypothesis 4. An internalization of the thinness ideal contributes to the desire to achieve thinness in this sample of first year college women. Although the predictive relationship between personal-emotional adjustment to college and drive for thinness is statistically significant, personal adjustment does not appear to account for much of the variance in this analysis.

Two additional multiple regression analyses were conducted. The first of these used the four subscales of the SACQ (Academic, Social, Personal-Emotional, and Attachment) and the two subscales off the SATAQ (Awareness and Internalization) as predictor variables, and the EDI-2 Bulimia subscale as the criterion variable. This stepwise analysis identified the SACQ Academic Adjustment subscale and the SATAQ Internalization subscale as significant predictors. However, these variables accounted for only $14.4 \%$ of the variance. This finding suggests that adjustment to college and the internalization of the thinness ideal contributes less to development of behavioral measures than attitudinal measures of eating disturbance.

The second stepwise analysis used the four subscales of the SACQ (Academic, Social, Personal-Emotional, and Attachment) and the two subscales off the SATAQ (Awareness and Internalization) as predictor variables, and the EDI-2 Body Dissatisfaction subscale as the predictor variable. This analysis identified the SATAQ Internalization and the SACQ PersonalEmotional subscale as significant predictors. However, these variables only accounted for $28 \%$ of the variance. Although this finding suggests that adjustment to college and the interna lization of the thinness ideal may contribute to the development of disturbed body image, the evidence is not robust. 


\section{Summary}

The analyses in the present investigation were designed to answer four research questions. Hypothesis 1 proposed that there would be greater between group than within group differences on measures of eating attitudes, eating behaviors, socio-cultural awareness, and/or socio-cultural internalization between friendship clusters. To test this hypothesis, the researcher used the UCINET IV (Borgatti, Everett, \& Freeman, 1992) statistical package to identify friendship clusters. A Multiple Analysis of Variance (MANOVA) was then computed, using the averages of the Eating Disorder Inventory-2 (EDI-2) Subscales (Drive for Thinness, Bulimia, and Body Dissatisfaction) and the Socio-cultural Attitudes Towards Appearance Questionnaire (SATAQ) Subscales (Awareness and Internalization) for each friendship cluster as dependent variables, and friendship cluster as the independent variable.

The omnibus test found an overall significant difference between the 32 friendship clusters on EDI-2 Drive for Thinness $(\mathrm{F}=1.62[1,31], \mathrm{p}<.05)$ and EDI-2 Body Dissatisfaction $(\mathrm{F}=1.68[1,31], \mathrm{p}<.05)$. There were no significant differences between the friendship clusters on the EDI-2 Bulimia, the SATAQ Awareness, or the SATAQ Internalization subscales. This suggests an overall difference between friendship clusters regarding eating attitudes and behaviors. When a Multiple Analysis of Covariance (MANCOVA) was computed on these 32 friendship clusters, using Body Mass Index (BMI) and Personal Emotional Adjustment subscale of the Student Adaptation to College Questionnaire (SACQ) as covariates, no significant differences were found on any of the dependent variables. This suggests that the body weight and 
the personal adjustment of first year college women may have some mediating effect in the social contagion process.

Two additional analyses were conducted in an effort to further answer the first research question. First, in an effort to improve external validity of the study, an additional MANOVA was conducted that examined only the friendship clusters that were drawn from residence hall floors with at least a 70 percent or higher participation rate. The independent variable was friendship cluster and the dependent variables were the averages for each cluster on the following subscales: EDI-2 Drive for Thinness, EDI-2 Bulimia, EDI-2 Body Dissatisfaction, SATAQ Awareness, and SATAQ Internalization. The omnibus test demonstrated significant between group differences for friendship clusters on the EDI-2 Drive for Thinness $(\mathrm{F}=2.68[1,12], \mathrm{p}<.05)$ subscale. However, there were no significant differences between friendship clusters on any of the other dependent variables. This further suggests overall differences in eating attitudes and behaviors between friendship clusters.

The second additional analysis was performed to compare differences between participants in friendship clusters and participants that were not in friendship clusters. A MANOVA was computed, using a dichotomous independent variable that indicated membership in friendship clusters or non-membership in friendship clusters. The EDI-2 Drive for Thinness, EDI-2 Bulimia, EDI-2 Body Dissatisfaction, SATAQ Awareness, and SATAQ Internalization subscales were used as dependent variables. The omnibus test found significant between group differences on the EDI-2 Bulimia $(F=5.46[1,1], p<$ .05) subscale and the SATAQ Internalization $(\mathrm{F}=6.76[1,1], \mathrm{p}<.05)$ subscale. There were no significant differences on the EDI-2 Body Dissatisfaction subscale, the EDI-2 
Drive for Thinness subscale, or the SATAQ Awareness subscale. This analysis points to overall differences in eating behaviors and the internalization of thinness ideal between individual participants in friendship clusters and those individuals who were not members of friendship clusters.

More specifically, participants identified by the UCINET IV program as being in friendship clusters had a Friendship Cluster Cohesion Index (FCCI) between 1 and .50, suggesting a close bond to other members of their cluster. Participants not identified by the UCINET IV program as being in friendship clusters had a FCCI between 0 and .50 , suggesting a lack of social connectedness to other participants. This finding demonstrates differences in eating behaviors and the internalization of the socio-cultural thinness norm between college women in who are socially connected and those college women who are less connected. These findings partially support Hypothesis 1 . It does appear that there are some significant between group differences in regards to eating attitudes and behaviors, and the internalization of the socio-cultural thinness ideal.

Hypothesis 2 proposed that there would not be differences in eating attitudes, eating behaviors, and socio-cultural awareness and internalization of attractiveness ideals between women in different residence hall floors. A MANOVA was computed with residence hall floor as the independent variable and EDI-2 Drive for Thinness, EDI-2 Bulimia, EDI-2 Body Dissatisfaction, SATAQ Awareness, and SATAQ Internalization as the dependent variables. The omnibus test found no significant between group differences on any of the dependent variables. Thus hypothesis 2 was supported.

Hypothesis 3 proposed that poor adjustment to college would be related to disordered eating attitudes and behaviors. To test this hypothesis, a correlation was used 
to identify relationships between the four subscales of the Student Adaptation to College Questionnaire (SACQ) and the three subscales of the EDI-2. Significant correlations were found between the SACQ Academic Adjustment subscale and the EDI-2 Bulimia subscale (-.30), and the EDI-2 Body Dissatisfaction subscale (-.31). Additional significant correlations were found between the SACQ Social Adjustment subscale and the EDI-2 Bulimia subscale (-.18), the EDI-2 Body Dissatisfaction subscale (-.24), and the EDI-2 Drive for Thinness subscale (-.18). Furthermore, the was a significant correlation between the SACQ PersonalEmotional Adjustment subscale and the EDI-2 Bulimia subscale(-.28). The strongest correlations existed between the SACQ PersonalEmotional Adjustment subscale and the EDI-2 Drive for Thinness subscale (-.35), and between the SACQ PersonalEmotional Adjustment subscale and the EDI-2 Body Dissatisfaction subscale (-.38). Thus, it appears that personal adjustment to college is related to disordered eating attitudes and behaviors, supporting Hypothesis 3.

Hypothesis 4 proposed that both socio-cultural awareness and socio-cultural internalization, to a greater extent, would be related to disturbed eating attitudes and behaviors. To test this hypothesis, a correlation was used to identify relationships between the three subscales of the EDI-2 and the two subscales of the SATAQ. Significant correlations were found between the SATAQ Awareness subscale and EDI-2 Drive for Thinness subscale (.39), and the EDI-2 Body Dissatisfaction subscale (.27). An additional correlation was found between the SATAQ Internalization subscale and the EDI-2 Bulimia subscale (.29). The strongest correlations existed between the SATAQ Internalization subscale and the EDI-2 Drive for Thinness subscale (.62), and between the SATAQ Internalization subscale and the EDI-2 Body Dissatisfaction subscale (.47). This 
suggests that the internalization of the socio-cultural attractiveness ideal is related to disordered eating attitudes and behaviors, which supports hypothesis 4 .

An additional analysis was conducted to further test Hypothesis 3 and Hypothesis 4. Multiple Regression Analyses was computed in an effort to identify predictive relationships between the student adjustment variables and the socio-cultural variables, and the eating attitudes and behaviors variables. When a stepwise model was used to examine predictors of the EDI-2 Drive for Thinness subscale, the SATAQ Internalization subscale was retained, and was determined to account for $38.2 \%$ of the variance. The finding demonstrates a predictive relationship between the internalization of the attractiveness ideal with a desire to achieve thinness, further supporting Hypothesis 4.

In summary, an overall significant difference was found between friend ship clusters on eating attitude and behavior variables. This finding was corroborated when examining only those friendship groups with participation rates of 70 percent or higher. Additionally, overall significant differences were found on an eating behavior variable and on the internalization of the socio-cultural attractiveness ideal when comparing participants in friendship clusters with participants not in friendship clusters. A relationship was established between personal adjustment to college and disordered eating attitudes. A second relationship was established between the internalization of the socio-cultural ideal of attractiveness and disordered eating attitudes. Finally, a predictive relationship was found between the internalization of the attractiveness ideal and the desire to achieve thinness. 


\section{Chapter 5}

\section{Discussion}

\section{$\underline{\text { Overview }}$}

The prevalence of disordered eating attitudes and behaviors among college women is alarmingly high. Although incidence rates of eating disorders among late adolescent and early adult females are estimated to be relatively low (between .5 and 3 percent of the population) (APA, 1994), the research examining the college women population suggests much higher percentages of eating disorders (Berg, 1988; Clark, Levine, \& Kinney, 1989; Coric \& Murstein, 1993; Halmi, Falk, \& Schwartz, 1981; Heatherton, Nichols, Mahamedi, \& Keel, 1995; Herzog, Norman, Rigotti, \& Pepose, 1986; Mitchell \& Ekert, 1987; Nelson, Hughes, Katz, \& Searight, 1999). In a recent study of college women, 32 percent of the sample scored above the clinical level on a measure of eating disorders (Okine, 2000). The figures are even more startling when considering those college women with disturbed eating patterns who do not fit the full criteria for an eating disorder. It has been estimated that somewhere between 50 and 80 percent of college women struggle with some type of disordered eating attitude or behavior (Franko \& Omori, 1999; Hesse-Biber, Marino, Watts-Roy, 1999; Kalodner \& Scarano, 1992; Mintz \& Betz, 1988).

Due to this apparent epidemic, many researchers have examined the college environment, studying variables that may contribute to disordered eating attitudes and behaviors (Berg, 1988; Bowden-Woodward \& Levitz, 1989; Brouwers, 1988; Hessebiber \& Marino, 1991; StreigalMoore, Silberstein, \& Rodin 1986). One popular etiological theory posits that societal standards regarding beauty may influence the 
development of body image disturbance, and, ultimately, may contribute to the etiology of eating disorders (Faith \& Share, 1993; Kalodner, 1997; Murray, Touyz, \& Beumont, 1996; Shaw and Walker, 1995; Stice, 1994; Stice, Nemeroff, \& Shaw, 1996). Some evidence suggests that this socio-cultural influence is intensified on college campus. For example, Connor-Greene, Streigal-Moore, and Cronan (1994) found that college women who were preoccupied with their weight believed that their environment at their college or university put a greater emphasis on appearance of beauty. Thus, it appears that the internalization of such a cultural norm may be related to disordered eating.

Some other factors that may contribute to the frequent development of eating problems on college campuses include the competitive environment that often exists at a university and the adjustment stress that individuals feel when they make the transition to college life. It has been demonstrated that competitive environments on college campuses may foster not only academic competition, but also social competition regarding the achievement of beauty (Bowden-Woodward \& Levitz, 1989; Brouwers, 1988; Streigal-Moore et al., 1986). Additionally, it has been a long held belief that college students are often under a great deal of academic, social, and psychological stress (Astin, 1977; Murphy \& Archer, 1997). Much of the personal and social stress that college students face originates from the adjustment that they are making to a new environment (Hesse-Biber et al., 1999). Recent research has demonstrated a robust, predictive relationship between poor personal adjustment to college and the development of disturbed eating attitudes and behaviors (VanLone \& Kalodner, 2000).

Based on the research presented in this chapter, it appears that variables specific to the college environment contribute to the high rates of eating disturbance among 
college women. However, the following question remains unanswered: Why do some college women develop eating problems, while others do not? One way to find an answer to this question is to examine how peer influence mediates the development of eating disturbance for college women. The influence that peers have on one another, especially during adolescence and early adulthood, are quite powerful. The power of peer influence has been shown to be a significant factor in the development of smoking (Barber, Bolitho, \& Bertrand, 1999; West, Sweeting, \& Ecob, 1999; Yarnold, 1999), alcohol (Clapp \& McDonnell, 2000; Marshal \& Chassin, 2000; Sieving, Perry, \& Williams, 2000), and illegal drug use (Alva, 1998; Farrell \& White, 1998; Oetting \& Donnermeyer, 1998) behaviors.

There has been some examination of the influence of peer groups in the eating disorder research. The first such study demonstrated how eating disturbance spread throughout a group of ballerinas (Druss \& Silverman, 1977). Another study showed how disordered eating attitudes and behaviors seemed to transpire among female college athletic teams (Brooks-Gunn, Burrow, \& Warren, 1988). In a particularly striking study, Crandall (1988) illustrated how similar eating behaviors of sorority members became more alike over time, suggesting the presence of a social contagion process. Similarly, Paxton, Schutz, Wertheim, and Muir (1999) demonstrated greater between group differences than within group differences on measures of eating attitudes and behaviors between adolescent friendship groups.

The current study provides evidence that implies the possibility of the social contagion of eating attitudes and behaviors among first year college women. The findings also demonstrate a relationship between poor adjustment to college and the 
development of eating problems. Additionally, the results of this study point to a relationship between the internalization of a cultural thinness norm and the development of disturbed eating attitudes. A more comprehensive discussion of these findings, as well as information obtained through additional analyses, will be discussed and related to past research. Limitations of this study will be presented, and, finally, suggestions for future research will be discussed.

Discussion of the Social Contagion of Eating Attitudes and Behaviors

Hypothesis 1 proposed that there would be differences in eating attitudes, eating behaviors, socio-cultural awareness, and socio-cultural internalization between friendship clusters. There is some evidence in the research that suggests that individuals develop similar eating attitudes and behaviors to those of their peers. Crandall (1988) was the first researcher to utilize the social contagion theory to explain the development of disordered eating behaviors. In his study, Crandall (1988) demonstrated that the eating behaviors of sorority members became more similar over time. Based on the results of his study, Crandall (1988) suggested that bulimia may be viewed as a social disease that individuals acquire from their friends, much like the way people acquire contagious biological diseases from each other.

In another important study, Paxton et al. (1999) examined small friendship groups (between 3 and 6 individuals per group) of tenth grade girls. When comparing the 79 friendship groups from this sample, Paxton et al. (1999) found greater between group differences than within group differences on the following dependent variables: body image concerns, dietary restraint, and extreme weight-loss behaviors. This study was influential in that it suggested that similarities in eating attitudes and behaviors may be 
more powerful in smaller friendship groups with greater social interaction, rather than in larger groups in which individuals are in further proximity and have less opportunity to interact with each other.

There is no published research to date, however, that examines the similarities in eating attitudes and behaviors among small friendship groups of first year college women. Due to the high levels of adjustment stress that college students often experience their first year of college (Astin, 1977; Hesse-Biber et al., 1999; Murphy \& Archer, 1997), coupled with the evidence of the inc reasing prevalence of eating problems and/or disorders among college women (Berg, 1988; Clark et al., 1989; Coric \& Murstein, 1993; Franko \& Omori, 1999; Halmi et al., 1981; Heatherton et al., 1995; Herzog et al., 1986; Hesse-Biber et al., 1999; Kalodner \& Scarano, 1992; Mintz \& Betz, 1988; Mitchell \& Ekert, 1987; Nelson et al., 1999, and Okine, 2000) this population appears to be ripe for just such an examination.

This current study of first year college women, using a methodology similar to that of the Paxton et al. (1999) study, provides some additional support for the social contagion of eating attitudes and behaviors. The evidence presented in the results section of this document suggests that college women have eating attitudes and behaviors similar to those of their self identified close friends. More specifically, when comparing 32 small, friendship clusters, an omnibus $\mathrm{F}$ test found greater between group differences than within group differences on measures of eating attitudes (Eating Disorders Inventory-2 [EDI-2] Drive for Thinness subscale and EDI-2 Body Dissatisfaction subscale). This finding is not surprising. The results, pointing to similarities in eating attitudes and behaviors among individuals in small friendship groups, are similar to the 
findings in the Paxton et al. (1999) study. Also, it is pertinent to predict that social influence may more easily occur at an attitudinal level rather than at a behavioral level. Although there is evidence of social influence occurring at the behavio ral level (Alva, 1998; Barber et al., 1999; West et al., 1999), there has been more research pointing to a social process influencing individuals at an attitudinal level (Beebe, Holbeck, Schober, Lane, \& Rosa, 1996; Beren, Hayden, Wifley, \& Steigal-Moore 1997; Brooks-Gunn, 1988; Clapp \& McDonnell, 2000; Murray, Touyz, \& Beaumont, 1995; Paxton, 1996). This study suggests that small friendship groups of first year college women have similar eating attitudes and behaviors.

The importance of this finding is that there are some differences between eating attitudes and behaviors between these small, friendship clusters. It is not important, however, to determine the direction of these differences. For the purposes of this study, learning which particular friendship groups have more eating problems than one another is not important. The intent is not to determine how specific factors regarding each friendship group may have led to the development of disturbed eating patterns. The fact that there are differences between groups, regardless of the direction of the difference, significantly answers the first research question in this study. Therefore, follow-up univariate analyses were not necessary.

The finding in this study that group members were not similar on bulimic behaviors, such as binge eating, is similar to the result found by Paxton et al. (1999), who found that group members were not similar on a measure of binge eating. This finding is in contrast to Crandall's (1988) finding that sorority members were more alike in regards to binge eating and Pike's (1995) finding that $10^{\text {th }}$ grade girls were also more alike in 
their binge eating behaviors. However, Pike (1995) also found no positive relationship among friend's binge eating in two other grade levels and suggested that cohort effects may be operating. Additionally, when comparing the results of this study with the Crandall (1988) study, one must consider the different populations. It may be argued that sorority members have even more intense pressure to adhere to a thinness ideal than do first year college women.

Although this study closely followed that methodology of the widely accepted Paxton et al. (1999) study, there are some questions regarding the validity of this design. First, some caution should be used in the interpretation of this result due to the high number of levels of the independent variable. Although a significant result was found, this analysis has marginal power. Second, it may be argued that the external validity of this study could be improved because some of the residence hall floors that were examined had low participation rates. For example, only 5 of the 14 first year students from residence hall floor 5 participated in the study, representing only 36 percent of the floor sample. Thus, it is assumed that additional friendship clusters may have been formed and identified in this study if a greater percentage of the sample had participated. Studying only floors with a higher participation rate would provide a clearer picture of the true differences friendship groups.

To account for both of these problems, the researcher conducted an additional analysis, identifying friendship groups generated only from those residence hall floors with a participation rate of 70 percent or higher. Using this criteria, the researcher used the UCINET IV program to identify 13 friendship clusters. These 13 friendship groups most likely accounted for a more accurate representation of friendship groups for this 
sample, improving the external va lidity of the study. This also allowed the researcher to reduce the number of levels of the independent variable, resulting in an increase in the power of the study. The results of this analysis found a significant difference between friendship clusters regarding individual reports of their desire to achieve thinness. The finding provides further support for the hypothesis that friendship group members will be more similar to each other regarding eating attitudes and behaviors, than they are to individuals outside of their friendship cluster. Due to the increase in power and improved external validity, this conclusion can be made with greater assurance.

A second additional analysis was conducted to provide additional support for Hypothesis 1. In this analysis, the researcher wanted to determine if individual's perceived social connections with others influenced their eating attitudes and/or behaviors. Recent literature has suggested that individuals who are more inclined to make meaningful social connections are less likely to develop disordered eating attitudes and behaviors. In one study, Okine (2000) demonstrated that higher levels of eating disorder symptomatology were associated with poorer attachment to peers. Additionally, Zelly (2000) found that individuals who reported less connection and social support from friends were found to have more disturbed eating patterns.

In this study, the researcher compared all of the individuals who were members of a friendship cluster, as identified by the UCINET IV program, with all participants who had not been identified as members of friendship clusters. This significantly reduced the levels of the independent variable (those in friendship groups and those not in friendship groups), and thus there was a resultant increase in power for this analysis. The result demonstrated significant differences between these two groups in regards to eating 
behaviors and the internalization of the cultural thinness ideal. Specifically, the differences were found on the EDI-2 Bulimia subscale, and the Socio-cultural Attitudes Towards Appearance Questionnaire (SATAQ) Internalization subscale. This finding is interesting in that it demonstrates behavioral differences between these groups. For this analysis, the direction of this difference is important. A follow-up univariate analysis shows that those individuals that were not identified as being members of friendships groups had significantly higher scores on the EDI-2 Bulimia subscale. Thus, it can be concluded that the se individuals have more problematic eating behaviors than the individuals that were determined to be members of friendship groups. As supported in the literature, the finding indicates that individuals who have a difficult time connecting with their peers, often develop disordered eating behaviors.

The second finding here is also interesting. It was determined that individuals determined to be in friendship groups were significantly different than those not included in friendship groups in regards to the internalization of the cultural thinness ideal. Again, direction is more important in this analysis, and, thus, a univariate analysis was conducted to determine which of the two groups were more likely to internalize sociocultural messages regarding thinness and beauty. Not surprisingly, it was found that individuals not identifying with friendships groups were more likely to internalize the thinness ideal, providing greater support for the hypothesis that individuals who are not adept at forming social connections are more likely to develop disturbances in eating attitudes and behaviors. In this case, these individuals appear to also be more susceptible to the influence and/or internalization of socio-cultural pressures to adhere to a thinness ideal. 
While this study appears to demonstrate evidence in support of Hypothesis 1, there is more question as to whether the study provides support for the social contagion of eating attitudes and behaviors. It appears clear, from the results of this study, that first year college women in small friendship groups tend to be more like other members of their friendships group, specifically in regards to eating attitudes. However, does this allow us to presume that there is a social contagion effect? Crandall (1988) warns that such an assumption could be premature. In his discussion of his own results, Crandall (1988) argues that one of two processes may be taking place. Either individuals may becoming more like each other over time (social contagion), or individuals may be attracted to other individuals who are more alike (assortment) (Crandall, 1988).

The same is to be said for the results of this study. We may hypothesize that the individuals are developing similar eating attitudes and behaviors of others in their small friendship groups. This hypothesis seems to fit with the literature. Researchers have suggested that disturbed eating and attitudes tend to run in social groups. Specifically, studies examining ballerinas (Druss \& Silverman, 1977), female athletes (Brooks-Gunn et al., 1988), lesbian women (Beren et al., 1997), gay males (Silberstein, Mishkind, Strie gal-Moore, Timko, \& Rodin, 1989), sorority members (Crandall, 1988), and high school girls (Paxton et al., 1999) have all suggested the possibility of a social contagion effect, in which members of these groups become more alike each other in regards to eating attitudes and behaviors.

However, in the majority of the studies, there is no evidence that the similarities could not be determined to be the result of assortment ("birds of a feather, flock together"). Crandall (1988) is the only researcher who attempts to tackle this problem. 
Due to the fact that his subjects develop friendships over time based on the amount that they binged, he argues that the social contagion process is taking place (Crandall, 1988). In this present study, however, the researcher was unable to definitely determine if the findings are the result of social contagion, because the eating attitudes and behaviors of the participants were not measured over time.

Hypothesis 2 proposed that there would not be differences between residence hall floor groups in regards to eating attitudes and behaviors, and the awareness and internalization of socio-cultural norms regarding thinness and beauty. In a recent study, VanLone and Kalodner (2000), believing that first college women on residence hall floors would significantly influence the eating attitudes and behaviors of each other, compared residence hall floor groups to each other, specifically looking for differences in eating attitudes and behaviors between the floor groups. This study found no significant between group differences on any of the measures of eating attitudes and behaviors, and the researchers determined that the floor groups were too large, and that there were most probably a number of sub-groupings on each floor (VanLone \& Kalodner, 2000). The results of this current study were quite similar. No significant between group differences were found on measures of eating attitudes, eating behaviors, socio-cultural awareness, and/or socio-cultural internalization. Thus, Hypothesis 2 was supported. Discussion of the Relationship Between Adjustment to College and Disordered Eating $\underline{\text { Attitudes and Behaviors }}$

Hypothesis 3 proposed that poor adjustment to college would be related to disturbed eating attitudes and behaviors. The literature suggests that the first year of college can be quite stressful for individuals (Astin, 1977; Murphy \& Archer, 1997; Sher, 
Wood, \& Gotham, 1996). Students in their first year of college often face academic, personal, and social transitions that, for many, can be difficult to manage (Baker \& Siryk, 1989). A number of researchers have further suggested that the adjustment process for first year college students may be related to their development of eating problems (Bowen-Woodward \& Levitz, 1989; Hesse-Biber \& Marino, 1991; Hesse-Biber et al., 1999; Striegel-Moore, Silberstein, Frensch, \& Rodin, 1989). One recent study, looked directly at the relationship between adjustment to college and eating disturbance, and specifically found that dieting attitudes and behaviors were predicted by poor personal and emotional adjustment to college (VanLone \& Kalodner, 2000).

In this study, several correlations were found between measures of student adjustment and measures of eating attitudes and behaviors. All correlations suggested that as adjustment to college increases, disturbed eating attitudes and behaviors decrease. Similarly to the results found in the aforementioned study (VanLone \& Kalodner, 2000), this relationship appears to be especially true when considering the personal and emotional adjustment of college women. The strongest correlations found in this study existed between the Student Adaptation to College Questionnaire (SACQ) PersonalEmotional subscale and the EDI-2 Drive for Thinness subscale (-.35), and between the SACQ Personal-Emotional subscale and the EDI-2 Body Dissatisfaction subscale (-.38). Thus, for this sample, it appears that poor personal and emotional adjustment is related to disordered eating attitudes and behaviors. This finding supports Hypothesis 3 and further suggests that adjustment to college seems to play an important role in the development of eating disturbance for the first year college student population. 
Discussion of the Relationship Between Socio-cultural Influence and Disordered Eating $\underline{\text { Attitudes and Behaviors }}$

Hypothesis 4 proposed that socio-cultural awareness and internalization of the attractiveness ideal of our Western society will be related to disordered eating attitudes and behaviors. A number of studies have suggested that social and cultural norms have some influence in the development of problematic eating attitudes and behaviors (Anderson \& DiDomenico, 1992; Faith \& Schare, 1993; Garner, Garfinkel, Schwartz, \& Thompson, 1980; Irving, 1990; Kalodner, 1997; Morris, Cooper, \& Cooper, 1989; Murray, Touyz, \& Beumont, 1996; Schwartz, Thompson, \& Johnson, 1982; Shaw \& Walker, 1995; Stice, 1994; Stice, Nemeroff, \& Shaw, 1996; Stice \& Shaw, 1994; Striegel-Moore, Silberstein, \& Rodin, 1986; Williamson, Cubic, \& Gleaves, 1993; Wiseman, Gray, Moismann, \& Ahrens, 1992). The socio-cultural theory posits that societal norms related to thinness and attractiveness may be internalized by women, lead to negative self-evaluations, negative affect, and body dissatisfaction, and ultimately lead to the development of disturbed eating patterns (Shaw \& Waller, 1990; Stice et al., 1996; Stice 1994; Williamson et al., 1993).

In this study, significant correlations were found between measures of sociocultural awareness and internalization, and eating attitudes and behaviors, providing support for Hypothesis 4. It was further hypothesized that the internalization of sociocultural norms regarding thinness and attractiveness would have stronger relationships with disturbed eating patterns, as internalizing such norms would lead to negative selfevaluations, negative affect, and body dissatisfaction. Not surprisingly, the strongest correlations were found between the SATAQ Internalization subscale and the EDI-2 
Drive for Thinness subscale (.62), and the SATAQ Internalization subscale and the EDI-2 Body Dissatisfaction subscale (.47). The finding that the internalization of these norms is related to body dissatisfaction corroborates previous research. The even more robust finding regarding the relationship between the internalization of the socio-cultural norms regarding thinness and attractiveness and the individual's drive to achieve thinness extends the research to highlight the apparent problematic effect of norm of thinness in our society.

The results of this study provide further support to Hypothesis 4 by pointing to a significant, predictive relationship between the internalization of the socio-cultural thinness ideal and the desire to achieve thinness. A stepwise, multiple regression analysis demonstrated that the SATAQ Internalization subscale accounted for $38.2 \%$ of the variance in the EDI-2 Drive for Thinness subscale. This is both statistically and clinically significant. This finding demonstrates that, in this sample of first year college women, the internalization of socio-cultural influences regarding thinness predicts the development of attitudes and behaviors regarding an individual's desire to achieve thinness. The result of this analysis parallels past research and provides strong support for Hypothesis 4.

\section{Summary of Findings}

Significant differences in eating attitudes and behaviors were found between small friendship groups. Significant differences in socio-cultural awareness and/or internalization were not found between small friendship groups. Significant differences in eating attitudes and behaviors were also not found between residence hall floor groups. While these findings supported Hypothesis 1 and Hypothesis 2, the question of social 
contagion remains unanswered. Although it appears that individuals have eating attitudes and behaviors that are more similar to members of their small friendship group than to those not in their friendships groups, this could be due to either social contagion or assortment.

In addition, there was support for the relationship between student adjustment to college and disordered eating attitudes and behaviors. It was demonstrated that as adjustment to college increases or improves, disturbed eating attitudes and behaviors decrease. More specifically, it was shown that healthy personal and emotional adjustment was most strongly related to a decrease in disordered eating patterns.

Finally, the findings also supported a relationship between the awareness and internalization of socio-cultural norms regarding thinness and the development of eating attitudes and behaviors. The strongest relationships were found between an internalization of these socio-cultural norms and measures of body dissatisfaction and the desire to achieve thinness. Additionally, it was demonstrated that the internalization of the socio-cultural thinness norm significantly predicted the desire to achieve thinness among participants in this sample.

\section{$\underline{\text { Implications for Practice }}$}

Based on the results of this study, small friendship groups should be considered as a targeted subculture for the primary, secondary, and tertiary prevention of eating problems and/or disorders. The findings of this study suggest that members of small friendship groups have eating attitudes and behaviors that are similar to each other. Regardless if this is due to social influence or peer selection, it is pertinent to suspect that 
intervening at this small group level may be an effective way to make changes $\mathrm{n}$ both attitudes and behaviors regarding eating.

The goal of primary prevention is to reduce the incidence of eating disorders among healthy individuals by emphasizing that disordered eating behavior is abnormal (Piran, 1997). Engaging with small groups at this level of intervention seems to have its merits. Paxton (1996) predicts that the more that members of friendship groups could work together to explore healthy ways of eating, the more powerful the program will in bringing about both individual and subculture change. Thus, targeting small groups in venues such as residence hall programs and small class discussions appears to be an effective approach to primary prevention. There is some evidence that small group discussions have been show to alter negative food and body related attitudes in young women (Huon, 1994).

While small group discussions have been demonstrated as successful interventions, some have warned against the iatrogenic effects of prevention programs (Garner, 1985; Mann, Nolen-Hoeksema, Huang, Burgard, Wright, \& Hanson, 1997). In these studies, it has been suggested that such discussions, if not managed correctly, can serve to normalize disordered eating attitudes and behaviors. In the study conducted by Mann et al. (1997), two popular female students provided information about eating disorders and related their personal stories of battling eating disorders. The result was that some women attending this program actually developed more eating problems. Mann et al. (1997) suggested that this may have occurred because the stories presented by the two women may have served to normalize, or even glamorize the eating disorders, leading to the adoption of disordered eating behaviors by attendees. Thus, it is important 
to consider the message being sent, and the individuals sending the message when providing any prevention program. Much care should be taken to create a healthy environment when preventing primary prevention for eating disorders through small discussions groups.

Paxton (1996) suggests that small group discussions could include (1) a focus on teaching skills to identify the source and triggers of body image concern and inclination to diet, (2) discussing the weight, shape, and dieting or eating behaviors of friends and then reframing these reflections of concern on the friend's part, and (3) discussing the attitudes and behaviors of friends as "fat talk," without personal implications for themselves. Paxton (1996) suggests that helping young women to understand the role of "fat talk" may diminish its power to evoke anxiety. Additionally, Paxton (1996) suggests teaching cognitive skills to assist individuals in managing the effects of teasing. Such techniques have been shown to work in primary prevention programs for smoking (Dent, Sussman, Burton, \& Flay, 1995; Murray, Richards, Luepker, \& Johnson, 1987).

The goal of secondary prevention of eating disorders is to convince individuals who already have some eating disorder symptoms to seek help (Piran, 1997). Friendship groups could be used as invaluable resources in the early detection of eating problems. Paxton (1996) suggests educating individuals regarding how to detect and respond to signs that their friends may be developing eating problems. There are two primary focuses here. The first is in helping students to recognize the signs of eating problems such as excessive dieting, bingeing behavior, and/or purging behaviors. The second goal is to educate women in small groups on how to be supportive rather than punitive with friends who may be developing problems. Individuals in these groups should also be 
educated on the resources available on their campuses, and how to assist a friend in getting access to such resources.

Tertiary prevention refers to the formal treatment, such as psychotherapy and/or psychiatry, of a clinically diagnosed eating disorder. Small groups may also be an effective intervention at this level. It has been shown that group therapy has helped to reduce the shame associated with eating problems, supplied a place for reality testing of distorted beliefs and self-perceptions among others who are also facing eating disorders, and provided an interpersonal context to facilitate links between eating disorders and interpersonal relationships (Fettes \& Peters, 1992; Oesterheld, McKenna, \& Gould, 1987). Again, it is important to effectively create a healthy culture that does not lead to the development of iatrogenic effects between group members. Thus, it is often important to focus on reducing shame, processing interpersonal issues, and challenging distorted beliefs, while avoiding discussions of both the numbers and techniques of group members' personal disordered eating behaviors.

The finding in this study regarding the relationship between poor personal and emotional adjustment to college and disturbed eating attitudes and behaviors also has practical implications. The results of this study, in addition to the similar results found in an earlier study (VanLone \& Kalodner, 2000), suggest that much attention should be afforded to the personal and emotional adjustment, especially in regards to first year college women. Programmatic efforts for the prevention of eating disturbance should not include much more than direct information regarding the eating attitudes and behaviors of first year students. Specific attention should also be provided to assist first year students with their personal and emotional adjustment to college. First year student programs, 
often delivered through the residence hall system, should not limit their focus to the academic and social adjustment of students. These programs should also provide opportunities for students to process their personal and emotional struggles, and educate and inform these students on resources available to them (mentor programs, counseling centers) if they are struggling on a more personal level.

Finally, the finding of a robust and predictive relationship between the internalization of the socio-cultural thinness ideal and the development of disturbed eating attitudes and behaviors has important implications for practice. Programmatic interventions at the small group level may be developed in an effort to combat the social and cultural influences that may contribute to the development of eating problems. Again, small group discussions that assist individuals in developing an awareness of these messages, as well as helping them to diminish the power of the negative affect associated with these messages may be helpful. More importantly, however, university campuses have an opportunity to make systemic changes on their campuses that may help to alter these social and cultural influences. Educational programs that reach the entire student population, as well as interventions intended to create healthy norms among athletic and social organizations may assist a campus in developing healthy norms regarding attractiveness and eating attitudes and behaviors.

\section{Limitations of the Study}

\section{$\underline{\text { Measurement }}$}

Eating attitudes and behaviors was measured by the Eating Disorders Inventory- 2 (EDI-2). The internal consistencies (Chronbach alpha) for each subscale are as follows: Body Dissatisfaction (.91), Bulimia (.81), and Drive for Thinness (.82), suggesting 
adequate internal validity. This measure has been widely used with the college student population, and strong psychometrics were expected.

Student adjustment to college was measured using the Student Adaptation to College Questionnaire (SACQ). The internal consistencies (Chronbach alpha) for each subscale are as follows: Academic (.92), Social (.92), and PersonalEmotional (.88). This measure was developed for use with the first year college student population and has been used with many other first year student samples. Strong internal validity was expected.

Socio-cultural attitudes regarding thinness and physical appearance were measured using the Socio-cultural Attitudes Towards Appearance Questionnaire (SATAQ). There was some question regarding the internal consistency of the two subscales of this measure, as this relatively new instrument has not been widely used with any population. The internal consistencies (Chronbach alpha) for the two subscales are as follows: Awareness (.66), and Internalization (.96). The alpha level for the Internalization subscale is acceptable. The internal consistency of the Awareness subscale is not at an acceptable level. It is possible that if this subscale more reliability measured the socio-cultural awareness construct, more could have been learned about the relationship between this construct and the development of disturbed eating attitudes and behaviors.

\section{$\underline{\text { Sampling }}$}

This sample was obtained from first year college women living in single sex residence halls at West Virginia University. Although specific demographic information was not collected from the sample, West Virginia University reports that 7 percent of first 
year students in the 2000 Spring Semester identify themselves as ethnic minorities (West Virginia University, 2001, para. 1). Because the entire sample was drawn exclusively from this population, results may not easily be extrapolated to a more ethnically diverse population. Additionally, women who decide to live in single sex residence hall floors may represent a population that has differences when compared to women opting to live in co-educational residence hall floors. Caution should be used in extended these results to all first year college women.

The participation rate in this study may also be considered a limitation. On some of the residence hall floors where data was gathered, less than half of the residents of those floors participated in the study. This most likely influenced the formation of friendship groups, and may have weakened the generalizability of this study. An effort was made to improve the external validity of the study by conducting an analysis that examined only those friendship groups coming from residence hall floors with a participation rate of 70 percent or higher. Although this analysis corroborated the results of the initial analysis, caution should be used in generalizing the results of this study.

\section{$\underline{\text { Research Design }}$}

The design of the present study does not involve random assignment, nor does it involve manipulation of independent variables. As a result, causal relationships cannot be inferred because this was not an experimental study.

Another possible limitation of this study is that eating behaviors were not observed. Instead, the researcher relied on the self report of participants in the study. The accuracy of the participants self-report may therefore be in question. There is some research that demonstrates the accuracy of women's self-reported body weight (Bowman 
\& DeLucia, 1992). This finding provides some support that the participants in this study may similarly be reporting accurate self reports of their eating behaviors.

Additionally, because this study used the Multivariate Analysis of Variance (MANOVA) approach to data analysis that assumes independence of individuals and groups, it was only possible to examine those individuals who indicated being a member of relatively discrete friendship groupings. Because a number of women in this study indicated being a member of more than one friendship group, this study's assumption of discreteness between groupings is an oversimplification of the nature of the social relationships of first year college women.

Finally, although this study allowed the researcher to determine between group differences among friendship groups, the design of this study was not able to differentiate if this was due to a social influence effect or a peer selection effect. Thus, the presence of social contagion could not be asserted, because the eating attitudes and behaviors of participants were not studied over time.

\section{$\underline{\text { Recommendations for Future Research }}$}

Based on the information gathered from this current study, longitudinal studies should be conducted to allow researchers to differentiate between the process of social influence/social contagion and the process of assortment/peer selection. One recommendation is to conduct a follow- up study with a similar research design that follows the participants throughout their first year of college. Individuals may be assessed two, three, or four times over this time period. This would allow researchers to see if participants in small friendship groups became more alike over time, thus supporting the social contagion theory. 
The current study contributes to the literature by offering a clearer understanding of how disordered eating attitudes and behaviors may develop in a social context. However, the study does not describe how these behaviors may escalate into full-blown eating disorders. Future studies may examine how social influence may contribute to not only the development of eating problems, but also to the development of clinical eating disorders such as anorexia nervosa, bulimia nervosa, and eating disorders not otherwise specified.

Due to questions concerning the generalizability of this study, it is important that similar studies be conducted on campuses with different demographics. It is important that such studies be conducted on college campuses with greater ethnic and racial diversity. It is also recommended that similar studies be conducted that assess the social context for women at different developmental periods in their college careers. Studies of upper-class women and women transitioning from college to graduation may provide a more complete picture of how the social context in college contributes to the development of eating problems and/or disorders.

Finally, in an effort to better understand how the social connections of college women influence their development of eating problems, it may be helpful to examine different types of friendship groupings. For example, it may be beneficial to examine if within-group similarity varies according to different types of friendship ties, such as the study of dyads or of larger friendship groups. Additionally, it may also provide more clarity to this process if researchers examined how an individual's position in a group (central vs. peripheral) may predict her eating attitudes and behaviors. 
Thus, this study contributes to the literature by demonstrating that members of small friendship groups of first year college women have similar eating attitudes and behaviors. Future studies may attempt to determine whether or not these similarities are due to a social contagion process. This could be done by conducting a similar study that compares the eating attitudes and behaviors of participants over time. This study also corroborates past research that demonstrates a relationship between personal and emotional adjustment to college and the development of disturbed eating attitudes and behaviors. Finally, this study also points to a relationship between the internalization of socio-cultural attitudes towards appearance and the development of eating disturbances. 


\section{References}

Alva, S. A. (1998). Self-reported alcohol use of college fraternity and sorority members. Journal of College Student Development, 39 (1), 3-10.

American Psychiatric Association. (1994). Diagnostic and statistical manual of $\underline{\text { mental disorders }}\left(4^{\text {th }}\right.$ ed.). Washington, DC: Author.

American Psychological Association. (1992). Ethical principles of psychologists and code of conduct. American Psychologist, 47, 1597-1611.

Anderson, A. E. \& DiDomenico. (1992). Diet vs. shape content of popular male and female magazines: A dose-response relationship to the incidence of eating disorders. International Journal of Eating Disorders, 11 (3), 283-287.

Asher, E. J. (1992). Student adaptation to college questionnaire. In J. J. Kramer \& J. C. Conoley (Eds.), Eleventh Mental Measurements Yearbook._Lincoln, NE: University of Nebraska Press.

Astin, A. (1977). Four critical years: Effect of college on beliefs, attitudes and knowledge. San Francisco: Jossey-Bass Publishers.

Baker, R. W., \& Siryk, B. (1984). Measuring adjustment to college. Journal of Counseling Psychology, 31, 179-189.

Baker, R. W., \& Siryk, B. (1986). Exploratory intervention with a scale measuring adjustment to college. Journal of Counseling Psychology, 33 (1), 31-38.

Baker, R. W., \& Siryk, B. (1989). Manual for the Student Adaptation to College Questionnaire (SACQ). Los Angeles: Western Psychological Services.

Barber, J. G., Bolitho, F., \& Bertrand, L. D. (1999). The predictors of adolescent smoking. Journal of Social Service Research, 26 (1), 51-66. 
Beebe, D. W., Holmbeck, G. N., Schober, A., Lane, M., Rosa, K. (1996). Is body focus restricted to self-evaluation? Body focus in the evaluation of self and others. International Journal of Eating Disorders, 20 (4), 415-422.

Ben-Tovim, D. I., \& Walker, M. K. (1994). The influences of age and weight on women's body attitudes as measured by the Body Attitudes Questionnaire. Journal of Psychosomatic Research, 38 (5), 477-481.

Berg, K. M. (1988). The prevalence of eating disorders in co-ed versus singlesex residence halls. Journal of College Student Development, 29, 125-131.

Beren, S. E., Hayden, H. A., Wilfley, D. E., \& Stiegel-Moore, R. H. (1997). Body dissatisfaction among lesbian college students. Psychology of Women Quarterly, $\underline{21}, 431-445$.

Bettencourt, B. A., Charlton, K., Eubanks, J., Kernahan, C., Fuller, B. (1999). Development of collective self-esteem among students: Predicting adjustment to college. Basic and Applied Social Psychology, 21 (3), 213-222.

Blaskovich, J., \& Tomaka, J. (1991). The self-esteem scale. In J. P. Robinson, P. R. Shaver, \& L. S. Wrightsman (Eds.). Measures of personality and social psychological attitudes. New York: Academic Press.

Borgatti, S. P., Everett, M. G., \& Freeman, L. C. (1992). UCINET IV Version 1.0 [computer software]. Natik, MA: Analytic Technol.

Bovasso, G. (1996). A network analysis of social contagion process in an organizational intervention. Human Relations, 49, (1), 1419-1435.

Bowen-Woodward, K., \& Levitz, L. S. (1989). Impact of the college environment on bulimic women. Journal of College Student Psychotherapy, 3, 181-190. 
Bowman, R. L., \& DeLucia, J. L. (1992). Accuracy of self-reported weight: A Meta-analysis. Behavior Therapy, 23, 637-655.

Brooks, J. H. \& DuBois, D. L. (1995). Individual and environmental predictors of adjustment during first year of college. Journal of College Student Development, 36 (4), 347-360.

Brooks-Gunn, J., Burrow, C., \& Warren, M.P. (1988). Attitudes toward eating and body weight in different groups of female adolescent athletes. International Journal of Eating Disorders, 7 (6), 749-757.

Brouwers, M. (1988). Depressive thought content among female college students with bulimia. Journal of Counseling and Development, 66, 425-428.

Chickering, A. W., \& Reisser, L. (1993). Education and identity (2 ${ }^{\text {nd }}$ ed.). San Francisco: Jossey-Bass Publishers.

Clapp, J. D., \& McDonnell, A. L. (2000). The relationship of perceptions of alcohol and peer drinking norms to alcohol problems reported by college students. Journal of College Student Development, 41 (1), 19-26

Clark, L. V., Levine, M. P., \& Kinney, N. E. (1989). A multifaceted and integrated approach to prevention, identification, and treatment of bulimia on college campuses. Journal of College Student Psychotherapy, 3, 257-298.

Conoley, J. C., \& Kraemer, J. J. (1989). Eleventh Mental Measurements Yearbook. Lincoln, NE: University of Nebraska Press.

Connor-Greene, P. A., Striegel-Moore, R. H., \& Cronan, S. (1994). Perceived social climate and weight preoccupation in college women. Eating Disorders: The Journal of Treatment and Prevention, 2 (2), 126-134. 
Connors, M. A. (1996). Developmental vulnerabilities for eating disorders. In L. Smolak, M. P. Levine, \& R. Striegel-Moore (Eds.), The developmental psychopathology of eating disorders (pp. 285-310). Mahwah, NJ: Erlbaum.

Coric, D., \& Murstein, B. I. 1993. Bulimia nervosa: Prevalence and psychological correlates in a college community. Eating Disorders: The Journal of Treatment and Prevention, 1 (1), 39-50.

Crandall, C. S. (1986). Sororities, Social Norms, Social Contagion, and Bulimia. Paper presented at the annual meeting of the American Psychological Association, Chicago.

Crandall, C. S. (1988). The social contagion of binge eating. Journal of Personality and Social Psychology, 55, 588-598.

Crowther, J. H., Lilly, R. S., Crawford, P. A., Shepherd, K. L, \& Oliver, L. L. (1990). The stability of the Eating Disorder Inventory. Paper presented at the Annual Meeting of the American Psychological Association, Boston, MA.

Crowther, J. H., \& Sherwood, N. E. (1997). Assessment. In D. M. Garner \& P. E. Garfinkel (Eds.), Handbook of treatment for eating disorders (pp. 34-49). New York: Guilford Press.

Dahmus, S., Bernardin, H. J., \& Bernardin, K. (1992). Student adaptation to college questionnaire. Measurement and Evaluation in Counseling and Development, 25, $139-142$.

Davies, C, \& Cowles, M. (1989). A comparison of weight and diet concerns and personality factors among female athletes and non-athletes. Journal of Psychosomatic $\underline{\text { Research, } 33}$ (5), 527-536. 
Davis, C., Shapiro, C. M., Elliot, S., \& Dionne, M. (1993). Personality and other correlates of dietary restraint: An age by sex comparison. Personality and Individual Differences, 14 (2), 297-305.

Dent, C. W., Sussman, S., Burton, D., \& Flay, B. R. (1995). Two-year outcomes of Project Towards no Tobacco Use. Journal of Consulting anf Clinical Psychology, 63, 676-677.

Druss, R. G., \& Silverman, J. A. (1979). Body image and perfectionism of ballerinas. General Hospital Psychiatry, 1, 115-121.

Dunn, P. K., \& Ondercin, P. (1981). Personality variables related to compulsive eating in college women. Journal of Clinical Psychology, 37 (1), 43-49.

Ennet, S. T., \& Bauman, K. E. (1994). The contribution of influence and selection to adolescent peer group homogeneity: The case of adolescent cigarette smoking. Journal of Personality and Social Psychology, 67 (4), 653-663.

Faith, M. S., \& Schare, M. L. (1993). The role of body image in sexually avoidant behavior. Archives of Sexual Behavior, 22 (4), 345-356.

Farrell, A. D, \& White, K. S. (1998). Peer influences and drug use among urban adolescents: Family structure and parent-adolescent relationship as protective factors. Journal of Consulting and Clinical Psychology, 66 (2), 248-258.

Fettes, P. A., \& Peters, J. M. (1992). A meta-analysis of group treatment for bulimia nervosa. International Journal of Eating Disorders, 11 (2), 97-110.

Fleming, J. S., \& Courtney, B. E. (1984). The dimensionality of self-esteem: Hierarchical facet model for revised measurement scales. Journal of Personality and Social Psychology, 46 (2), 404-421. 
Francis, L. J., \& Wilcox, C. (1995). Self-esteem: Coopersmith and Rosenberg compared. Psychological Reports, 76, 1050.

Franko, D. L. (1998). Secondary prevention of eating disorders in college women at risk. Eating Disorders: The Journal of Treatment and Prevention, 6, 29-40.

Franko, D. L., \& Omori, M. (1999). Sub-clinical eating disorders in adolescent women: A test of the continuity hypothesis and its psychological correlates. Journal of Adolescence, 22 (3), 389-396.

Frederick, C. M., \& Grow, V. M. (1996). A mediational model of autonomy, self-esteem, and eating disorders attitudes and behaviors. Psychology of Women Quarterly, 20, 217-228.

Friedlander, M. L., \& Siegal, S. M. (1990). Separation-individuation difficulties and cognitive-behavioral indicators of eating disorders among college women. Counseling Psychology, 37 (1), 74-78.

Fryer, S., Walker, G., \& Kroese, B. S. (1997). Stress, coping, and disturbed eating attitudes in teenage girls. International Journal of Eating Disorders, 22 (4), 427 436.

Garbarino, C. \& Strange, C. (1993). College adjustment and family environment of students reporting parental alcohol problems. Journal of College Student Development, 34, 261-266.

Garner, D. M. (1991). Eating Disorder Inventory-2 (EDI-2): Professional Manual. Odessa, FL: Psychological Assessment Resources.

Garner, D. M. (1985). Iatrogenesis in anorexia nervosa and bulimia nervosa. International Journal of Eating Disorders, 4, 701-726. 
Garner, D. M., Garfinkel, P. E., Schwartz, D., \& Thompson, M. (1980). Cultural expectation of thinness in women. Psychological Reports, 47, 483-491.

Garner, D. M., Olmstead, M. P., \& Polivy, J. (1983). The Eating Disorder Inventory: A measure of cognitive-behavioral dimensions of anorexia nervosa and bulimia. In P. L. Darby, P. E. Garfinkel, D. M., Garner, \& D. V. Coscina (Eds.). Anorexia nervosa: Recent developments in research (pp. 173-184). New York: Alan R Liss.

Gralen, S. J., Levine, M. P., Smolak, L., \& Murnen, S. K. (1990). Dieting and disordered eating during early and middle adolescence: Do the influences remain the same? International Journal of Eating Disorders, 9 (5), 501-512.

Gray-Little, B., Williams, V. S. L., \& Hancock, T. D. (1997). An item response theory analysis of the Rosenberg Self-Esteem Scale. Personality and Social Psychology Bulletin, 23 (5), 443-451.

Greeno, C. G., Jackson, C., Williams, E. L., Fortmann, S. P. (1998). The effect of perceived control over eating on the life satisfaction of women and men. International journal of Eating Disorders, 24 (4), 415-419.

Griffiths, R. A., Beumont, P. J. V., Russell, J., Schotte, D., Thornton, C., Touyz, S., \& Varano, P. (1999). Socio-cultural attitudes toward appearance in dieting and disordered eating and nondieting disordered subjects. European Eating Disorders Review, 7 (3), 193-203.

Grissett, N. I., \& Norvell, N. K. (1992). Perceived social support, social skills, and quality of relationships in bulimic women. Journal of Consulting and Clinical Psychology, 60 (2), 293-299. 
Haemmerlie, F. M., Robinson, D. A. G., \& Carmen, R. C. (1991). Type A personality traits and adjustment to college. Journal of College Student Development, $\underline{32}, 81-82$.

Hagborg, W. J. (1993). The Rosenberg Self-Esteem Scale and Harter's SelfPerception Profile for Adolescents: A concurrent validity study. Psychology in the Schools, 30, 132-136.

Hagborg, W. J. (1996). Score of middle school aged student on the Rosenberg Self-Esteem Scale. Psychological Reports, 78, 1071-1074.

Halmi, K. A. (1994). A multimodal model for understanding and treating eating disorders. Journal of Women's Health, 3 (6), 487-493.

Halmi, K. A., Falk, J. R., \& Schwartz, E. (1981). Binge-eating and vomiting: A survey of a college population. Psychological Medicine, 11, 697-706.

Hannan, W. J., Wrate, R. M., Cowen, S. J., \& Freeman, C. P. L. (1995). Body mass index as an estimate of body fat. International Journal of Eating Disorders, 18 (1), 91-97.

Heatherton, T. F., Nichols, A. L. M., Mahamedi, F., \& Keel, P. (1995). Body weight, dieting, and eating disorder symptoms among college students, 1982 to 1992. American Journal of Psychiatry, 152 (11), 1623-1629.

Heinberg, L. J., Thompson, J. K., \& Stormer, S. (1995). Developmental and validation of the socio-cultural attitudes toward appearance questionnaire. International Journal of Eating Disorders, 17 (1), 81-89.

Hensley, W. E., \& Roberts, M. K. (1976). Dimensions of Rosenberg's selfesteem scale. Psychological Reports, 38, 583-584. 
Herzog, D. B., Norman, D. K., Rigotti, N. A., \& Pepose, M. (1986). Frequency of bulimic behaviors and associated social maladjustment in female graduate students. Journal of Psychiatric Research, 20 (4), 355-361.

Hesse-Biber, S. (1989). Eating patterns and disorders in a college population: Are college women's eating problems a new phenomenon. Sex Roles, 20, 71-89.

Hesse-Biber, S., \& Marino, M. (1991). From high school to college: Changes in women's self-concept and its relationship to eating problems. Journal of Psychology, $\underline{125}(2), 199-216$.

Hesse-Biber, S., Marino, M., \& Watts-Roy, D. (1999). A longitudinal study of eating disorders among college women. Gender and Society, 13 (3), 385-408.

Higgins, E. T., \& Kruglanski, A. W. (1996). Social psychology: Handbook of basic principles. New York: Guilford Press.

Huon, G. F. (1994). Towards the prevention of dieting-induced disorders: Modifying negative food and body related activities. International Journal of Eating Disorders, 16, 395-399.

Irving, L. M. (1990). Mirror images: Effects of the standard of beauty on the self and body esteem of women exhibiting varying levels of bulimic symptoms. Journal of Social and Clinical Psychology, 9 (2), 230-242.

Irving, L. M., DuPen, J., \& Berel, S. (1998). A media literacy program for high school females. Eating Disorders: The Journal of Treatment and Prevention, 6, 119-131. Joiner, T. E. \& Heatherton, T. F. (1998). First and second order factor structure of five subscales of the Eating Disorder Inventory. International Journal of Eating Disorders, 23, 189-198. 
Kalodner, C. R. (1997). Media influences on male and female non-eatingdisordered college students: A significant issue. Eating Disorders: The Journal of Treatment and Prevention, 5 (1), 47-57.

Kalodner, C. R. \& Scarano, G. M. (1992). A continuum of nonclinical eating disorders: A review of behavioral and psychological correlates and suggestions for intervention. Journal of Mental Health Counseling, 14 (1), 30-41.

Kashubeck, S., \& Mintz, L. B. (1996). Eating disorder symptomatology and substance use in college females. Journal of College Student Development, 37, (4), 396404.

Kashubeck, S., Walsh, B., \& Crowl, A. (1994). College atmosphere and eating disorders. Journal of Counseling and Development, 72 (6), 640-645.

Kennet, D. J., \& Nesbitt, C. (1998). The influence of body mass index and learned resourcefulness skills on body image and lifestyle practices. Patient Education \& Counseling, 33 (1), 1-12.

Kenny, D., \& Adams, R. (1994). The relationship between eating attitudes, body mass index, age, and gender in Australian university students. Australian Psychologist, $\underline{29}(2), 128-134$.

Kenny, M. E. \& Donaldson, G. A. (1992). The relationship of parental attachment and psychological separation to the adjustment of first-year college women. Journal of College Student Development, 33, 431-438.

Kenny, M. E. \& Stryker, S. (1996). Social network characteristics and college adjustment among racially and ethnically divers first-year students. Journal of College Student Development, 37 (6), 649-658. 
Klemchuk, H. P., Hutchinson, C. B., \& Frank, R. I. (1990). Body dissatisfaction and eating-related problems on the college campus. Journal of Counseling Psychology, $\underline{37}(3), 297-305$.

Klump, K. L., McGue, M., \& Iacono, W. G. (2000). Age differences in genetic and environmental influences on eating attitudes and behaviors in preadolescent and adolescent female twins. Journal of Abnormal Psychology, 109 (2), 239-251.

Kolody, B., \& Sallis, J. F. (1995). A prospective study of ponderosity, body image, self-concept, and psychological variables in children. Journal of Development and Behavioral Pediatrics, 16 (1), 1-5.

Lee, S., Lee, A. M., Leung, T., \& Yu, H. (1997). Psychometric properties of the eating disorder inventory (EDI) in a nonclinical Chinese population in Hong Kong. International Journal of Eating Disorders, 21 (2), 187-194.

Leith, L.M. (1994). Foundations of exercise and mental health. Morgantown, WV: Fitness Information Technology.

Levine, M. P., \& Smolak, L. (1992). Toward a developmental psychopathology of eating disorders. In J. Crowther, S. Hobfall, M. Stephens, \& D. Tennenbaum (Eds.), The etiology of bulimia: The individual and familial contexts. Washington, DC: Hemisphere.

Levine, M. P., Smolak, L., Moodey, A. F., Shuman, M. D., \& Hessen, L. D. (1994). Normative developmental challenges and eating disturbances in middle school girls. International Journal of Eating Disorders, 15, (1), 11-20. 
Lopez, F. G., Campbell, V. L., \& Watkins, C. E. (1988). Family structure, psychological separation, and college adjustment: A canonical analysis and crossvalidation. Journal of Counseling Psychology, 35 (4), 402-409.

Low, C. A. \& Handal, P. J. (1995). The relationship between religion and adjustment to college. Journal of College Student Development, 36 (5), 406-412.

Lowry, R., Galuska, D. A., Fulton, J. E., Wechsler, H., Kann, L., \& Collins, J. L. (2000). Physical activity, food choice, and weight management goals and practices among U. S. college students. American Journal of Preventative Medicine, 18 (1), 18-27.

Mann, T., Nolen-Hoeksema, S., Huang, K., Burgard, D., Wright, A., \& Hanson, K. (1997). Are two interventions worse than none? Joint primary and secondary prevention of eating disorders in college females. Health Psychology, 16, 215-225

Marshal, M. P., \& Chassin, L. (2000). Peer influence on adolescent alcohol use: The moderating role of parental support and discipline. Applied Developmental Science, $\underline{4}(2), 80-88$.

Martz, D. M., Graves, K. D., \& Sturgis, E. T. (1997). A pilot peer-leader eating disorders prevention program for sororities. Eating Disorders: The Journal of Treatment and Prevention, 5 (4), 294-308.

Meyer, D. F. (1997). Codependency as a mediator between stressful life events and eating disorders. Journal of Clinical Psychology, 53 (2), 107-116.

McClintock, M. K. (1971). Menstrual synchrony and suppression. Nature, 229, 244-245.

McCurdy, B. A., \& Kelly, D. B. (1997). Correlations of the MMPI-2 Low SelfEsteem Scale with two self-esteem measures. Psychological Reports, 81, 826. 
Mintz, L. B., \& Betz, N. E. (1988). Prevalence and correlates of eating disordered behaviors among undergraduate women. Journal of Counseling Psychology, 35 (4), 463 471.

Mitchell, J. E., \& Eckert, E. D. (1987). Scope and significance of eating disorders. Journal of Consulting and Clinical Psychology, 55 (5), 628-634.

Mitchell, J. E., Hatsukami, D., Pyke, R. L., \& Echert, E. D. (1986). The bulimia syndrome: Course of the illness and associated problems. Comprehensive Psychiatry, 27 (2), 165-170.

Monteath, S. A., \& McCabe, M. P. (1997). The influence of societal factors on female body image. Journal of Social Psychology, 137 (6), 708-727.

Morris, A., Cooper, T., \& Cooper, P. J. (1989). The changing shape of female fashion models. International Journal of Eating Disorders, 8 (5), 593-596.

Mukai, T., Kambara, A., \& Sasaki, Y. (1998). Body dissatisfaction, need for social approval, and eating disturbances among Japanese and American college women. Sex Roles, 39 (9-10), 751-763.

Murphy, M. C., \& Archer, J. (1996). Stressors on the college campus: A comparison of 1985 and 1993. Journal of College Student Development, 37 (1), 20-28.

Murphy, L. L., Conoley, J. C., \& Imapaza, J. C. (1994). Student adaptation to college questionnaire. Tests in Print IV. Lincoln, NE: University of Nebraska Press.

Murray, D. M., Richards, P. S., Luepker, R. V., \& Johnson, C. A. (1987). The prevention of cigarette smoking in children: Two and three year follow- up comparisons of four prevention strategies. Journal of Behavioral Medicine, 10, 595-611. 
Murray, S. H., Touyz, S. W., \& Beaumont, P. J. V. (1996). The influence of personal relationships on women's eating behavior and body satisfaction. Eating Disorders: The Journal of Treatment and Prevention, 4 (3), 243-252.

Nelson, W.L., Hughes, H. M., Katz, B., \& Searight, H. R. (1999). Anorexic eating attitudes and behaviors of male and female college students. Adolescence, 34 (135), 621-633.

Oetting, E. R., \& Donnermeyer, J. F. (1998). Primary socialization theory: The etiology of drug use and deviance. Substance Use and Misuse, 33 (4), 995-1026.

Okine, K. N. (2000). The relationship aspects of eating disorder symptomatology. Dissertation Abstracts International, 61 (6), 3287.

Oesterheld, J. R., McKenna, M. S., \& Gould, N. B. (1987). Group psychotherapy of bulimia: A critical review. International Journal of Group Psychotherapy, 37 (2), 163185.

Palladino-Schulthesis, D. E. \& Blustein, D. L. (1994). Role of adolescent-parent relationships in college student development and adjustment. Journal of Counseling Psychology, 41 (2), 248-255.

Pascarella, E. T., \& Terenzini, P. T. (1991). How college affects students: Findings and insights from twenty years of research San Francisco: Jossey-Bass Publishers.

Paxton, S. J. (1996). Prevention implications of peer influences on body image dissatisfaction and disturbed eating in adolescent girls. Eating Disorders: The Journal of Treatment and Prevention, 4 (4), 113-347. 
Paxton, S. J. (1999). Peer relations, body image, and disordered eating in adolescent girls: Implications for prevention. In N. Piran, M. P. Leving, \& C. SteinerAdair (Eds.), Preventing eating disorders: A handbook for interventions and special challenges (pp. 134-147). Philadelphia: Brunner/Mazel.

Paxton, S. J., Schutz, H. K., Wertheim, E. H., \& Muir, S. L. (1999). Friendship clique and peer influences on body image concerns, dietary restraint, extreme weight-loss behaviors, and binge eating in adolescent girls. Journal of Abnormal Psychology, 108 (2), 255-266.

Person, M., \& Mitchell, L. (2000). Smoke rings: Social network analysis of friendship groups, smoking and drug taking. Drugs: Education, Prevention, \& Policy, 7 (1), 21-37.

Pike, K. M. (1995). Bulimic symptomology in high school girls. Psychology of Women Quarterly, 19 (3), 373-396.

Pike, K. M., \& Rodin, J. (1991). Mothers, daughters, and disordered eating. Journal of Abnormal Psychology, 100 (2), 198-204.

Pipher, M. (1994). Reviving Ophelia: Saving the lives of adolescent girls. New York: Ballantine Books.

Piran, N. (1997). Prevention of eating disorders: Directions for future research. Psychopharmacology Bulletin, 33 (3), 419-523.

Piran, N. (1996). The reduction of preoccupation with body weight and shape in schools: A feminist approach. Eating Disorders: The Journal of Treatment and Prevention, 4 (4), 323-333. 
Polivy, J., \& Herman, C. P. (1985). Dieting and binging. American Psychologist, 40 (2), 193-201.

Pollack, W. S. (2000). Real boys voices. Random House, Inc.: New York.

Prentice, D. A., \& Miller, D. T. (1993). Pluralistic ignorance and alcohol use on campus: Some consequences of misperceiving the social norm. Journal of Personality and Social Psychology, 64 (2), 243-256.

Prentice, D. A., \& Miller, D. T. (1996). Pluralistic ignorance and the perpetuation of social norms by unwitting actors. Advances in Experimental Social Psychology, 28, 161-209.

Pritchard, M. E., King, S. L, Czajka-Narins, D. M. (1997). Adolescent body mass indices and self-perception. Adolescence, 32 (128), 863-880.

Pyle, R. L., Mitchell, J. E., \& Echert, E. D. (1981). Bulimia: A report of 34 cases. Journal of Clinical Psychiatry, 42, 60-64.

Rice, K. G. (1992). Separation-individuation and adjustment to college: A longitudinal study. Journal of Counseling Psychology, 39 (2), 203-213.

Rice, K. G. \& Whaley, T. J. (1994). A short-term longitudinal study of withinsemester stability and change in attachment and college student adjustment. Journal of College Student Development, 35, 324-330.

Rodgers, J. L., \& Rowe, D. C. (1993). Social contagion and adolescent sexual behavior: A developmental EMOSA model. Psychological Review, 100 (3), 479-510.

Rose, J. S., Chassin, L., Presson, C. C., \& Sherman, S. J. (1999). Peer influences on adolescent cigarette smoking: A prospective sibling analysis. $\underline{\text { Merrill-Palmer }}$ Quarterly, 45 (1), 62-84. 
Rosen, J. C., Compas, B. E., \& Tacy, B. (1993). The relation among stress, psychological symptoms, and eating disorder symptoms: A prospective analysis. International Journal of Eating Disorders, 14 (2), 153-162.

Rosenberg, M. (1965). Society and the adolescent self-image. Princeton, NJ: Princeton University Press.

Sandberg, D. A. \& Lynn, S. J. (1992). Dissociative experiences, psychopathology and adjustment, and child and adolescent maltreatment in female college students. Journal of Abnormal Psychology, 101 (4), 717-723.

Sanftner, J. L., Crowther, J. H., Crawford, P. A., \& Watts, D. D. (1996). Maternal influences (or lack thereof) on daughters' eating attitudes and behaviors. Eating Disorders: The Journal of Treatment and Prevention, 4 (2), 147-159.

Saracoglu, B., Minden, H., \& Wilchesky, M. (1989). The adjustment of students with learning disabilities to university and its relationship to self-esteem and selfefficacy. Journal of Learning Disabilities, 22 (9), 590-592.

Scarano, G. M. \& Kalodner, C. R. (1994). A description of the continuum of eating disorders: Implications for intervention and research. Journal of Counseling and Development, 72, 356-361.

Schoemaker, C., van Strien, T., \& van der Staak, C. (1994). Validation of the eating disorder inventory in a no nclinical population using transformed and untransformed responses. International Journal of Eating Disorders, 15 (4), 387-393.

Schwartz, D. M., Thompson, M. G., \& Johnson, C. L. (1982). Anorexia nervosa and bulimia: The socio-cultural context. International Journal of Eating Disorders, 1 (3), 20-36. 
Schwitzer, A. M., Bergholz, K., Dore, T., \& Salimi, L. (1998). Eating disorders among college women: Prevention, education, and treatment responses. $\underline{\text { Journal of }}$ American College Health, 46 (5), 199-207.

Sharkey, B. J. (1997). Fitness and Health. Champaign, IL: Human Kinetics.

Sharpe, T. M., Ryst, E., Hinshaw, S. P., \& Steiner, H. (1997). Reports of stress: A comparison between eating disordered and non-eating disordered adolescents. $\underline{\text { Child }}$ Psychiatry and Human Development, 28 (2), 117-132.

Shatford, L. A., \& Evans, D. R. (1986). Bulimia as a manifestation of the stress process: A LISREL casual modeling analysis. International Journal of Eating Disorders, $\underline{5}(3), 451-473$.

Shaw, J. \& Waller, G. (1995). The media's impact on body image: Implications for prevention and treatment. Eating Disorders: The Journal of Treatment and Prevention, 3 (2), 115-123.

Sher, K. J., Wood, P. K., \& Gotham, H. J. (1996). The course of psychological distress in College: A prospective high-risk study. Journal of College Student Development, 37 (1), 42-50.

Shevlin, M. E., Bunting, B. P., \& Lewis, C. A. (1995). Confirmatory factor analysis of the Rosenberg Self-Esteem Scale. Psychological Reports, 76, 707-710.

Shisslak, C. M., Crago, M., \& Estes, L. S. (1995). The spectrum of eating disorders. International Journal of Eating Disorders, 18 (3), 209-219.

Shisslak, C. M., Crago, M., McKnight, K. M., Estes, L. S., Gray, N., \& Parnaby, O. G. (1998). Potential risk factors associated with weight control behaviors in 
elementary and middle school girls. Journal of Psychosomatic Research, 44 (3-4), 301313.

Shisslak, C. M., Crago, M., Renger, R., \& Clark-Wagner, A. (1998). Self-esteem and the prevention of eating disorders. Eating Disorders: The Journal of Treatment and Prevention, 6, 105-117.

Silber, E., \& Tippet, J. S. (1965). Self-esteem: Clinical assessment and measurement validations. Psychological Reports, 16, 1017-1071.

Silberstein, L. R., Mishkind, M. E., Striegal-Moore, R. H., Timko, C., \& Rodin, J. (1989). Men and their bodies: A comparison of homosexual and heterosexual men. Psychosomatic Medicine, 51, 329-336.

Sieving, R. E., Perry, C. L., \& Williams, C. L. (2000). Do friendships change behaviors, or do behaviors change friendships? Examining paths of influence in young adolescents' alcohol use. Journal of Adolescent Health, 26 (1), 27-35.

Silverstein, B., Perdue, P., Wolf, C., \& Pizzolo, C. (1988). Bingeing, purging, and estimates of parental attitudes regarding female achievement. Sex Roles, 19 (11/12), $723-733$.

Skowron, E. A., \& Friedlander, M. L. (1994). Psychological separation, selfcontrol, and weight preoccupation among elite women athletes. Journal of Counseling and Development, 72, 310-315.

Smith, M. A. \& Baker, R. W. (1987). Freshman decideness regarding academic major and adjustment to college. Psychological Reports, 61, 847-853.

St. Clair, M. (1996). Object relations and self psychology. Pacific Grove, CA: Brooks Cole Publishing Company. 
Stice, E. (1994). Review of the evidence for a socio-cultural model of bulimia nervosa and a exploration of the mechanisms of action. Clinical Psychology Review, 14 (7), 633-661.

Stice, E., Nemeroff, C., \& Shaw, H. E. (1996). Test of the dual pathway model of bulimia nervosa: Evidence for dietary restraint and affect regulation mechanisms. Journal of Social and Clinical Psychology, 15 (3), 340-363.

Stice, E., \& Shaw, H. E. (1994). Adverse effects of the media portrayed thin ideal on women and linkages to bulimic symptomology. Journal of Social and Clinical Psychology, 13 (3), 288-308.

Striegel-Moore, R. H., Dohm, F. A., Soloman, E. E., Fairburn, C. G., Pike, K. M., \& Wilfley, D. E. (2000). Subthreshold binge eating disorder. International Journal of Eating Disorders, 27 (3), 270-278.

Striegel-Moore, R. H., \& Kearney-Cooke, A. (1994). Exploring parents' attitudes and behaviors about their children's physical appearance. International Journal of Eating Disorders, 15 (4), 377-385.

Striegel-Moore, R. H., Silberstein, L. R., Frensch, P., \& Rodin, J. (1989). A prospective study of disordered eating among college students. International Journal of Eating Disorders, 8 (5), 499-509.

Striegel-Moore, R. H., Silberstein, L. R., \& Rodin, J. (1986). Toward an understanding of risk factors for bulimia. American Psychologist, 41 (3), 246-263.

Strober, M. (1984). Stressful life events associated with bulimia in anorexia nervosa. International Journal of Eating Disorders, 3 (2), 3-16. 
Strong, K. G., \& Huon, G. F. (1998). An evaluation of a structural model for studies of the initiation of dieting among adolescent girls. Journal of Psychosomatic Research, 44 (3-4), 315-326.

Sundgot-Borgen, J. (1994). Risk and trigger factors for the development of eating disorders in female elite athletes. Medicine and Science in Sports and Exercise, 26 (4), 414-419.

Swassing, C. S. (1989). Review of the Eating Disorder Inventory. In J. C. Conoley \& J. J. Kraemar (Eds.). Tenth Mental Measurements Yearbook. Lincoln. NE: University of Nebraska Press.

Taub, D. E., \& Blinde, E. M. (1992). Eating disorders among adolescent female athletes: Influence of athletic participation and sport team member ship. Adolescence, 27 (108), 833-848.

Taylor, C. B., Sharpe, T., Shisslak, C., Bryson, S., Estes, L. S., Gray, N., McKnight, K. M., Crago, M., Kraemer, H. C., \& Killen, J. D. (1998). Factors associated with weight concerns in adolescent girls. International Journal of Eating Disorders, 24 (1), 31-42.

Thombs, D. L., Rosenberg, J. M., Mahoney, C. A., \& Daniel, E. L. (1996). Weight-loss expectancies, relative weight, and symptoms of bulimia in young women. Journal of College Student Development, 37 (4), 405-414.

Thompson, J. K., Coovert, M. D., \& Stormer, S. M. (1999). Body image, social comparison, and eating disturbance: A covariance structure modeling investigation. International Journal of Eating Disorders, 26, 43-51. 
Thompson, J. K., Heinberg, L. J., Altabe, M., \& Tantle ff-Dunn, S. (1999).

Exacting beauty: Theory, assessment, and treatment of body image disturbance.

Washington DC: American Psychological Association.

Tylka, T. L., \& Subich, L. M. (1999). Exploring the construct validity of the eating disorder continuum. Journal of Counseling Psychology, 46 (2), 268-276.

VanLone, J. S., \& Kalodner, C. R. (2000). Student Adjustment and Disordered Eating Among College Women. Paper presented at the meeting of the American College Personnel Association, Washington, DC.

Van Strien, T. (1985). Eating behavior, personality traits and body mass in women. Addictive Behaviors, 10 (4), 333-343.

Warren, B. J., Stanton, A. L., \& Blessing, D. L. (1990). Disordered eating patterns in competitive female athletes. Interna tional Journal of Eating Disorders, 9 (5), 565-569.

Wassenaar, D., le Grange, D., Winship, J., \& Lachenicht, L. (2000). The prevalence of eating disorder pathology in a cross-ethnic population of female students in South Africa. European Eating Disorders Review, 8 (3), 225-236.

Wear, R. W., \& Pratz, O. (1987). Test-retest reliability for the Eating Disorder Inventory. International Journal of Eating Disorders, 6, 767-769.

Welch, G. (1988). Selected multivariate statistical techniques and eating disorders. Unpublished doctoral dissertation, University of Otago, New Zealand.

Weller, L. Weller, A., Avinir, O. (1995). Menstrual synchrony: Only in roommates who are close friends? Physiology and Behavior, 58 (5), 883-889. 
West, P., Sweeting, H. \& Ecob, R. (1999). Family and friends' influences on the uptake of regular smoking from mid-adolescence to early adulthood. Addiction, 94 (9), 1397-1411.

West Virginia University (2000). Retrieved August 20, 2001, from West Virginia University Web site: http://www.wvu.edu/ research.html.

Wheeler, L. (1966). Toward a theory of behavioral contagion. Psychological Review, 73 (2), 179-192.

Wilfley, D. E., \& Rodin, J. (1995). Cultural influences on eating disorders. In K. D. Brownell \& C. G. Fairburn (Eds.), Eating disorders and obesity: A comprehensive handbook (pp. 199-205). New York: Guilford.

Williamson, D. A., Cubic, B. A., \& Gleaves, D. H. (1993). Equivalence of body image disturbances in anorexia and bulimia nervosa. Journal of Abnormal Psychology, $\underline{102}, 177-180$.

Windle, M. (2000). Parental, sibling, and peer influences on adolescent substance abuse and alcohol problems. Applied Developmental Science, 4 (2), 98-110.

Wiseman, C. V., Gray, J. J., Moismann, J. E., \& Ahrens, A. H. (1992). Cultural expectations of thinness in women: An update. International Journal of Eating Disorders, $\underline{11}(1), 85-89$.

Wolf, E. M., \& Crowther, J. H. (1983). Personality and eating habit variables as predictors of severity of binge eating and weight. Addictive Behaviors, 8, 335-344.

Wood, A., Waller, G., \& Gowers, S. (1994). Predictors of eating psychopathology in adolescent girls. Eating Disorders Review, 2 (1), 6-13. 
Yarnold, B. M. (1999). Cigarette use among Miami’s public school students, 1992: Father versus peers, availability and family drug/alcohol problems. Journal of Social Service Research, 24 (3-4), 103-139.

Yates, W. R. (1992). Weight factors in normal weight bulimia nervosa: A controlled family study. International Journal of Eating Disorders, 11 (3), 227-234. Zamostny, K. P., Slyter, S. L., \& Rois, P. (1993). Narcissistic injury and its relationship to early trauma, early resources, and adjustment to college. Journal of Counseling Psychology, 40 (4), 501-510.

Zelley, E. D. (2000). Interpersonal communication incompetence and disordered eating: The relationship among support, competition, and conflict in female friendships. Dissertation Abtracts International, 61 (12), 4617. 
Appendix A

\section{Thank you for participating in this study. This Information will be used to help us learn more about residence hall community life, friendship, and eating attitudes and behaviors. All responses will be kept confidential. \\ Using the code sheet provided for you, please answer the following questions:}

1. Write down the numbers of your best friends, that is, the women in your residence hall that you hang around with the most and are closest to.

2. Is there one particular "group" you normally hang around with? (circle your answer)

(a) Yes.

(b) No, I hang around with a number of "groups" or with people from a number of different "groups".

(c) No, I spend most of my time alone.

(d) No, I spend most of my time with one other friend.

3. If you answered (a) "yes" to the previous question, write down the numbers of women in the group you hang around with.

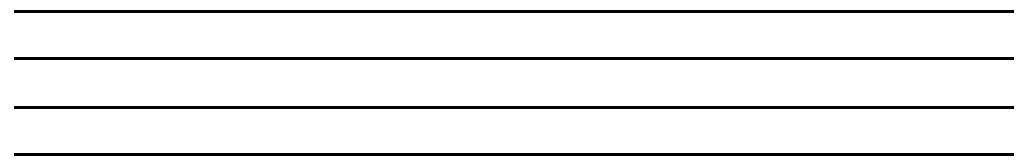

4. If you answered (b) to question 2, write down the numbers of women from the different "groups" you hang around with.

5. Do you hang out more often with friends outside of your residence hall? (circle) Yes No

If you answered yes, how many of these friends do you normally hang out?

\section{Please answer the following short questions:}

What is your Height in feet/inches?

What is your Weight in pounds? 
Appendix B

\section{Please ans wer the following questions. For each of the items, decide if the item is how much this describes you.}

$$
\begin{aligned}
& \mathbf{A}=\text { Always } \\
& \mathbf{U}=\text { Usually } \\
& \mathbf{O}=\text { Often } \\
& \mathbf{S}=\text { Sometimes } \\
& \mathbf{R}=\text { Rarely } \\
& \mathbf{N}=\text { Never }
\end{aligned}
$$

1. I think my stomach is too big.

A U O S R N

2. I eat when I am upset.

A U O S R N

3. I eat sweets and carbohydrates without feeling nervous.

A U O S R N

4. I think that my thighs are too large.

A U O S R N

5. I stuff myself with food.

A U O S R N

6 . I think about dieting.

A U O S R N

7. I think that my stomach is just the right size.

A U O S R N

8. I have gone on eating binges where I felt that I could not stop.

A U O S R N

9. I feel extremely guilty about overeating.

A U O S R N

10. I feel satisfied with the shape of my body.

A U O S R N

11. I think about bingeing (overeating).

A U O S R N

12. I am terrified of gaining weight.

A U O S R N

13. I like the shape of my buttocks.

A U O S R N

14. I eat moderately in front of others and stuff myself when they're gone.

A U O S R N

15. I exaggerate or magnify the importance of weight.

A U O S R N

16. I think my hips are too big.

A U O S R N

17. I have thought about trying to vomit in order to lose weight.

A U O S R N

18. I am preoccupied with the desire to be thinner.

A U O S R N

19. I think that my thighs are just the right size.

A U O S R N

20. I eat or drink in secrecy.

A U O S R N

21. If I gain a pound, I worry that I will keep gaining weight.

A U O S R N

22. I think my buttocks are too large.

A U O S R N

23. I think that my hips are just the right size.

A U O S R N 
Appendix C

\section{Please answer the following questions. For each of the items, mark your answer from strongly disagree (SD) to strongly agree (SA) with each statement.}

1. Women who appear in TV shows and movies project the type of SD --------- SA

appearance that I see as my goal.

2. I believe that clothes look better on thin models.

$\begin{array}{lllll}1 & 2 & 3 & 4 & 5\end{array}$

3. Music videos that show thin women make me wish that I were thin.

$\begin{array}{lllll}1 & 2 & 3 & 4 & 5\end{array}$

4. I do not wish to look like the models in the magazines and on TV.

$\begin{array}{lllll}1 & 2 & 3 & 4 & 5\end{array}$

5. I tend to compare my body to people in magazines and on TV.

$\begin{array}{lllll}1 & 2 & 3 & 4 & 5\end{array}$

6. In our society, fat people are not regarded as unattractive.

$\begin{array}{lllll}1 & 2 & 3 & 4 & 5\end{array}$

7. Photographs of thin women make me wish that I were thin.

$\begin{array}{lllll}1 & 2 & 3 & 4 & 5\end{array}$

8. Attractiveness is very important if you want to get ahead in our culture.

$\begin{array}{lllll}1 & 2 & 3 & 4 & 5\end{array}$

9. It's important for people to work hard on their figures/physiques

$\begin{array}{lllll}1 & 2 & 3 & 4 & 5\end{array}$

if they want to succeed in today's culture.

10. Most people do not believe that the thinner you are, the better you look.

$\begin{array}{lllll}1 & 2 & 3 & 4 & 5\end{array}$

11. People think that the thinner you are, the better you look in clothes.

$\begin{array}{lllll}1 & 2 & 3 & 4 & 5\end{array}$

12. In today's society, it's not important to always look attractive.

$\begin{array}{lllll}1 & 2 & 3 & 4 & 5\end{array}$

13. I wish I looked like a swimsuit model.

$\begin{array}{lllll}1 & 2 & 3 & 4 & 5\end{array}$

14. I often read magazines like Cosmopolitan, Vogue, and Glamour and

$\begin{array}{lllll}1 & 2 & 3 & 4 & 5\end{array}$ compare my appearance to the models.

15. At times I think I am no good at all.

16. I take a positive attitude toward myself.

17. All in all, I am inclined to feel that I am a failure.

$\begin{array}{lllll}1 & 2 & 3 & 4 & 5\end{array}$

18. I wish I could have more respect for myself.

$\begin{array}{lllll}1 & 2 & 3 & 4 & 5\end{array}$

19. I certainly feel useless at times.

$\begin{array}{lllll}1 & 2 & 3 & 4 & 5\end{array}$

20. I feel that I am a person of worth, at least on an equal plane as others.

$\begin{array}{lllll}1 & 2 & 3 & 4 & 5\end{array}$

21. On the whole, I am satisfied with my self.

22. I feel I do not have much to be proud of.

$\begin{array}{lllll}1 & 2 & 3 & 4 & 5\end{array}$

23. I feel that I have a number of good qualities.

$\begin{array}{lllll}1 & 2 & 3 & 4 & 5\end{array}$

24. I am able to do things as well as most other people.

$\begin{array}{lllll}1 & 2 & 3 & 4 & 5\end{array}$ 